\title{
MODELING AND ANALYSIS OF A PV GRID-TIED SMART INVERTER'S SUPPORT FUNCTIONS
}

\author{
A thesis \\ presented to \\ The Faculty of California State University, \\ San Luis Obispo \\ In Partial Fulfillment \\ of the Requirements for the Degree \\ Master of Science in Electrical Engineering
}

by

Benjamin Anders Johnson

May 2013 
(C) 2013

Benjamin Anders Johnson

ALL RIGHTS RESERVED 


\section{COMMITTEE MEMBERSHIP}

TITLE:

Modeling and Analysis of a PV Grid-Tied Smart

Inverter's Support Functions

AUTHOR:

Benjamin Anders Johnson

DATE SUBMITTED:

May 2013

COMMITTEE CHAIR:

Dr. Taufik, Professor

Electrical Engineering Department

COMMITTEE MEMBER: Dr. Ahmad Nafisi, Professor

Electrical Engineering Department

COMMITTEE MEMBER: Dr. Ali Shaban, Professor

Electrical Engineering Department 


\begin{abstract}
Modeling and Analysis of a PV Grid-Tied Smart Inverter's Support Functions Benjamin Anders Johnson
\end{abstract}

The general trends in the past decade of increasing solar cell efficiency, decreasing PV system costs, increasing government incentive programs, and several other factors have all combined synergistically to reduce the barriers of entry for PV systems to enter the market and expand their contribution to the global energy portfolio. The shortcomings of current inverter functions which link PV systems to the utility network are becoming transparent as PV penetration levels continue to increase. The solution this thesis proposes is an approach to control the inverters real and reactive power output to help eliminate the problems associated with PV systems at their origin and in addition provide the grid with ancillary support services. The design, modeling, and analysis of a grid-tied PV system was performed in the PSCAD software simulation environment. Results indicate that in the presence of grid disturbances the smart inverter can react dynamically to help restore the power system back to its normal state. A harmonic analysis was also performed indicating the inverter under study met the applicable power quality standards for distributed energy resources.

Keywords: Smart Inverter, Reactive Power Control, Voltage Regulation, Frequency

Control, Solar, Photovoltaic, PV, Grid Tied 


\section{ACKNOWLEDGEMENTS}

First and foremost I would like to express my thanks to my parents, Brian and Jackie Johnson, for providing me with love, support, and encouragement on a daily basis

during my years in academia and in the completion of this thesis. Without them I would be nowhere near what I have become today.

Next, I would like to thank my advisor, professor, and friend, Dr. Taufik. I have had the pleasure of working with him on this thesis and learning from him in the classroom where I discovered my love for power systems and power electronics engineering through his passionate instruction.

I also owe a great deal of thanks to my girlfriend Jamie Ervin. She continually was my stress reliever over the years, and always supported me during the many hours I dedicated to studying.

Lastly, I want to acknowledge my colleague and good friend Timothy D. Haskell. The majority of hours I spent studying, writing lab reports, and preparing for exams were with you. I couldn't have done it without you bud!

Disclaimer:

SDG\&E does not endorse or accept the conclusions or results of this study. 


\section{TABLE OF CONTENTS}

LIST OF TABLES

LIST OF FIGURES ............................................................................................................IX

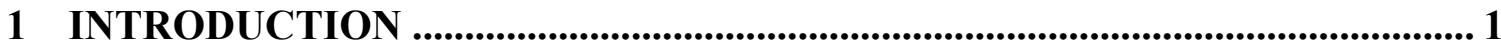

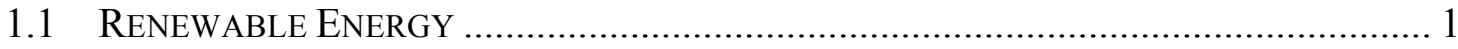

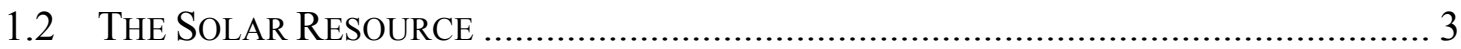

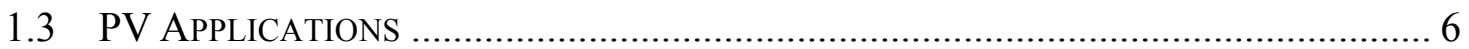

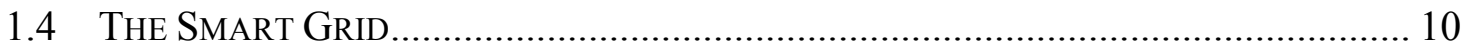

2 BACKGROUND ........................................................................................................ 12

2.1 VolTAGE AND FREQUENCY FlUCTUATIONS ................................................ 12

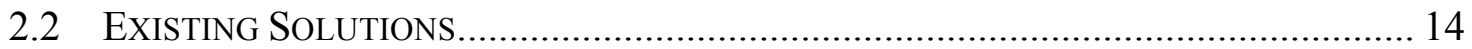

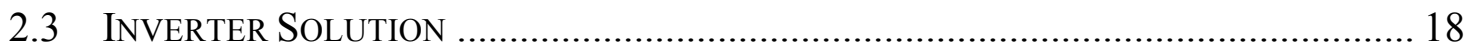

3 DESIGN REQUIREMENTS AND PSCAD MODELING.................................. 20

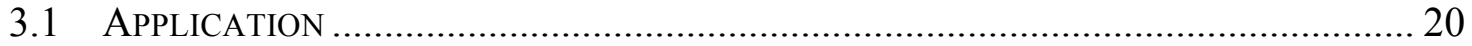

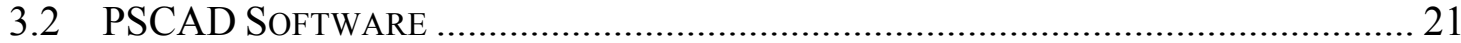

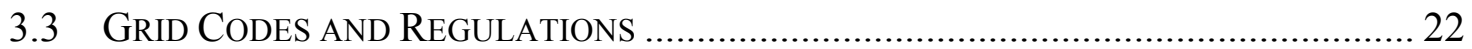

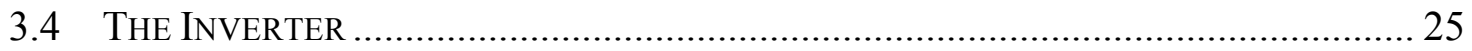

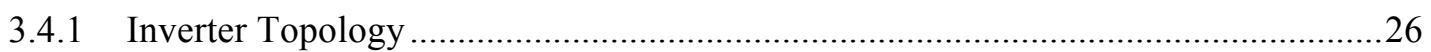

3.4.2 Power Electronic Switches .................................................................................26

3.4.3 Sinusoidal Pulse Width Modulation .......................................................................2

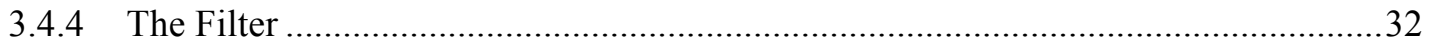

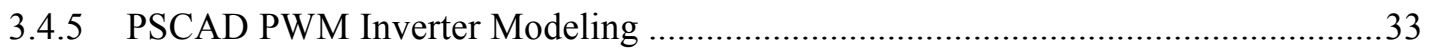

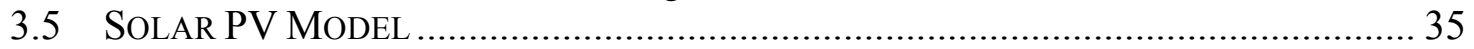

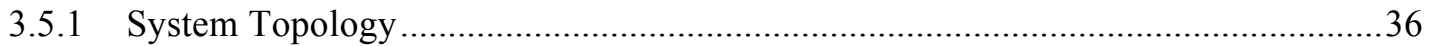

3.5.2 PV Characteristics ..........................................................................................

3.5.3 Maximum Power Point Tracking ..............................................................................39

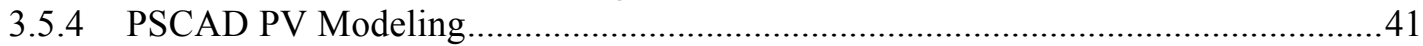

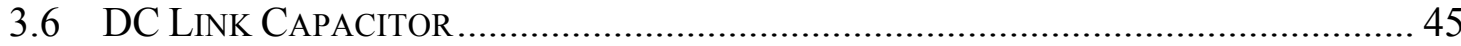

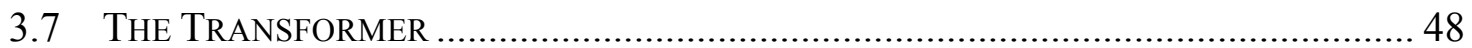

3.7.1 Winding Connection Type …………………………………………………....4

3.7.2 Primary and Secondary Winding Voltages …………………………………….......49

3.7.3 PSCAD Transformer Modeling.........................................................................50

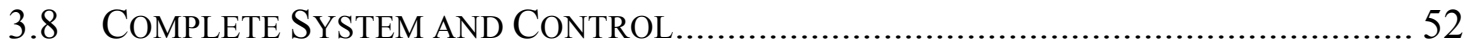

3.8.1 Active Power Control.....................................................................................

3.8.2 Reactive Power Control.........................................................................................

3.8.3 Voltage Regulation and Ride Through................................................................56

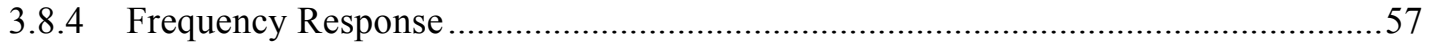

3.8.5 Remote Curtailment and Ramping …………………………………………....58

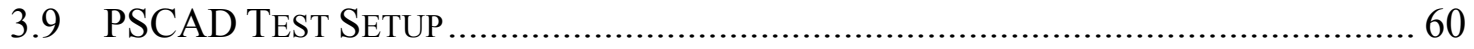

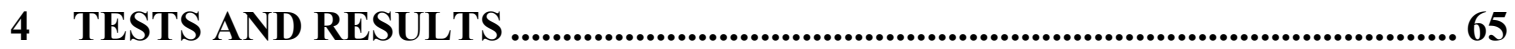

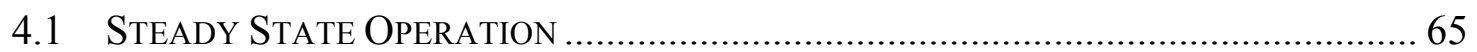

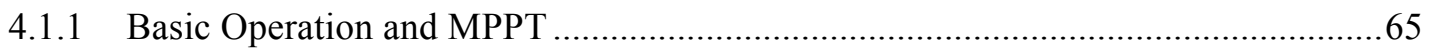

4.1.2 Harmonic Analysis ...............................................................................................69 


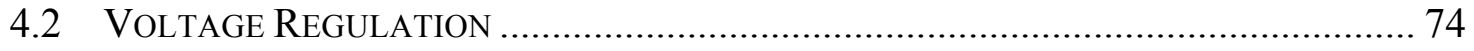

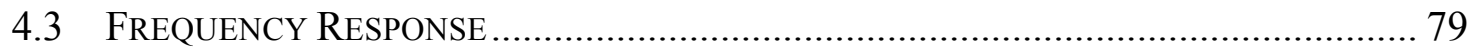

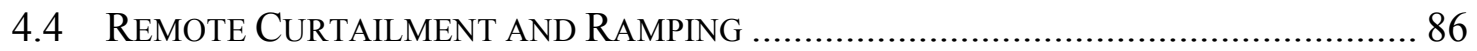

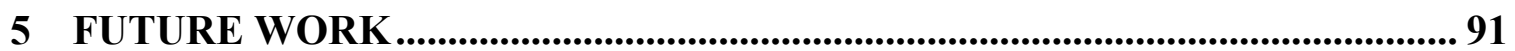

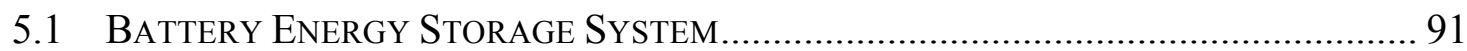

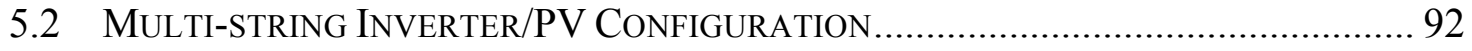

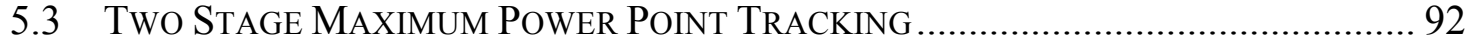

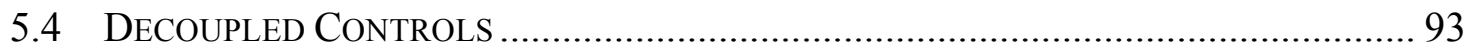

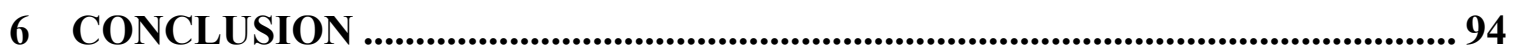

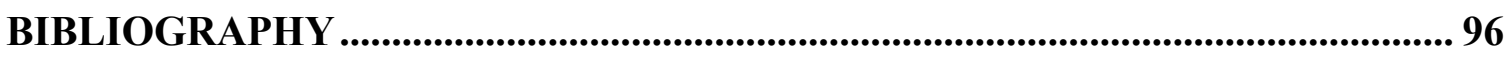

APPENDIX A: VOLTAGE AND CURRENT HARMONIC DATA...................... 100 


\section{LIST OF TABLES}

Table 3.1: Interconnection System Response to Abnormal Voltages [26] ...................... 23

Table 3.2: Interconnection System Response to Abnormal Frequencies [26]................. 23

Table 3.3: Maximum Allowable Injected Current Harmonic Amplitudes [30]............... 24

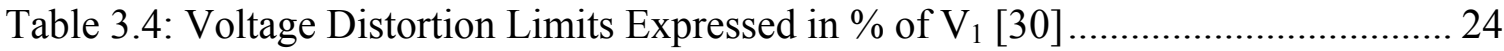

Table 3.5: SPWM Switching Logic [32] ................................................................. 30

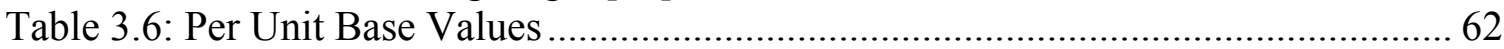

Table 4.1: PV Input Parameters For Basic Functionality Test ..................................... 65

Table 4.2: Comparison of Applicable Voltage Distortion Limits and Measured Harmonic Content *See Appendix A ................................................... 73

Table 4.3: Comparison of Applicable of Current Distortion Limits and Measured Harmonic Content *See Appendix A .................................................... 74

Table 4.4: Voltage Regulation Test Conditions.......................................................... 75

Table 4.5: Frequency Response Test Conditions $*(+=$ Switched on $) \ldots \ldots \ldots \ldots \ldots \ldots \ldots \ldots \ldots . . . . . . . . . . . . . .79$

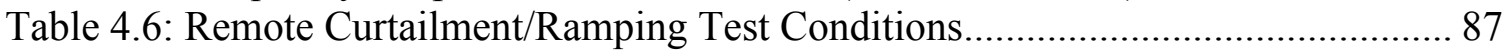

Table A.1: Voltage Harmonic Magnitudes at the PCC During Steady State Operation 100 Table A.2: Current Harmonic Magnitudes at the PCC During Steady State Operation. 101 


\section{LIST OF FIGURES}

Figure 1.1: Renewable Share of Global Final Energy Consumption, 2010 [2] ................ 2

Figure 1.2: Total World Capacity of Solar PV (1995-2011) [2]..................................... 3

Figure 1.3: Laboratory PV Cell Efficiencies (1975-2010) [5]..................................... 5

Figure 1.4: Average PV Module Prices, All Technologies (1980-2008) [5] ..................... 5

Figure 1.5: General Grid Connected PV System .................................................... 6

Figure 1.6: Global Installed PV by Connection Type [7] ............................................ 8

Figure 1.7: U.S. PV Capacity by Connection Type (2000-2010) [5] .............................. 8

Figure 1.8: U.S. Number of Installations by System Classification [5] .......................... 9

Figure 2.1: Typical Sagging Voltage Profile of Radial Distribution System .................. 12

Figure 2.2: Effect of PV Over-Generation on Radial Distribution System ...................... 13

Figure 2.3: Shunt \& Series Type FACTS Devices ..................................................... 17

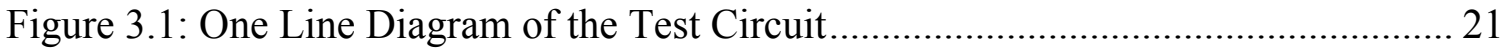

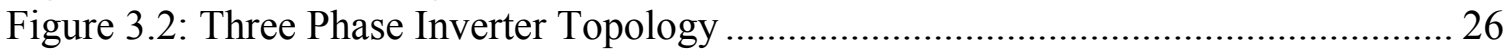

Figure 3.3: SPWM Reference Sinusoidal and Triangle Waveforms $(\mathrm{ma}=1)$................. 28

Figure 3.4: SPWM Reference Sinusoidal and Triangle Waveforms (Zoomed In).......... 29

Figure 3.5: Unfiltered and Filtered $\mathrm{V}_{\mathrm{AB}}$ Voltage Waveforms (Three Cycles) ................ 31

Figure 3.6: Unfiltered and Filtered $\mathrm{V}_{\mathrm{AB}}$ Voltage Waveforms (Half Cycle) .................... 31

Figure 3.7: Three Phase Inverter in PSCAD with Snubber Circuits and Clamping

Diodes.............................................................................................. 33

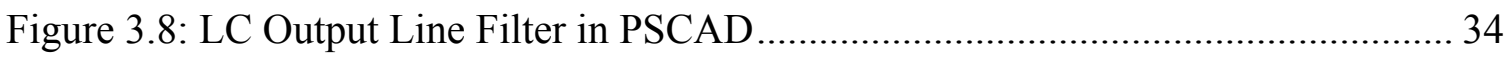

Figure 3.9: Snubber Circuit Component Parameters in PSCAD ................................... 34

Figure 3.10: Reference Sin and Triangle Waveform Generators in PSCAD .................. 35

Figure 3.11: Comparators and Drivers for IGBT Gate Signals in PSCAD ..................... 35

Figure 3.12: Centralized PV Inverter System Topology ............................................. 36

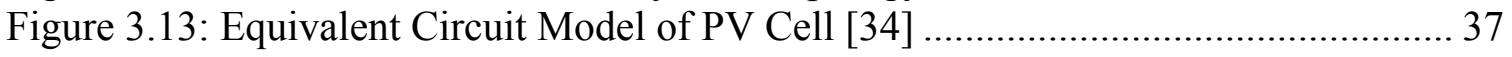

Figure 3.14: Typical I-V and Power Curves for a Solar Cell ....................................... 38

Figure 3.15: Incremental Conductance Algorithm Flowchart [34] [35] ........................ 41

Figure 3.16: Solar Panel and MPPT PSCAD Components .......................................... 42

Figure 3.17: PV Cell and Array Parameter Menus in PSCAD ...................................... 42

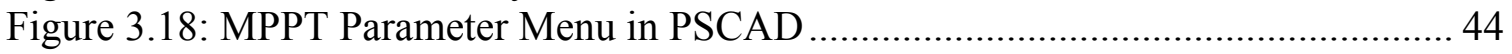

Figure 3.19: PV Inverter Modeled in PSCAD .............................................................. 44

Figure 3.20: Output Power of inverter Showing AC and DC Components..................... 46

Figure 3.21: Output Power Ripple Due to Voltage Ripple [36] ..................................... 48

Figure 3.22: Single Line Diagram of Three Phase Delta-Wye Transformer Model in

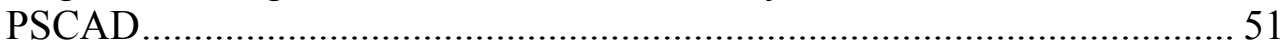

Figure 3.23: Transformer Input Parameter Menu PSCAD ............................................ 51

Figure 3.24: Complete Grid Tied PV Inverter Power Stage Modeled in PSCAD........... 52

Figure 3.25: Simple Two-Port Network ......................................................................... 53

Figure 3.26: Real Power, Power Angle, and MPPT Control Modeled in PSCAD .......... 54

Figure 3.27: Reactive Power, Voltage, and Modulation Index Control Modeled in

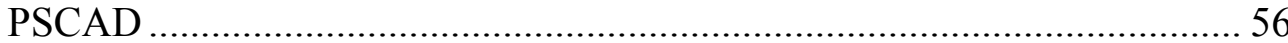

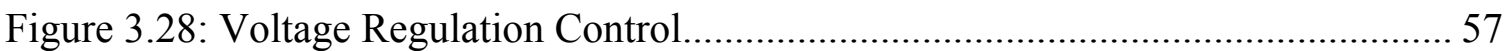

Figure 3.29: Complete Active Power Control Scheme.................................................. 59

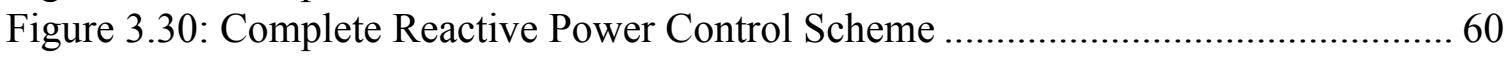


Figure 3.31: One Line Diagram of Test Circuit Modeled in PSCAD ........................... 61

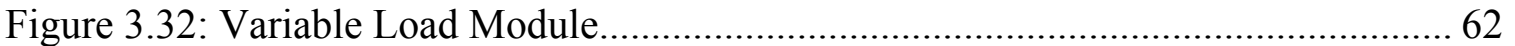

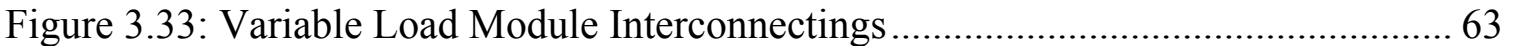

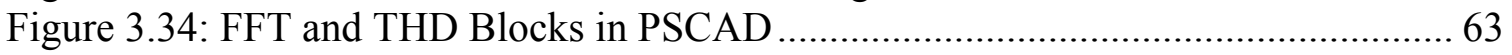

Figure 3.35: Voltage and Current Harmonic Amplitudes in \% of Rated Value ............... 64

Figure 4.1: PV Array Voltage, Current, and Power with Varying Irradiance and

Temperature

Figure 4.2: Inverter Real and Reactive Output Power, Power Angle, and Modulation Index Under Varied Solar Irradiance and Temperature ...............................6.6.6. 68

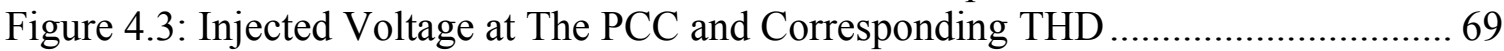

Figure 4.4: Injected Current at The PCC and Corresponding THD ............................ 70

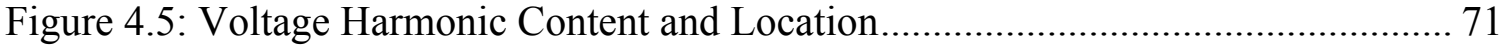

Figure 4.6: Current Harmonic Content and Location ................................................... 71

Figure 4.7: Current Harmonic Amplitudes Expressed as \% of Rated Current ................ 72

Figure 4.8: Voltage Harmonic Amplitudes Expressed as \% of Rated Voltage ............... 72

Figure 4.9: PCC Bus Voltage With Inverter Operating at Unity Power Factor .............. 76

Figure 4.10: PCC Bus Voltage With Voltage Regulating Capability Enabled................. 76

Figure 4.11: Inverter Real and Reactive Output Power, Power Angle, and Modulation Index Operating at Unity Power Factor ................................................ 77

Figure 4.12: Inverter Real and Reactive Output Power, Power Angle, and Modulation Index Operating with Voltage Regulating Capability Enabled.................... 78

Figure 4.13: System Frequency for Run \#1 ........................................................... 80

Figure 4.14: Active and Reactive Powers, Power Angle, and Modulation Index for

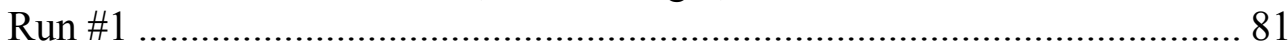

Figure 4.15: PCC Voltage for Run \#1 ....................................................................... 82

Figure 4.16: System Frequency for Frequency Response Run \#2 .............................. 84

Figure 4.17: Active and Reactive Powers, Power Angle, and Modulation Index for

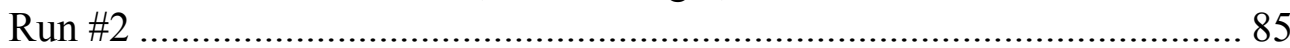

Figure 4.18: PCC Voltage for Frequency Response Run \#2 ....................................... 86

Figure 4.19: Inverter Real and Reactive Output Power, Power Angle, and Modulation Index Operating Based on Reference Values ......................................... 88

Figure 4.20: PCC Voltage with Inverter Operating in Remote Curtailment/Ramping Mode

Figure 4.21: PV Array Voltage, Current. and Power with Inverter Operating in Remote Curtailment/Ramping Mode 90 


\section{Introduction}

This study analyzes the effect grid tied photovoltaic (PV) inverters can have in improving power system stability. Further, this study looks into the active and reactive power output capabilities of grid tied PV inverters and how their control can influence the power systems voltage and frequency. Aside from local sensing and control, the ability to remotely regulate the inverters output is considered. A grid connected PV inverter system is created and modeled in PSCAD software to examine the effects and benefits of the new smart features.

\subsection{Renewable Energy}

The global population has grown considerably over the past two decades and will continue to grow at an increasing rate based on historical trends. Every year the addition of humans to this Earth will increase and the resources required to support them will also increase. Of the resources, one of the most vital to support the technological advancing population is energy.

The energy crisis became transparent in the late 1900's and birthed the desire to find additional energy resources to meet rising energy demands [1]. One option was to increase generation of currently used energy sources such as nuclear, fossil fuel, etc. And the other was to explore new renewable energy alternatives. Many different renewable energy sources have emerged as feasible solutions and each one of them has their own positive and negative attributes. As a whole, renewable energy sources all share the fact that their fuel is primarily free and they produce minimal to no waste. These factors are the main incentive for countries to begin incorporating renewables into their energy portfolio. 
An estimated $16.7 \%$ of global energy consumption in 2010 was supplied by renewable energy [2]. A further breakdown of where the world's energy came from in 2010 is shown in Figure 1.1. Only 16.7\% of global energy coming from renewables may not seem to be a vast amount, however in 2011 nearly half of the new electric power capacity installed was from renewables alone. The percentage of energy from renewables has increased every year for the past several years, and is predicted to continue with this trend in the future.

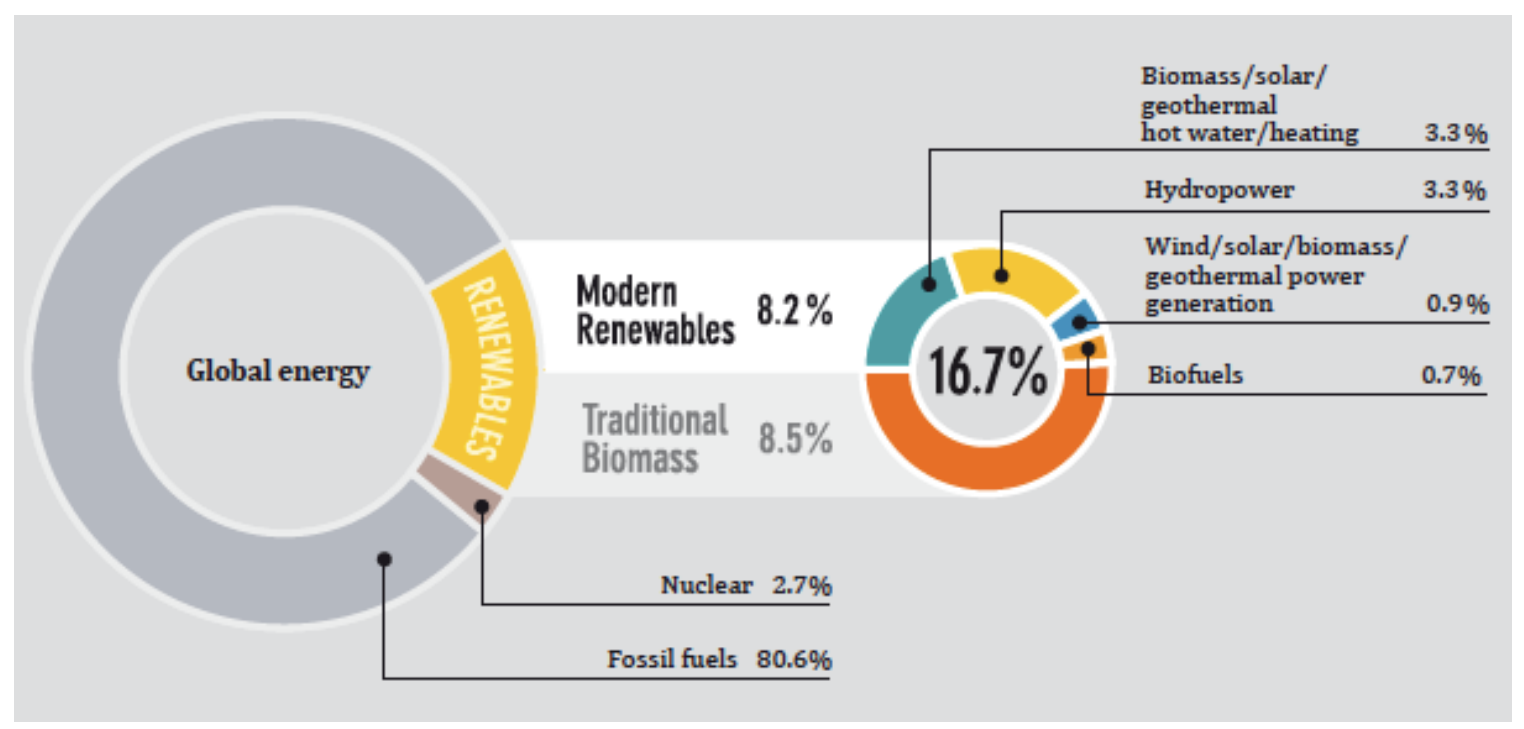

Figure 1.1: Renewable Share of Global Final Energy Consumption, 2010 [2]

Further analyzing Figure 1.1, the largest source of energy used globally is fossil fuels. Two of the largest other sources of energy are nuclear and hydropower. Fossil fuels are non-renewable and generate harmful pollution when burned for energy. Nuclear power plants have the potential to be a great energy source. However, they generate toxic nuclear waste that has to be buried and also always poses the risk of a meltdown, which could be catastrophic for the neighboring environment. Hydropower generation requires damming a river or body of water, disrupting its natural flow, and completely changing the surrounding ecosystem. A form of renewable energy gaining recent 
popularity is solar. Solar energy is one of the cleanest forms of energy available, converting energy from the sun to electricity without any waste or harmful byproducts. Solar is the renewable energy source this thesis will be focusing on.

\subsection{The Solar Resource}

The sun is a tremendously powerful energy source; in fact the earth's surface receives enough energy from the sun in one hour to meet its energy requirements for one year [3]. Solar technology was originally created to power some of the first satellites used in space in the 1950's [1]. When the technology was in its early form its uses were limited, to such applications as space, due to economic practicality. However, in the last five years the solar market has experienced rapid growth. From 2010 to 2011 an additional 30GW of new solar PV capacity was added globally, bringing the total world capacity to 70GW [2]. Figure 1.2 shows the exponential increase, especially over the last five years, of PV capacity.

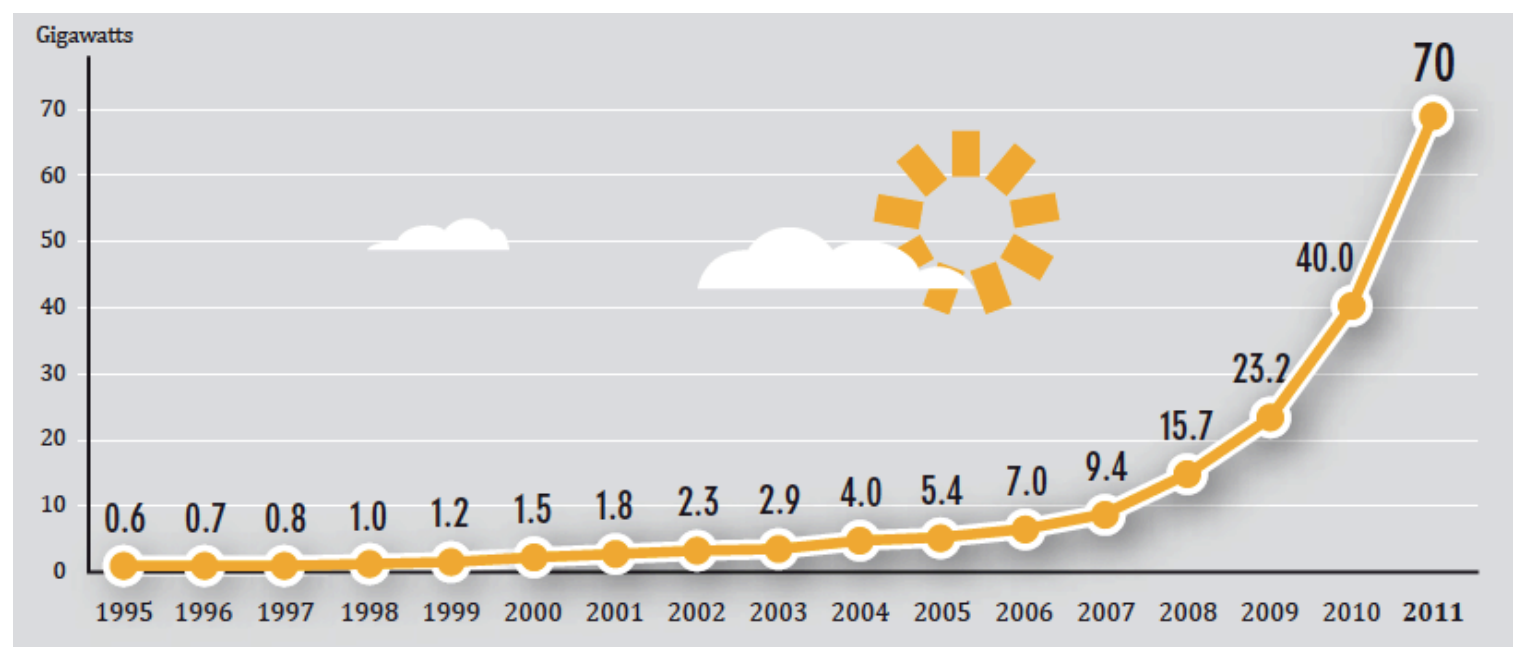

Figure 1.2: Total World Capacity of Solar PV (1995-2011) [2]

The growth of installed PV can be attributed to many factors but the main reasons are increases in environmental considerations, new state laws and regulations, purchase 
incentives, increases in PV cell technology and efficiency, and decreases in overall system cost [1]. Increasing PV cell efficiency can be seen in Figure 1.3. The figure shows there are multiple types of materials used in the manufacturing of PV cells, all with different efficiencies, but the general trend is that they are all increasing. PV cell materials are not chosen simply because they boast the greatest efficiency. The best materials for PV cells offer the greatest cost to efficiency tradeoffs. An example of this is that thin film technology has a lower efficiency than crystalline silicon cells, however due to the lower cost, it is more effective in some cases to mass produce the less efficient cell. The decreasing cost of panels is seen in Figure 1.4. With the decreasing cost, increasing efficiency, and government incentives such as California Governor's Executive Order S14-08 [4], which stated that the State of California would supply thirty-three percent of its electrical load from renewable sources by 2020 , there is no doubt that the demand and use of solar technology will rise. 


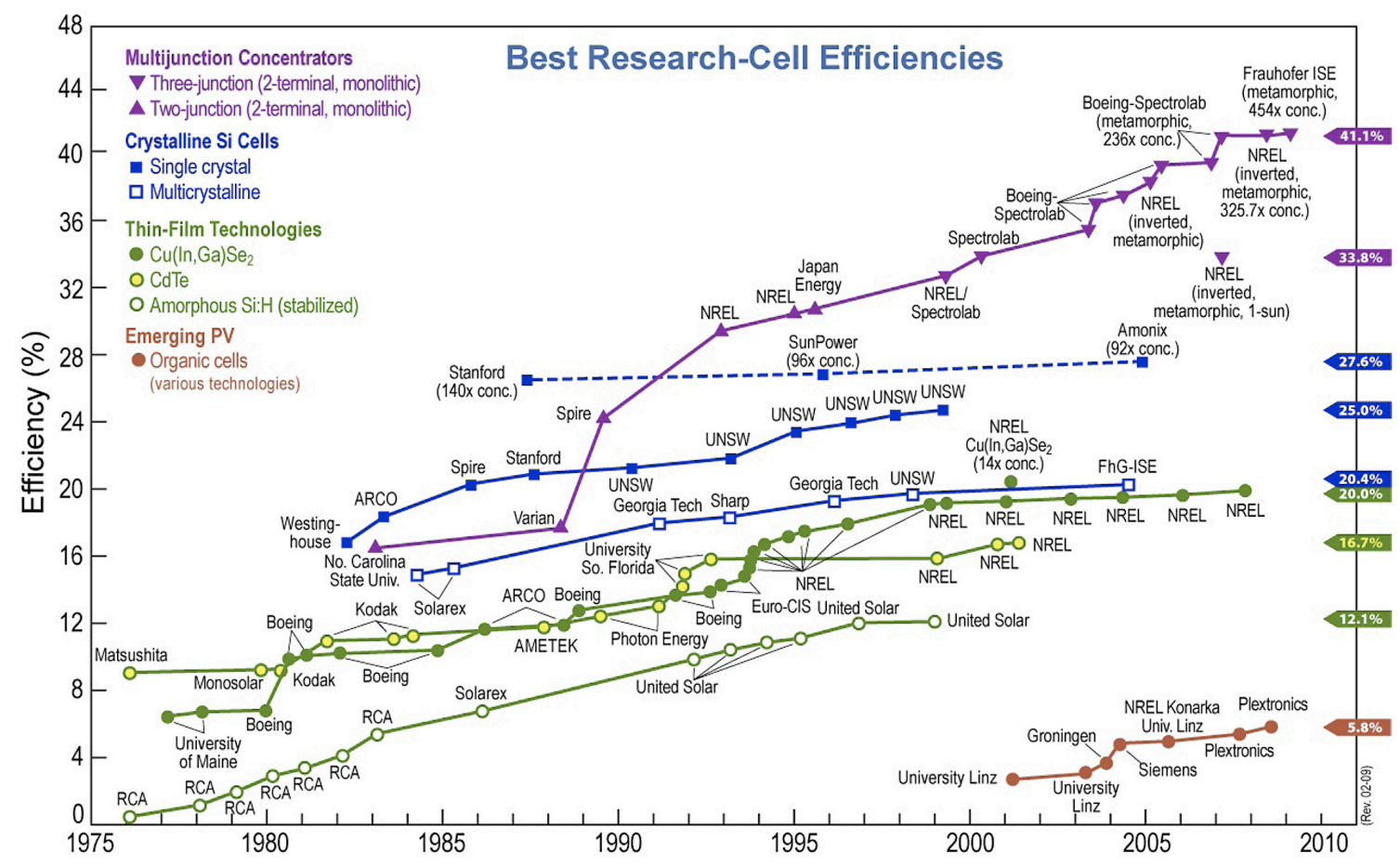

Figure 1.3: Laboratory PV Cell Efficiencies (1975-2010) [5]

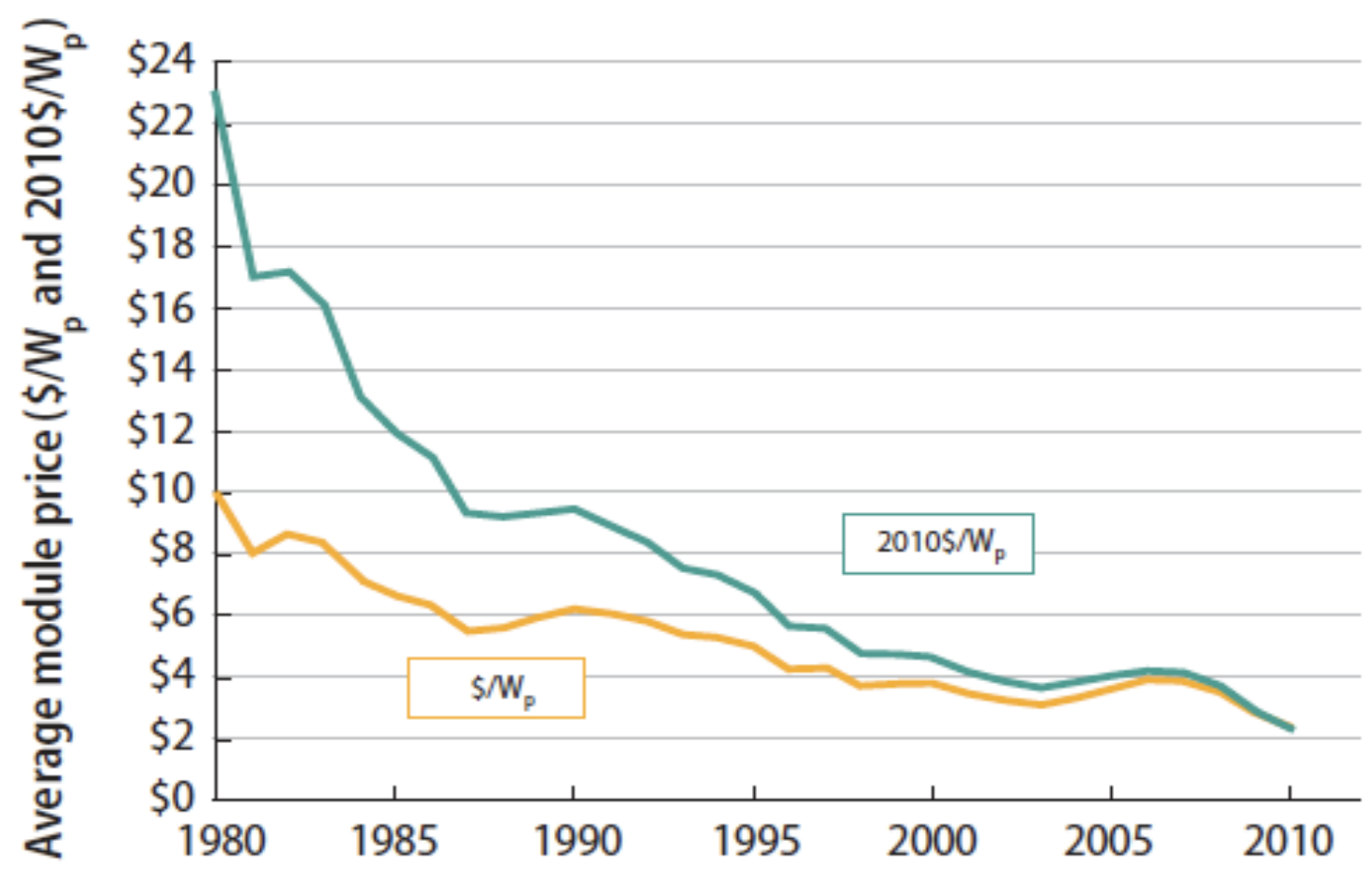

Figure 1.4: Average PV Module Prices, All Technologies (1980-2008) [5] 


\subsection{PV Applications}

Solar applications range from solar farms that can generate hundreds of megawatts such as the $550 \mathrm{MW}$ Topaz solar farm [6] to small residential rooftop systems that only generate a few kilowatts. The ability for PV systems to vary greatly in magnitude is a demonstration of how scalable and modular solar systems are. Looking at every type of solar application, at the highest level each one can be lumped into one of the two main types of PV system categories, either grid tied or off grid.

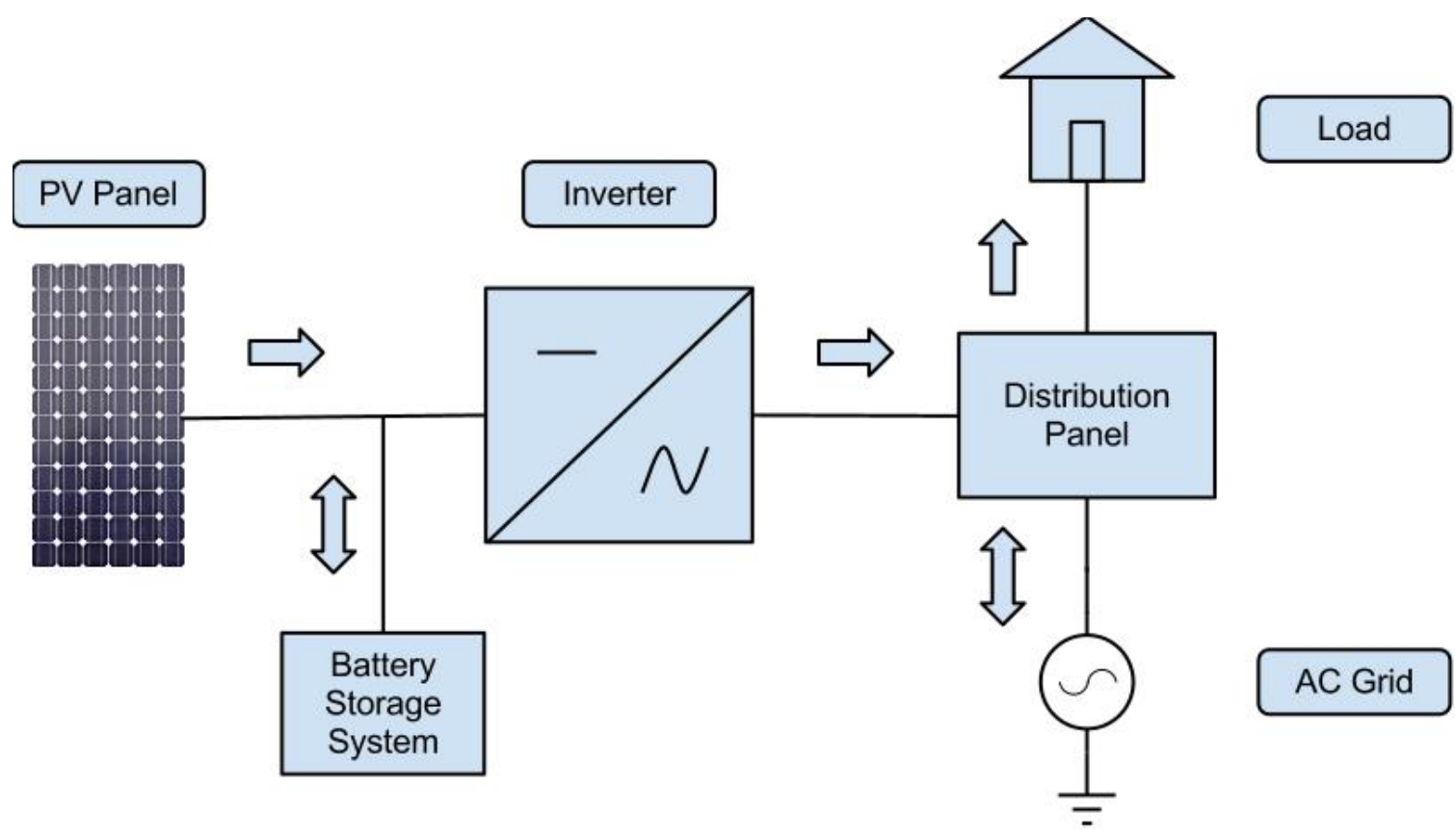

Figure 1.5: General Grid Connected PV System

Off grid systems supply a local load and when the panel's generation exceeds the load the excess energy is usually stored in a battery system for later use. Grid tied systems are connected to the local utility network and can supply power back to the power grid when the panels generation exceeds the local loads demand. Some grid connected systems still have battery storage capability. For a residential system the local load is a home and everything inside consuming power. Both off grid and grid tied 
systems can help offset a customers net energy consumption, but grid tied systems have the potential for the customer to sell back generated power at cost to the utility.

When solar systems first emerged off grid systems held a larger share of the market than grid tied systems but it did not take long for grid tied systems to overtake off grid systems [5]. Figure 1.6 depicts the large global increase in grid tied systems recently. The shift from off grid systems to grid tied systems is even more prevalent in the United States [5]. At the end of 2010 the U.S. had an estimated $2.5 \mathrm{GW}$ of installed solar capacity and $2.1 \mathrm{GW}(82 \%)$ was grid connected. Figure 1.7 shows the United States PV Capacity by connection type. Aside from looking just at the type of PV system, another interesting trend is observing the size of the installed system by classifying it as either residential or utility scale. Figure 1.8 displays not only overall growth in the annual number of PV installations in the U.S. but more importantly how the number of residential installations holds the majority of the market and is increasing the fastest. 


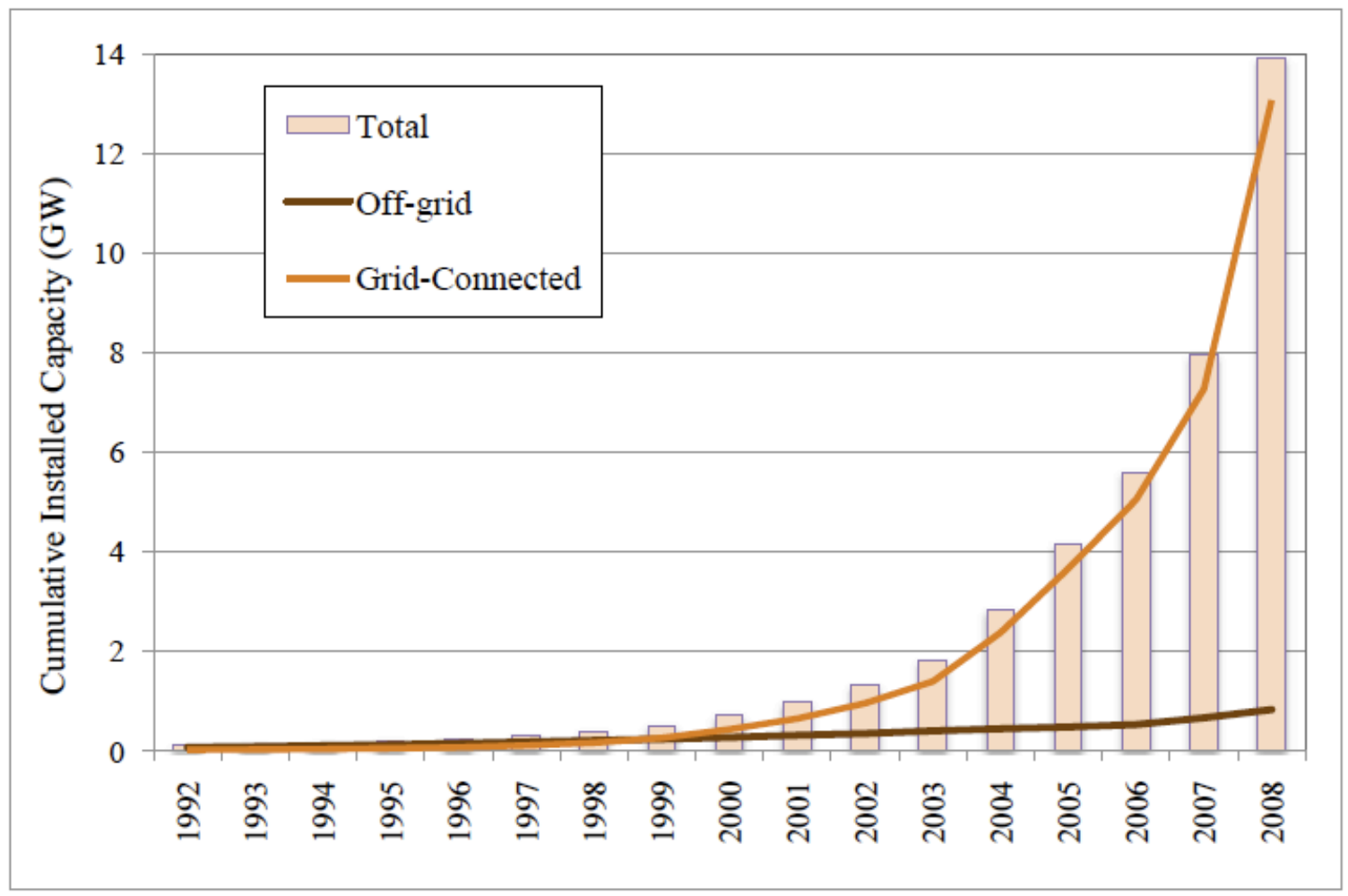

Figure 1.6: Global Installed PV by Connection Type [7]

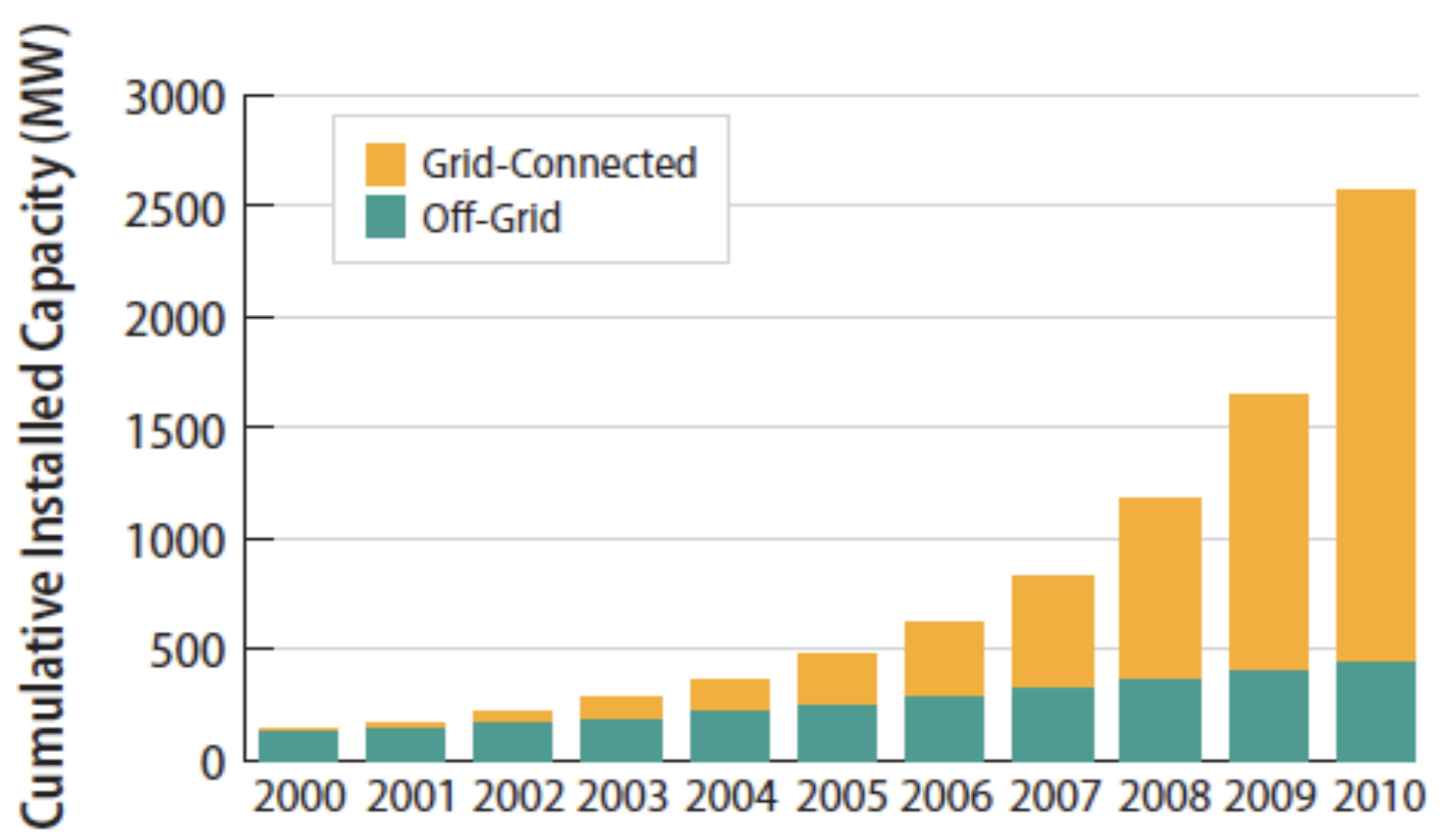

Figure 1.7: U.S. PV Capacity by Connection Type (2000-2010) [5] 


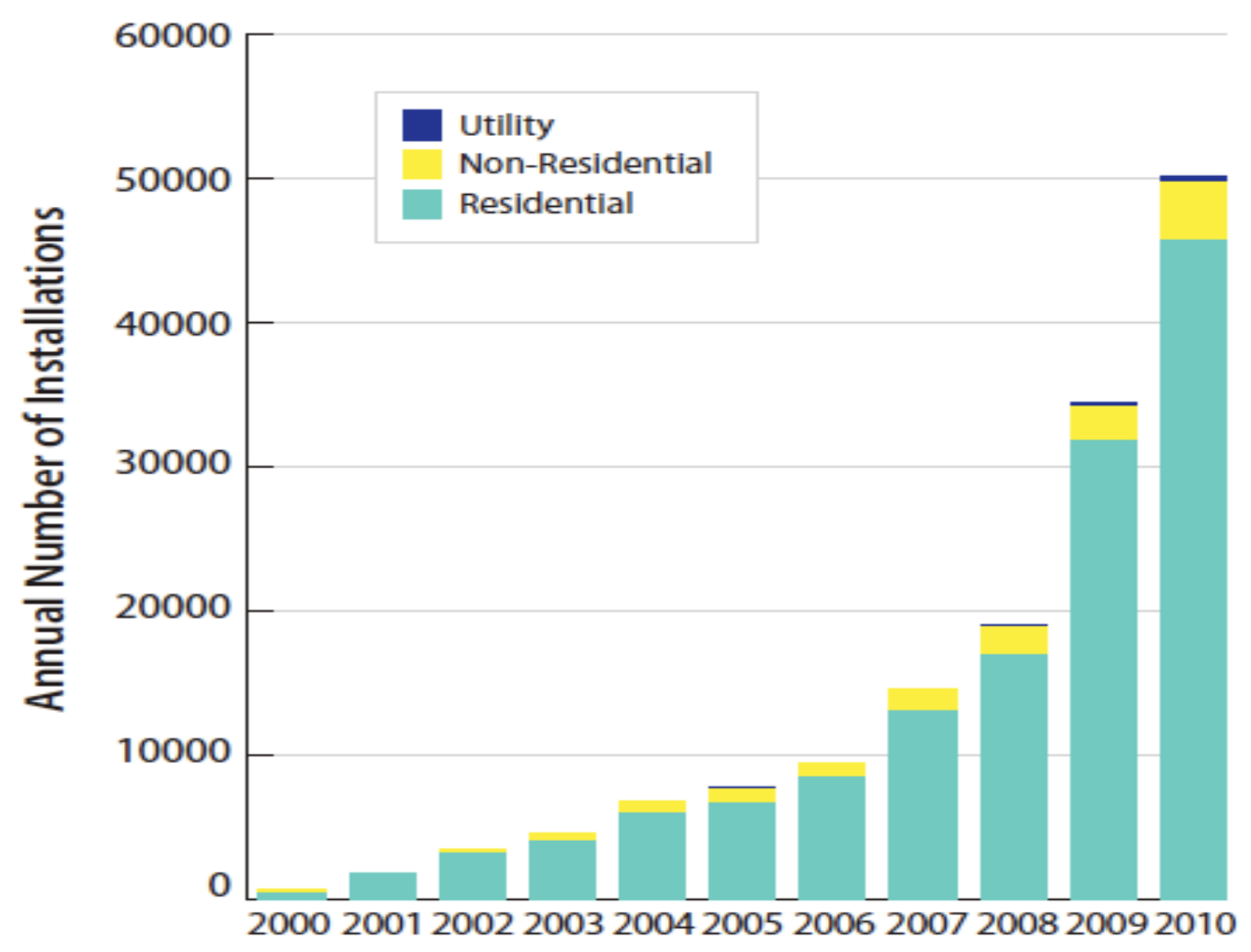

Figure 1.8: U.S. Number of Installations by System Classification [5]

Based on trends in the figures presented earlier, there has been a very large increase in solar capacity. Moreover, there has been tremendous growth in the grid connected residential size applications of solar [5]. Special considerations need to be taken into account with the increase in distributed generation. Distributed generation is the use of smaller generating sources located near the load [8]. The rise in distributed generation is completely changing the power grid. Traditionally, power is generated remotely from where it is being used and is transmitted great distances, incurring loss, over transmission/distribution lines until it finally reaches the load. More importantly, the power flow was unidirectional and fairly constant, from source to load. Now with the rise in distributed generation, power is flowing in both directions depending on the load 
demand, current generation of the grid connected solar systems, and other grid connected renewable sources. This bidirectional power grid is one attribute of what is today being called the "smart grid".

\subsection{The Smart Grid}

The concept of the smart grid is a very large and complex topic. A definition by the U.S. Department of Energy is given as:

An automated, widely distributed energy delivery network, the Smart Grid will be characterized by a two-way flow of electricity and information and will be capable of monitoring everything from power plants to customer preferences to individual appliances. It incorporates into the grid the benefits of distributed computing and communications to deliver real-time information and enable the near-instantaneous balance of supply and demand at the device level [8].

Analyzing the definition, concentrating on the power stage and less on the communication aspects of the smart grid concept, it is apparent that the new grid will require every attached device to also be "smart" and make control decisions on their own instantaneously or from remote input. The smart capabilities will allow for any and all types of renewable energy sources to interface to the grid and in essence allow for higher levels of distributed generation to be attainable.

The dynamic bidirectional power flow property of the evolving power grid is critical for the ability to bring more renewable resources on locally. Conversely, the current infrastructure of the power grid is the same as what it was originally constructed for, a static unidirectional power highway [9]. As intermittent power sources such as solar, which could completely stop generation when a cloud is overhead, are grid connected, the power grid must be dynamic and react to the sudden change in input power to maintain system stability. On the same note, if a grid disturbance is detected smart devices connected to the grid should react in such a manner to help fix the grid 
back to its normal state even if that is not the devices primary function. In transitioning to the smart grid, the physical transmission lines of the grid are not necessarily what needs to be updated, but the control philosophy, real time monitoring of the grids current health, and self-healing ability are all qualities the smart grid requires that can be implemented by making the devices attached to the grid smarter. 


\section{Background}

Grid tied PV systems at the distribution level can have a large impact on the power systems voltage, frequency, power flow, and reliability [10] [11] [12]. This is especially true if the solar system is of large size, if the system is at the end of a weak feeder, or a combination of the two. Many solutions have been proposed and installed in attempt to help correct system instability.

\subsection{Voltage and Frequency Fluctuations}

In an ideal situation the voltage profile along a transmission or distribution line is flat. However, this is hardly ever the case. The most common voltage profile is a sagging one in which the line voltage slowly drops in magnitude as the distance from the power source grows [9]. An example of a sagging voltage profile of a typical radial distribution system can be seen in Figure 2.1.

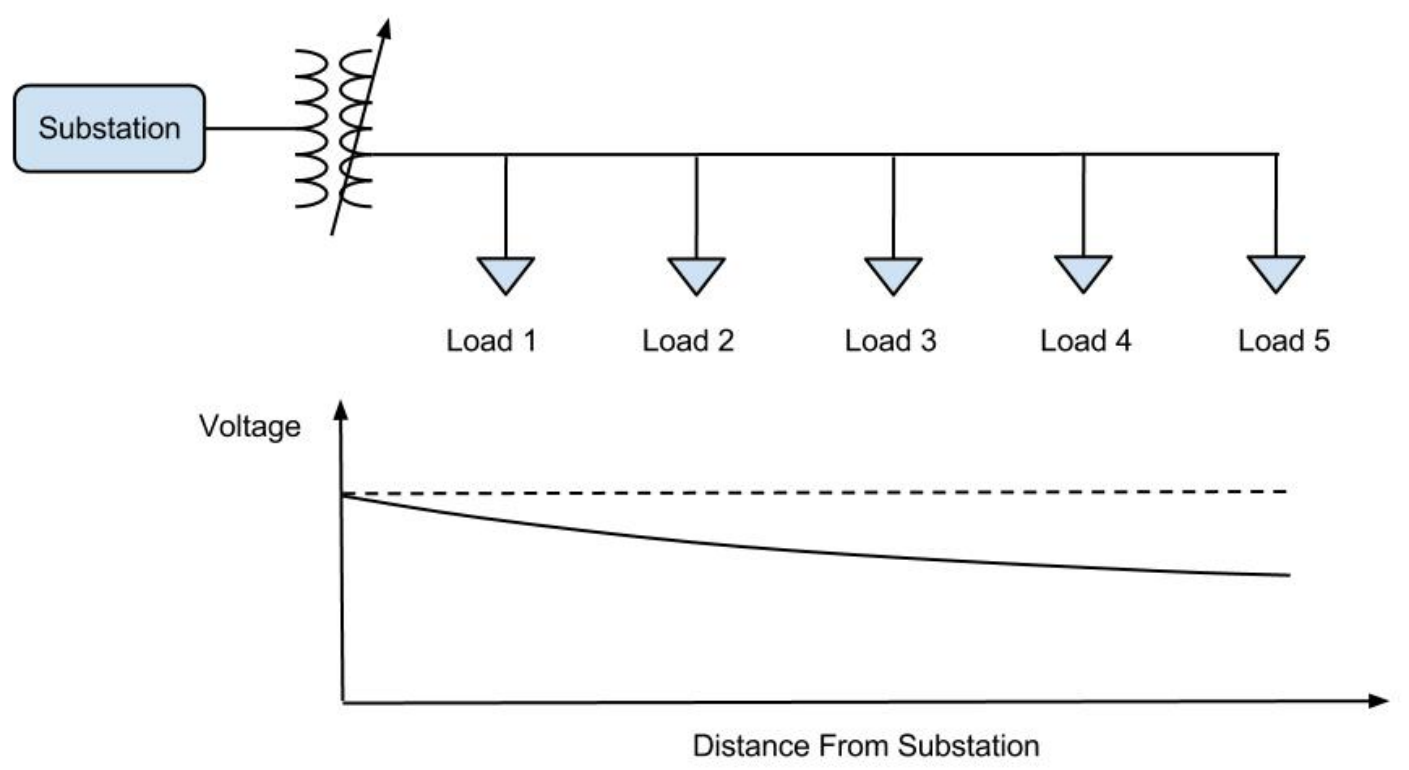

Figure 2.1: Typical Sagging Voltage Profile of Radial Distribution System 
The voltage drop problem is due to the impedance in the conductor, and it becomes worse during heavy loading conditions [13]. Aside from various loading conditions and sagging voltage profiles the voltage may periodically fluctuate due to line outages, dropped generation, unusually high or low load conditions and other disturbances [14].

Currently, the large increase in distributed generation has caused a different effect on the voltage profile. When the grid connected distributed resources, solar for example, inject more power to the grid than the local area needs the voltage tends to rise in that area [15]. The voltage profile is most impacted when the injected power of the grid tied resource is greater than the load on its feeder [13]. A rising, or swelling voltage profile can also occur during light loading conditions. A combination of light loading and large generation, easily realizable for solar power when people are at work during the day and the sun is shinning its brightest, can have a significant influence on the feeder voltage [16]. In some cases the voltage rises to a level such that it becomes greater than specified limits and certain generation systems have to be disconnected from the grid, wasting potential clean renewable energy production [17].

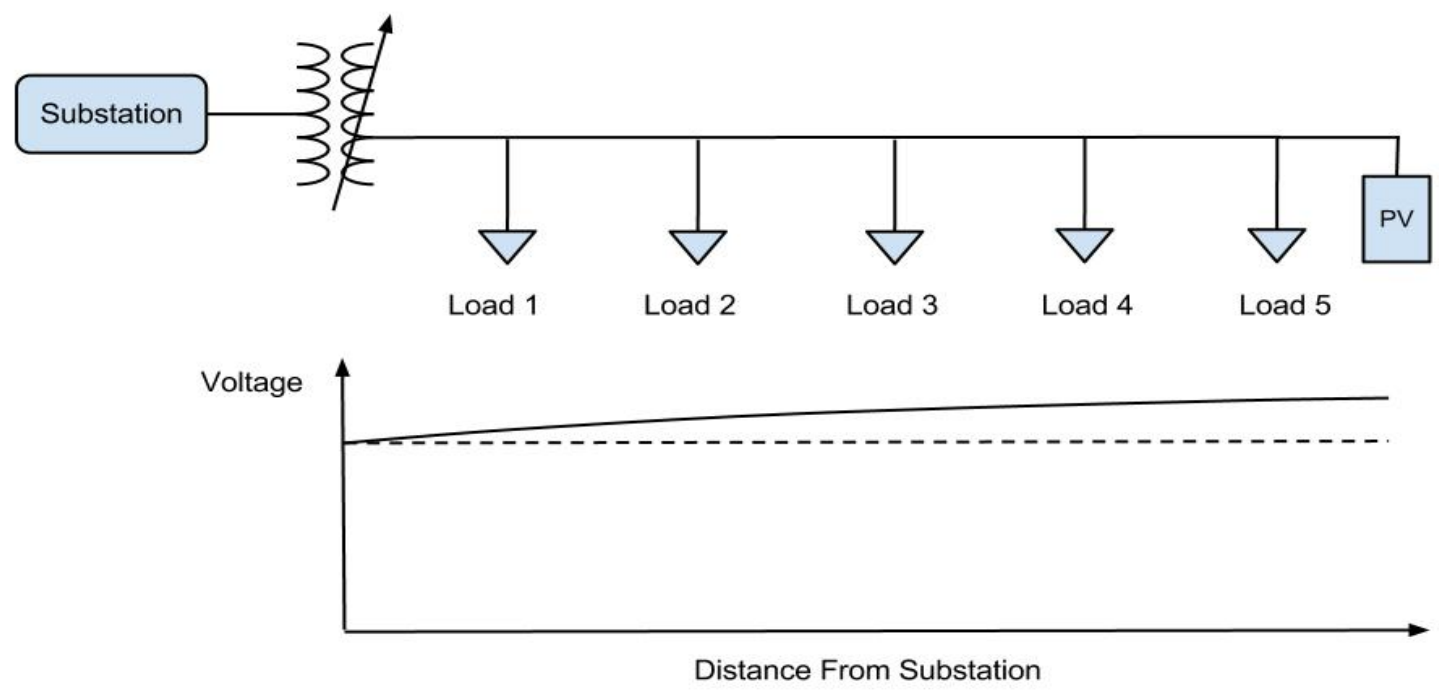

Figure 2.2: Effect of PV Over-Generation on Radial Distribution System 
Frequency can vary in a power system when there is an imbalance between power generation and demand [11]. Sudden changes in generation can occur if there is a sudden loss of a generator or other power source, which could be caused by numerous system contingencies. Knowing frequency can be affected by a sudden change in generation, as solar power generation grows to become a larger and larger percentage of total generation, its unpredictable characteristics are going to become detrimental to the system frequency and overall system stability if something is not done.

Solutions to help support voltage and frequency at the distribution level range from simple to sophisticated. The primary concern at this lower level is the voltage regulation. Frequency is less of a concern far away from large generating sources because the system frequency is the same everywhere along the transmission and distribution lines whereas the voltage is not. Further, the ratio of a typical feeder load compared to the power capability of the connected grid is typically small, meaning the system frequency cannot be greatly influenced by variations on that feeder. When frequency is below or above the nominal value the solution is not typically implemented at the distribution level but instead larger power plants that play a greater role in frequency regulation are controlled to either increase or decrease their generation to maintain it [11]. However, as sources continue to emerge locally at the distribution level, such as residential PV, it will not be long until their collective generation will be able to modify the system frequency.

\subsection{Existing Solutions}

The typical equipment implemented to regulate voltage at the distribution level are on load tap changing (LTC) transformers, step voltage regulators (SVR), and 
switched capacitor banks (SCB) [9] [18]. A load tap changing transformer is simply a transformer in which the output, known as the tap, on one of the windings is variable in such a way that a certain number of turns may be selected. By changing the number of effective turns on one of the transformers windings the voltage of the tap is adjustable. An LTC is automatically controlled in most cases to regulate a bus voltage within specified limits due to varying voltage drops caused by varying loads. A switched voltage regulator operates in a similar method to the way LTCs do on substation transformers, it is essentially an autotransformer with adjustable taps to step voltage up and down. SVRs are usually used on feeders with a large voltage drop where a LTC cannot keep the voltage within tolerance. SCBs are paralleled capacitor banks installed along a feeder that switch on when voltage is below a certain value, when switched on the SCBs inject lagging reactive power (leading current) which helps increase the sagging voltage.

Load tap changing transformers and voltage regulators have been implemented at the distribution level successfully for a long time but as the integration of higher levels of distributed generation appear problems with their ability to control voltage begin to develop [12]. The main drawback, which prevents them from regulating voltage levels, is their relatively slow operation compared to the rapid fluctuations in generation from renewables. Another problem caused by the variable distributed generations output is the increased number of tap switches the device performs over a day attempting to compensate the changing generation [18] [19] [20]. Increased operations decrease the devices lifespan and increase the amount of maintenance that must be done on the device [20]. In this study [21] LTCs duties might increase and/or become excessive with added 
local generation. The duties, briefly stated, are added control features that must be implemented by the LTC when reverse power flow occurs. Some old LTC transformers may not be capable of implementing the mentioned new control features; the same argument can be applied to SVRs.

Switched capacitor banks are employed to increase sagging voltage profiles. As described earlier, the addition of more distributed generation can cause feeder voltage to rise, and for a swelling voltage profile, SCBs cannot help mitigate the problem. Another disadvantage of SCBs, which also applies to LTCs and SVRs, is their intrinsic step based control [18]. The regulating devices themselves can only operate at discrete levels and not over a continuous range. For example, a SCB has only so many capacitors it can combine in parallel and can only inject lagging reactive power in steps of that discrete number of combinations. Traditional methods for voltage compensation, including LTCs, SVRs, and SCBs, are becoming outdated with the increase in distributed generation and cannot effectively regulate the new voltage problems distributed generation introduces to the power system.

Another relatively new method for voltage compensation and power flow control in utility networks is the use of Flexible AC Transmission Systems (FACTS) devices. FACTS devices primarily have been used in transmission applications but the need for voltage regulation improvement at the distribution level has expanded their uses. All of the FACTS devices can be categorized into two types, series and shunt devices [22]. Series devices are inline with the transmission line and are best used to control power flow. Shunt devices are connected in parallel to the transmission line and are most effective at providing reactive power compensation to the system. The advantageous 
FACTS devices to distribution networks are the shunt connected devices because of their ability to improve voltage profiles, correct power factor, and reduce line loss [23]. The main types of FACTS devices are the Static VAR Compensator (SVC), Static Synchronous Compensator (STATCOM), Thyristor-Controlled Series Capacitor (TCSC), Static Synchronous Series Compensator (SSSC), and Unified Power Flow Controller (UPFC) [22]. The SVC and STATCOM are shunt devices, the TCSC and SSSC are series devices, and the UPFC is a hybrid series-shunt device. Detailed mathematical descriptions of each of their operations and functions can be found in [24] [25].

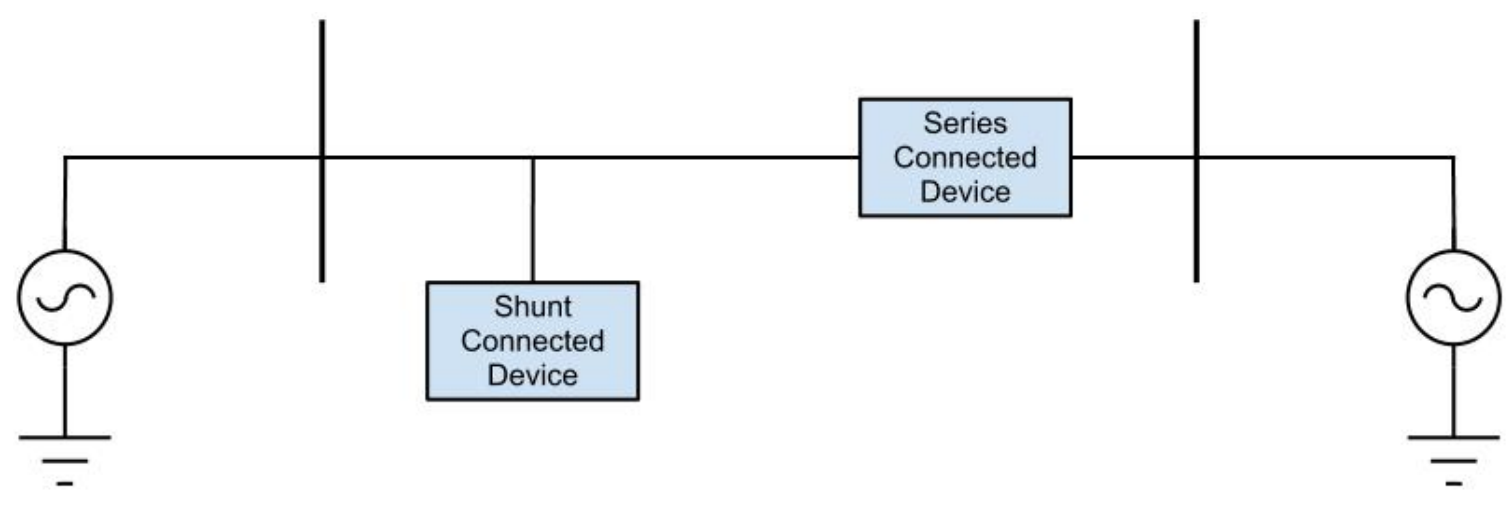

Figure 2.3: Shunt \& Series Type FACTS Devices

A SVC consists of a fixed inductor in parallel with a thyristor switched capacitor, or a fixed capacitor in parallel with a thyristor switched inductor [22]. Either configuration results in similar operation, a variable reactance connected in shunt to the distribution line. Based on the firing angle of the thyristors the device has a variable reactance that can provide leading or lagging reactive power to help increase or decrease the voltage level on the line. This is an improvement over the switched capacitor banks because the effective reactance can be capacitive or inductive, meaning it can compensate for voltage sags and swells. 
Briefly, a STATCOM is composed of a DC energy storage system and an inverter to convert the $\mathrm{DC}$ energy to an $\mathrm{AC}$ form [22]. When the produced AC voltage of the inverter is of higher magnitude than the voltage on the shunt connected line lagging reactive power is injected having a capacitive effect. When the magnitude of voltage produced is less than the line voltage leading reactive power is absorbed. The type of inverter used determines how the magnitude of the voltage produced by the inverter is controlled. For transmission scale applications the device is referred to as a STATCOM, at the distribution level the device is known as a D-STATCOM. At the distribution level the benefits of shunt FACTS devices over traditional forms of voltage regulation described previously is the ability to inject both leading or lagging reactive power almost instantaneously over a continuous range. The extremely fast operation of variable reactive power makes the SVC and STATCOM ideal in controlling feeders with unpredictable distributed energy resources. The disadvantage of using shunt FACTS devices is that extra equipment, the FACTS device itself, must be bought and installed to help prevent the negative effects of the distributed resource. The solution to this is to use the inverter in the distributed resource in a similar way to how the STATCOM is operated. Instead of adding additional equipment to mitigate a problem, why not let the device that is causing the problem regulate itself.

\subsection{Inverter Solution}

An inverter is the hardware link between the AC power grid and DC generating distributed resources. Most of the voltage swell problems arise because the inverter is required, by grid code, to operate at unity power factor [15] [26] and cannot provide any reactive power support or real power curtailment to help fix the problems it is creates. 
The most logical solution to this problem is to allow advanced controls to be implemented by the inverter to regulate voltage and frequency rather than adding another compensation device such as a STATCOM or switched capacitor bank to deal with the problem.

A smart inverter is a grid tied inverter with the advanced controls to regulate voltage and frequency by command or autonomously. There has been an ongoing effort in attempt to allow grid tied PV inverters to provide the grid with support functions but the lack of a standard and ongoing drafts of IEEE 1547 has held the implementation back. The focus of this thesis is to design and model a smart inverter receiving input from solar PV generation in the PSCAD software environment that will implement the following features for use in a low voltage distribution network provided by San Diego Gas and Electric. First, the smart inverter will be able to actively participate in voltage regulation. This means if the grid voltage is sagging or swelling the smart inverters output will adjust accordingly to alleviate the abnormality. Second, the smart inverter will sense the grid frequency and provide output functionality capable of maintaining it at nominal value. Third, if a nearby disturbance occurs the smart inverter will provide ride through support in effort to maintain system voltage until protection equipment can clear the fault or disturbance. Lastly, the smart inverter will have ramping and remote curtailment abilities. These abilities allow the smart inverter to operate at various levels of output power automatically or from remote command. 


\section{Design Requirements and PSCAD Modeling}

On the market today grid tied inverters exist in many forms. Every application requires a careful design and selection of the components that make up the inverter system. In addition to application specific design constraints every grid tied inverter must meet certain grid codes and regulations based on the installation location.

\subsection{Application}

The design problem of this thesis is based on a circuit provided by San Diego Gas and Electric (SDG\&E). The test circuit is a three phase $12.47 \mathrm{kV}$ distribution line which begins at a substation before the feeder splits into two sections servicing loads in radial fashion as the line continues. The circuit can be seen in Figure 3.1. The problem in this circuit is the 2MW PV generation located at the end of the lower branch of the circuit. During very sunny and clear days when PV panels operate at their highest output power the voltage along the feeder where it is connected begins to rise above tolerable limits. This is due to over generation in the area and the inverter not providing any reactive power support to help regulate the voltage. 

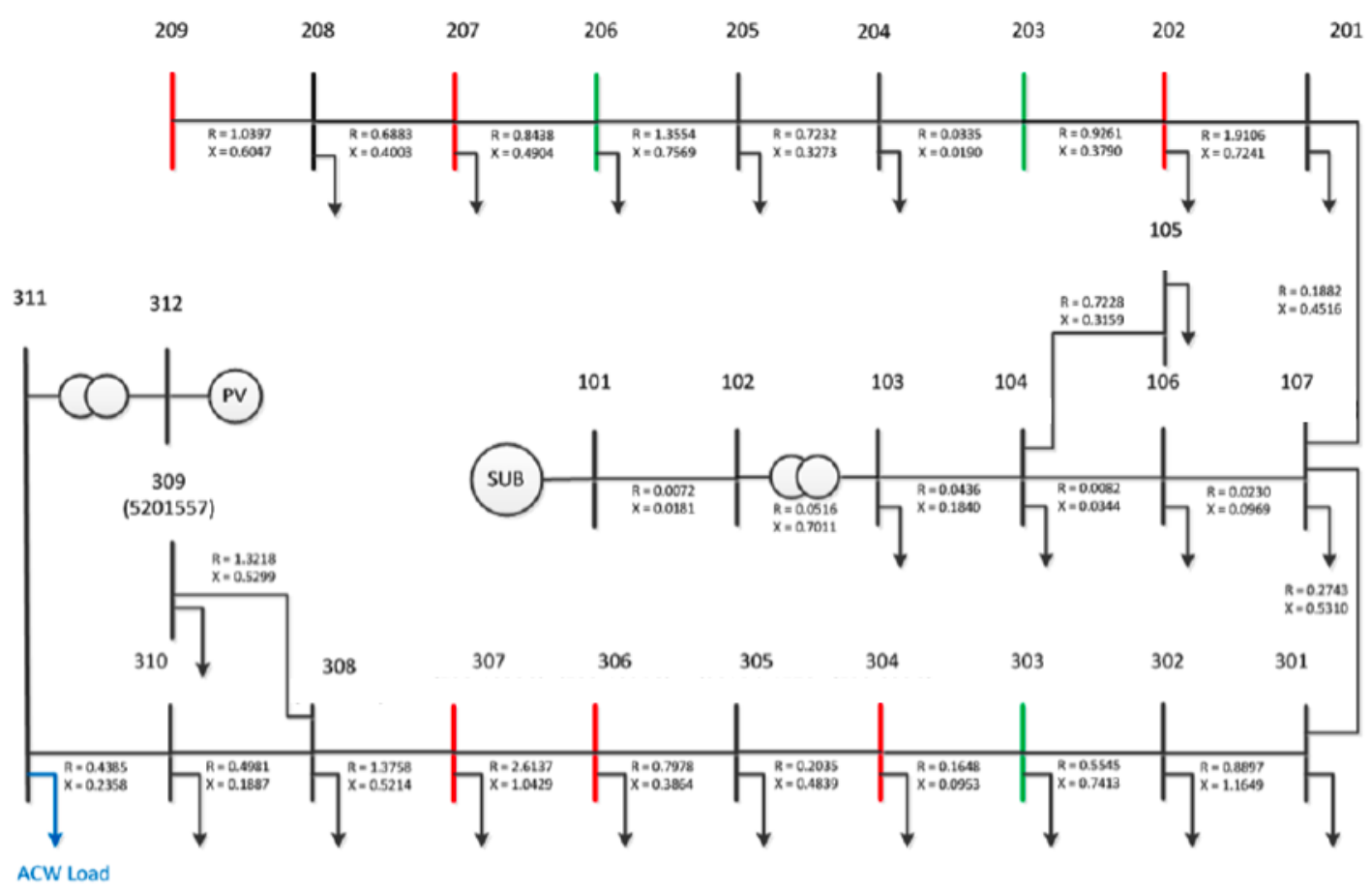

Figure 3.1: One Line Diagram of The Test Circuit

\subsection{PSCAD Software}

PSCAD stands for Power System Computer Aided Design and is the software selected to design, model and analyze the PV inverter system in this thesis. PSCAD is the GUI wrapper that works around the EMTDC (Electromagnetics Transients including DC) solution engine that is text based [27]. The simulation environment includes a default master library that includes typical circuit components of a Spice library but goes one step further in complexity by also including items ranging from advanced power electronic devices all the way to rotating machine models such as a synchronous generator. The strength and uniqueness of the program is the ability to integrate complex power electronic circuits with large power systems consisting of transmission lines and large rotating machines and view the system responses in the time and frequency domains! 


\subsection{Grid Codes and Regulations}

In order to exchange power with the grid certain requirements must be met to ensure the quality and stability of the power system is maintained. The standards for connecting distributed resources with an electric power system are defined in IEEE 1547. The IEEE 1547 standard was originally created in 2003 and since then many subsequent versions have been released and some are still under draft [28]. The main drawback of the standard is that when created it was just the beginning of the rapid growth in photovoltaics and other distributed resources. Certain provisions were outlawed that now due to increasing PV penetration and advancements in power electronics can be seen as necessary and easily implemented functions. One, and arguably the most controversial, provision is that these resources should not regulate the voltage at the point of common coupling (PCC) [29].

As discussed in the background section of this study, increasing levels of PV can have adverse affects on a power systems voltage and different equipment has been installed to counteract it. Allowing the inverter or other power conversion devices to help the voltage problem they create by generating or absorbing the required reactive power to maintain nominal voltage at the $\mathrm{PCC}$ is a main attribute of the inverter in this design. Obviously, this goes directly against the IEEE 1547 standard but by providing the necessary simulation results of this study one hopes this control strategy can be adopted as a viable solution to the voltage problem.

The distributed resource interconnection standard has also outlined specific allowable limits for voltage and frequency of the power system the distributed resources are connected to. If the specified limits are exceeded the distributed resource must 
disconnect from the grid within the maximum clearing time if the disturbance is still present. The voltage limits, frequency limits, and clearing times are shown in Table 3.1 and Table 3.2. These limits were put into place to eliminate unwanted grid islands from forming when neighboring power lines are tripped off and for safety when disturbances are present. The operational limits in the tables will be used during the design and testing of the proposed inverter.

Table 3.1: Interconnection System Response to Abnormal Voltages [26]

\begin{tabular}{|c|c|}
\hline $\begin{array}{c}\text { Voltage Range } \\
\text { (\% of the base voltage })\end{array}$ & $\begin{array}{c}\text { Clearing Time } \\
(\mathrm{s})\end{array}$ \\
$\mathbf{V}<\mathbf{5 0}$ & 0.16 \\
\hline $\mathbf{5 0} \leq \mathbf{V}<\mathbf{8 8}$ & 2 \\
\hline $\mathbf{1 1 0}<\mathbf{V}<\mathbf{1 2 0}$ & 1 \\
\hline $\mathbf{V} \geq \mathbf{1 2 0}$ & 0.16 \\
\hline
\end{tabular}

Table 3.2: Interconnection System Response to Abnormal Frequencies [26]

\begin{tabular}{|c|c|c|}
\hline DR Size & Frequency Range (Hz) & Clearing Times (s) \\
\hline \multirow{2}{*}{$\leq 30 \mathrm{~kW}$} & $>60.5$ & 0.16 \\
\hline & $<59.3$ & 0.16 \\
\hline \multirow[t]{3}{*}{$\geq 30 \mathrm{~kW}$} & $>60.5$ & 0.16 \\
\hline & $\begin{array}{c}<\{59.8 \text { to } 57\} \\
\text { (adjustable set point) }\end{array}$ & $\begin{array}{l}\text { Adjustable } 0.16 \text { to } \\
300\end{array}$ \\
\hline & $<57.0$ & 0.16 \\
\hline
\end{tabular}

In addition to the voltage and frequency requirements specified by IEEE 1547, the standard also defines necessary power quality requirements for PV inverters based on the harmonic content. The harmonic content standards are actually taken from another standard known as IEEE 519-1992, which is titled Recommended Practices and Requirements for Harmonic Control in Power Systems [30]. The IEEE 519-1992 standard sets specific limits for allowable current and voltage harmonics in power systems, these limits are shown in Table 3.3 and Table 3.4. 
Table 3.3: Maximum Allowable Injected Current Harmonic Amplitudes [30]

\begin{tabular}{|c|c|c|c|c|c|c|}
\hline $\begin{array}{c}\text { Harmonic } \\
\text { Range }\end{array}$ & $\mathrm{n}<11$ & $11 \leq \mathrm{n}<17$ & $17 \leq \mathrm{n}<23$ & $23 \leq \mathrm{n}<35$ & $35 \leq \mathrm{n}$ & TDD \\
\hline $\begin{array}{c}\text { \% Rated } \\
\text { Current }\end{array}$ & 4 & 2 & 1.5 & 0.6 & 0.3 & 5 \\
\hline
\end{tabular}

Table 3.4: Voltage Distortion Limits Expressed in \% of $V_{1}[30]$

\begin{tabular}{|c|c|c|}
\hline PCC Voltage & $\begin{array}{c}\text { Individual } \\
\text { Harmonic } \\
\text { Magnitudes (\%) }\end{array}$ & THD $_{\mathrm{V}}(\%)$ \\
\hline $\mathrm{V} \leq 69 \mathrm{kV}$ & 3 & 5 \\
\hline $69 \leq V \leq 161$ & 1.5 & 2.5 \\
\hline$V \geq 161 \mathrm{kV}$ & 1 & 1.5 \\
\hline
\end{tabular}

The current distortion limits in Table 3.3 are ratios of the harmonic amplitudes divided by the rated current expressed as a percent. Shown in the table are the limits of only the odd harmonics, the even harmonics that fall in the labeled harmonic ranges are limited to be less than a quarter of the prescribed limit of the odd harmonics shown. For example, the amplitude of the sixth harmonic must be less than one percent of the amplitude of the rated current. After all the individual harmonics are considered, the total distortion must not exceed a total demand distortion (TDD) of 5\%. TDD is a measure of the unwanted harmonic content compared to the current rating of the circuit, expressed as [22]:

$$
\mathrm{TDD}=\frac{\sqrt{\sum_{n=2}^{\infty} I_{n, r m s}^{2}}}{I_{\text {rated,rms }}}
$$

The voltage distortion limits in Table 3.4 explain that any single harmonic beyond the fundamental shall not exceed $3 \%$ of the fundamentals amplitude. For voltage, instead of quantifying distortion with the TDD measurement, total harmonic distortion (THD) is 
used. THD is a measure of the unwanted harmonic content compared to the fundamental, expressed as [22]:

$$
\mathrm{THD}_{\mathrm{V}}=\frac{\sqrt{\sum_{n=2}^{\infty} V_{n, r m s}^{2}}}{V_{1, r m s}}
$$

The current and voltage distortion standards described in this section will be taken into consideration in evaluating the PV inverters performance.

\subsection{The Inverter}

Fundamentally, an inverter converts direct current (DC) power into alternating current (AC) power. How this is achieved varies greatly between inverter topologies and control schemes and each has advantages and disadvantages. The inverter of interest in this thesis is a PV grid tied inverter meaning the input is DC power being generated by connected solar panels and the output power is $60 \mathrm{~Hz}$ three phase AC power interfaced to the electrical grid. 


\subsubsection{Inverter Topology}

The inverter topology selected for this design is a basic six switch three phase configuration. This configuration was chosen because it is simple, well documented, and a great topology to start with to add ancillary inverter features to. The topology consists of six switches arranged in three parallel branches, where each branch has two switches in series. The DC input to the inverter is applied to the top and bottom of the three parallel branches. The three phase AC output is produced in between the two switches in each of the three branches. The described topology is shown in Figure 3.2.

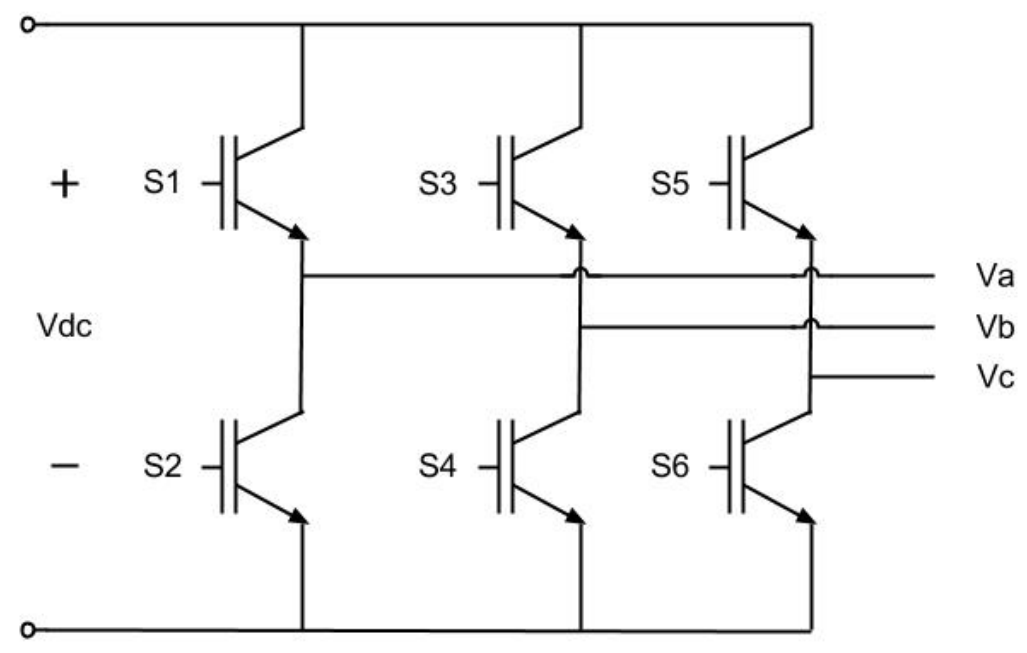

Figure 3.2: Three Phase Inverter Topology

\subsubsection{Power Electronic Switches}

The switches, which are used to chop the DC voltage, were chosen to be Insulated-Gate Bipolar Transistors (IGBTs). IGBTs are a somewhat recent development [31]. They are quite similar to power transistors except for one major improvement. Power transistors require a current to be applied at the gate in order to force the transistor to conduct while IGBTs require a voltage at the gate terminal. This advancement allows the IGBT to be controlled by an applied gate voltage, with minimal current flow, which 
gives them the ability to switch much faster than the current driven power transistors.

IGBTs also have much higher voltage $(\sim 6500 \mathrm{~V})$ and current $(\sim 2400 \mathrm{~A})$ ratings then other switching devices [32]. These characteristics make them optimal for high-power highfrequency applications such as a voltage sourced inverter.

\subsubsection{Sinusoidal Pulse Width Modulation}

The AC output waveforms shape and quality is directly related to how the conduction intervals of the switches are controlled. Methods for controlling the switches range from simple to complex. The method chosen for this application was unipolar sinusoidal pulse width modulation (SPWM). This control technique is very well known and was used because it allows the control of three very important output waveform variables. These three variables are the phase, magnitude, and frequency of the generated AC waveform whose importance will be discussed in a later section. SPWM is a control technique that requires three reference sinusoidal waveforms (for three phase operation) of the same frequency as the desired output waveform and one high frequency triangle waveform known as the carrier signal [32]. The signal deciding when the appropriate switch should conduct or remain off is determined by comparing the magnitudes of the sinusoidal and triangle waveforms. Between the comparing logic and the gate terminal of the IGBT is a driving circuit providing the necessary voltage and power to operate the switch. The three reference sinusoidal waveforms can be modeled as follows:

$$
\begin{gathered}
V_{\text {Aref }}=\mathrm{A} \sin \left(2 \pi f_{r} t+\theta\right) \\
V_{B \text { ref }}=\mathrm{A} \sin \left(2 \pi f_{r} t+\theta-120^{\circ}\right) \\
V_{\text {Cref }}=\mathrm{A} \sin \left(2 \pi f_{r} t+\theta+120^{\circ}\right)
\end{gathered}
$$


where $\mathrm{A}$ is the amplitude of the reference sine wave also known as the modulation index $(m a), f_{\mathrm{r}}$ is the desired frequency of the output waveform, and $\theta$ is a phase shift that can be introduced. $\mathrm{V}_{\text {TRI }}$ is the triangular reference waveform varying from -1 to 1 with a duty cycle of $50 \%$ at a frequency $\mathrm{f}_{\mathrm{c}}$ much higher than that of $\mathrm{f}_{\mathrm{r}}$. The modulation index is technically the ratio of the amplitudes of the reference sine waves to the triangular carrier signal, but since the triangle waveform typically has an amplitude of one, the amplitude of the reference sine waves can be considered the amplitude modulation factor. For switches 1 and 2 the switching logic is derived from comparing $\mathrm{V}_{\mathrm{A} \text { ref }}$ and $\mathrm{V}_{\mathrm{TRI}}$. The two signals on top of each other are shown in Figure 3.3 and Figure 3.4 from PSCAD.

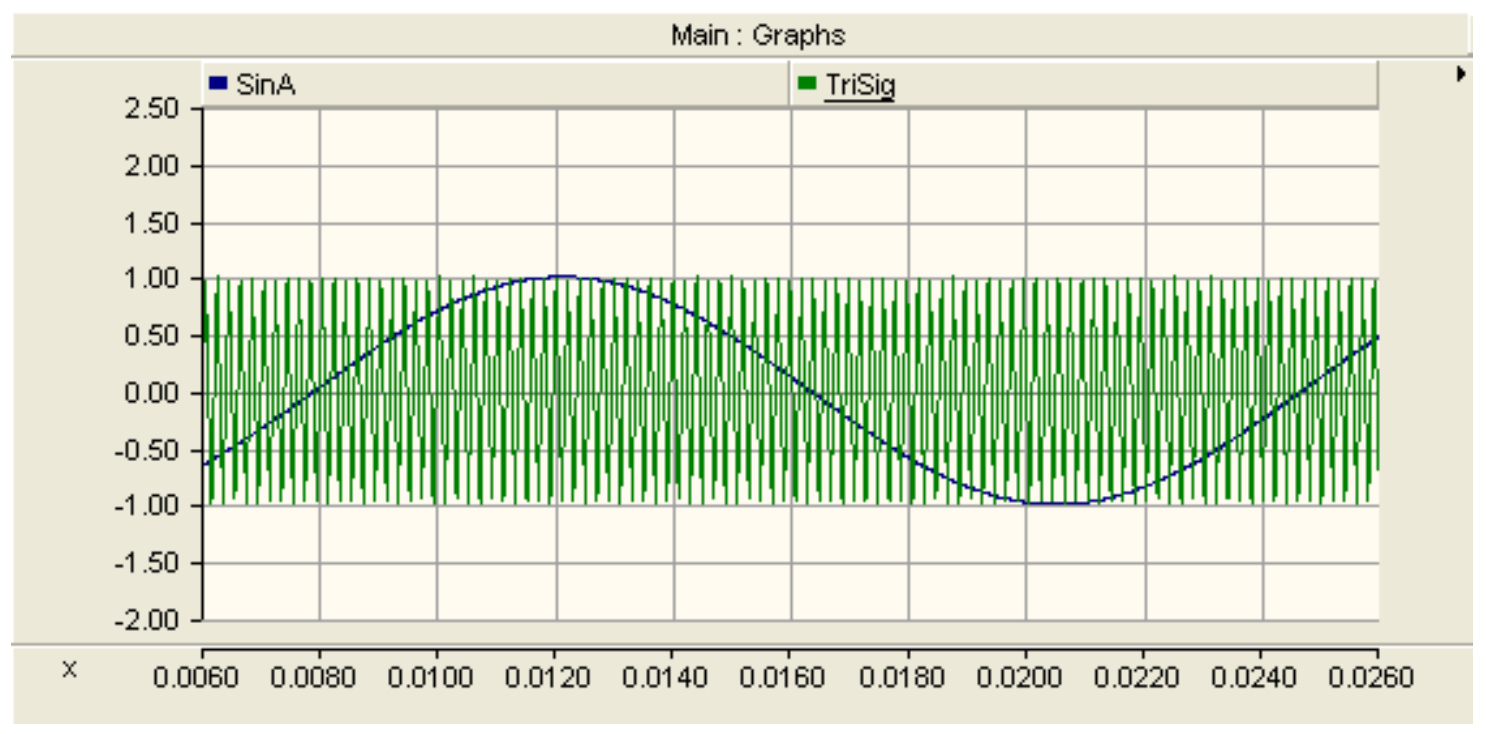

Figure 3.3: SPWM Reference Sinusoidal and Triangle Waveforms $(\mathrm{ma}=1)$ 


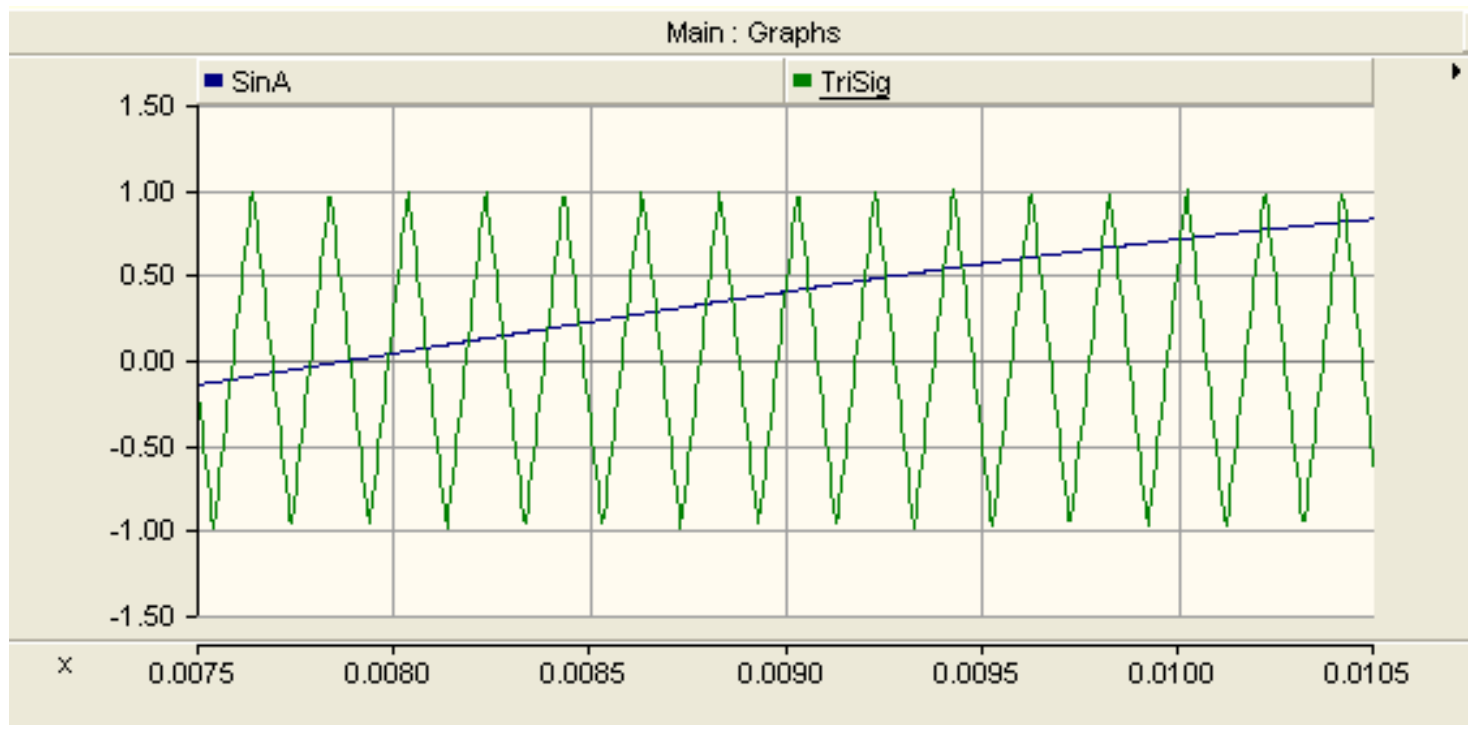

Figure 3.4: SPWM Reference Sinusoidal and Triangle Waveforms (Zoomed In)

When $\mathrm{V}_{\mathrm{A} \text { ref }}$ is larger than $\mathrm{V}_{\text {TRI }}$ switch 1 is turned on, switch 2 is turned off, and the output phase voltage $\mathrm{V}_{\mathrm{AN}}$ is equal to the inverters $\mathrm{DC}$ input voltage $\mathrm{V}_{\mathrm{DC}}$. For the instances when $\mathrm{V}_{\mathrm{A} \text { ref }}$ is less than $\mathrm{V}_{\mathrm{TRI}}$ switch 1 is turned off, switch 2 is turned on, and the output phase voltage $\mathrm{V}_{\mathrm{AN}}$ is equal to zero. The switching signals for switches $3,4,5$, and 6 and output phase voltages $\mathrm{V}_{\mathrm{BN}}$ and $\mathrm{V}_{\mathrm{CN}}$ can be determined similarly to how switches 1 and 2 were created but using $\mathrm{V}_{\mathrm{B} \text { ref }}$ and $\mathrm{V}_{\mathrm{C} \text { ref }}$ respectively. The complete switching logic is summarized in Table 3.5. 
Table 3.5: SPWM Switching Logic [32]

\begin{tabular}{|c|c|c|c|}
\hline \multirow{2}{*}{ Switch } & \multirow{2}{*}{$\begin{array}{l}\text { Applicable } \\
\text { Sin Wave }\end{array}$} & \multicolumn{2}{|c|}{ Switch Logic } \\
\hline & & $\mathrm{V}_{\text {SIN }}>\mathrm{V}_{\mathrm{TRI}}$ & $\mathrm{V}_{\mathrm{SIN}}<\mathrm{V}_{\mathrm{TRI}}$ \\
\hline S1 & \multirow{2}{*}{$\mathrm{V}_{\mathrm{A}}$} & ON & OFF \\
\hline S2 & & OFF & ON \\
\hline S3 & \multirow{2}{*}{$\mathrm{V}_{\mathrm{B}}$} & ON & OFF \\
\hline S4 & & OFF & $\mathrm{ON}$ \\
\hline S5 & \multirow{2}{*}{$\mathrm{V}_{\mathrm{C}}$} & $\mathrm{ON}$ & OFF \\
\hline S6 & & OFF & ON \\
\hline
\end{tabular}

By performing simple subtraction between the phase voltages $V_{A N}$ and $V_{B N}$ the more useful line-to-line voltage $\mathrm{V}_{\mathrm{AB}}$ is determined. This waveform switches from zero to $V_{D C}$ in a pulse width modulated form for the first half of the output cycle and then from zero to $-\mathrm{V}_{\mathrm{DC}}$ for the second half of the cycle. These waveforms do not appear sinusoidal but after filtering the waveforms the fundamental components can be extracted. The fundamental component is a sinusoidal wave with the same frequency and phase as the reference sinusoidal signal $(60 \mathrm{~Hz})$ and amplitude linearly proportional to the modulation index multiplied to the inverter DC input voltage. It should be noted that the relationship is only linear as long as the modulation index is limited to vary from zero to one, this is the linear operating region for the chosen PWM control scheme. Mathematically the fundamental component of the line to line RMS voltages are described by:

$$
\tilde{V}_{1_{L L}}=\frac{\sqrt{3}}{2 \sqrt{2}} * m a * V_{D C}
$$

The unfiltered and filtered line to line voltages are shown in Figure 3.5 and Figure 3.6. 


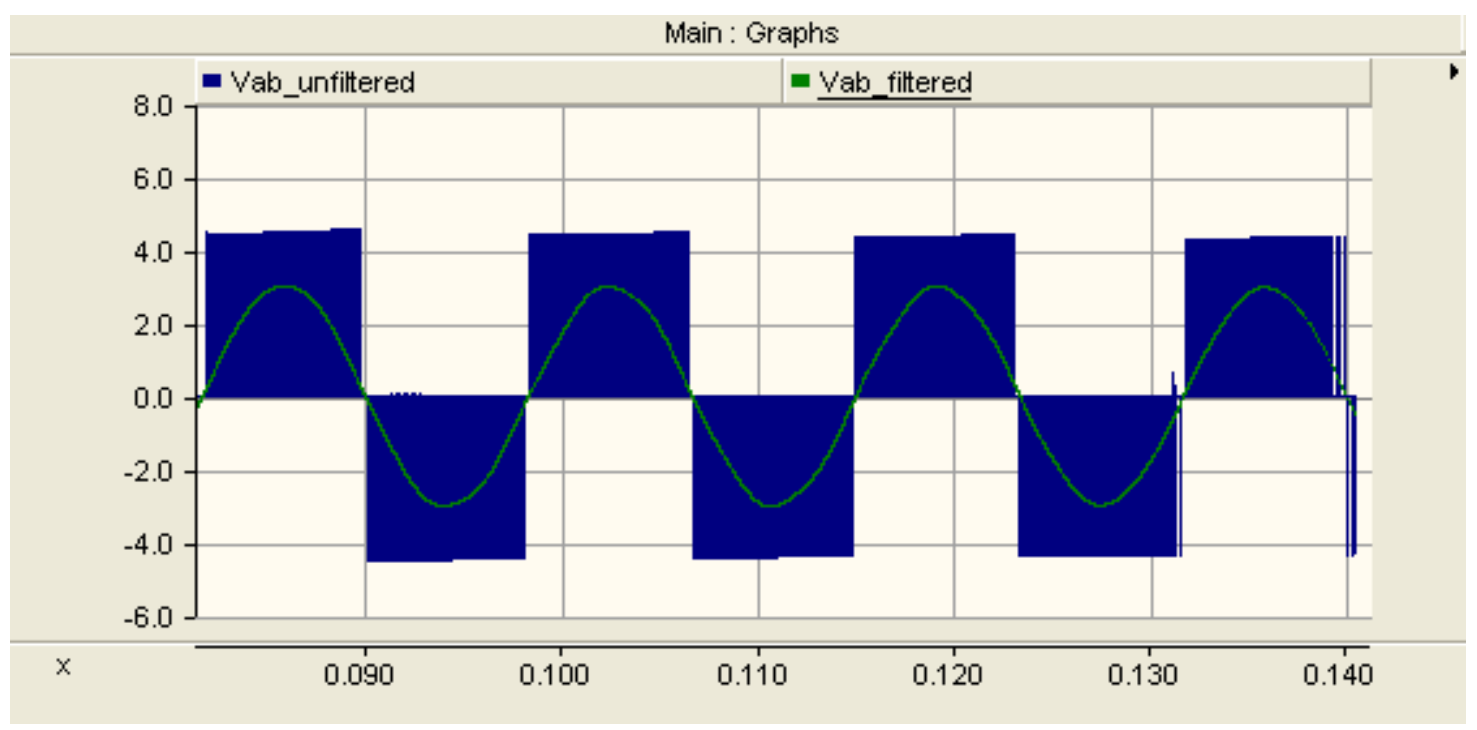

Figure 3.5: Unfiltered and Filtered $V_{\mathrm{AB}}$ Voltage Waveforms (Three Cycles)

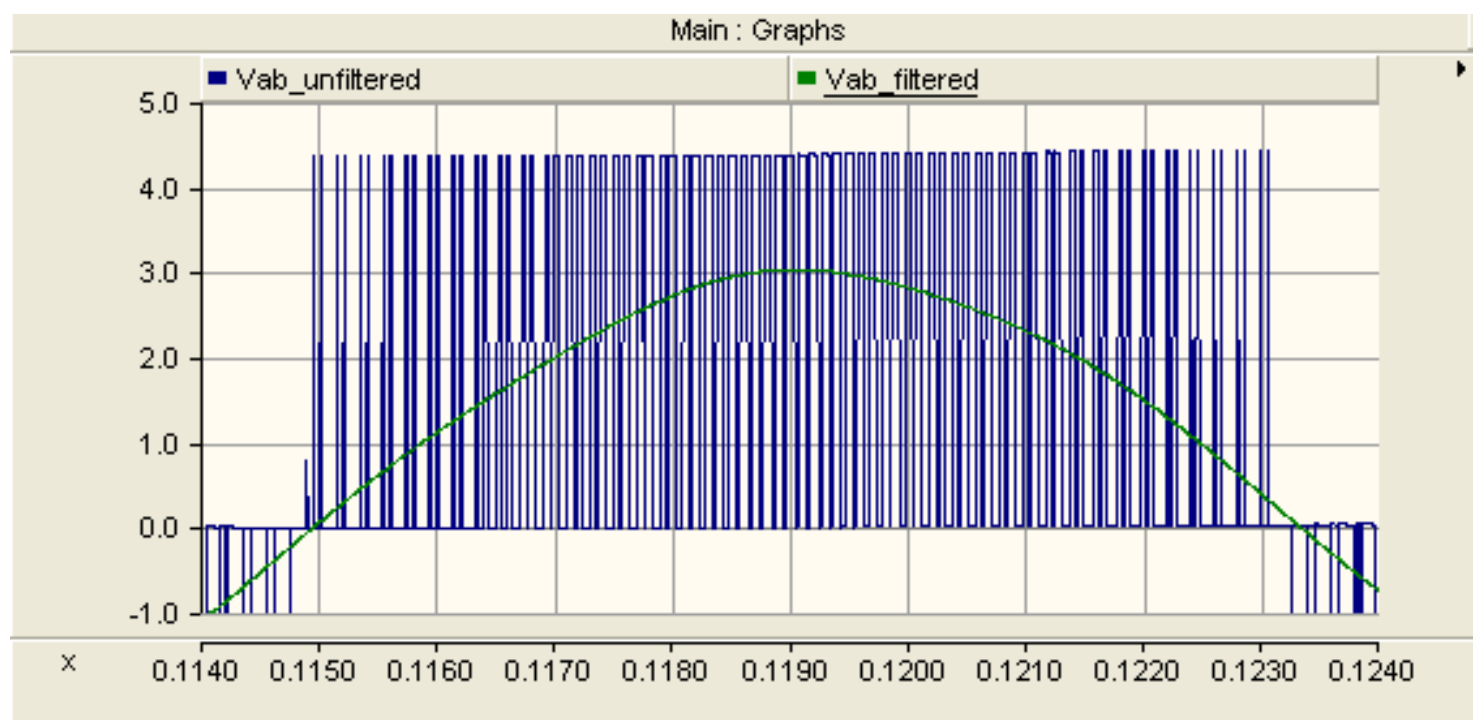

Figure 3.6: Unfiltered and Filtered $\mathbf{V}_{\mathrm{AB}}$ Voltage Waveforms (Half Cycle)

In order to minimize the output waveform harmonics the carrier frequency $f_{c}$ of the triangle waveform must be chosen to be an odd triple multiple of the reference frequency [32]. Normally, as mentioned earlier, the carrier frequency is a few orders of magnitude larger than the reference frequency. Since the inverter of interest is grid tied the reference frequency is $60 \mathrm{~Hz}$. The carrier frequency was designed to be $4.98 \mathrm{kHz}$ to satisfy the above conditions reasonably. 


\subsubsection{The Filter}

The filter after the PWM inverter is a vital component to ensure the voltage and current waveforms being injected into the grid are high quality sinusoidal waveforms. One huge benefit of using the high frequency PWM switching technique is the undesirable harmonic content of the unfiltered signal occurs around the switching frequency, which is usually much higher than the fundamental [22]. The benefit of this is that since the harmonic content is at a much higher frequency than the fundamental the filtering requirements are less drastic, smaller components can be used, and overall the filter will be less expensive. A simple first order low pass LC filter can be used to extract the fundamental component and attenuate the higher frequency content.

The PWM inverter in this design has a carrier frequency of $4.98 \mathrm{kHz}$ and a fundamental frequency of $60 \mathrm{~Hz}$. And because unipolar switching is employed, the harmonic content will appear at:

$$
f_{\text {harmonic }}=n * f_{\text {carrier }} \pm 2 * f_{\text {fund }}
$$

where $\mathrm{n}$ is an integer (because of the chosen carrier frequency) representing the ratio of the carrier frequency to the fundamental. Therefore, theoretically the first harmonic content will not appear until $4.86 \mathrm{kHz}$ and $5.10 \mathrm{kHz}$, the $81^{\text {st }}$ and $85^{\text {th }}$ harmonics. The inductor and capacitor values for the LC filter were chosen as $200 \mathrm{uH}$ and $2 \mathrm{mF}$ respectively. These values were selected to filter out the unwanted harmonic content to meet the requirements of PV inverters specified in Table 3.3. The LC line filter is shown in Figure 3.8. 


\subsubsection{PSCAD PWM Inverter Modeling}

The inverter modeled in PSCAD is shown in Figure 3.7. The only additional components on the inverter are attached to the IGBT's. Connected in parallel to each IGBT is a snubber circuit and clamping diode. The snubber circuit helps to reduce switching loss by modifying the switching trajectory and the diode helps prevent large voltage spikes from being imposed across the switch [22]. Values selected for the snubber resistance and capacitance were unchanged from the default value assigned by PSCAD, shown in Figure 3.9.

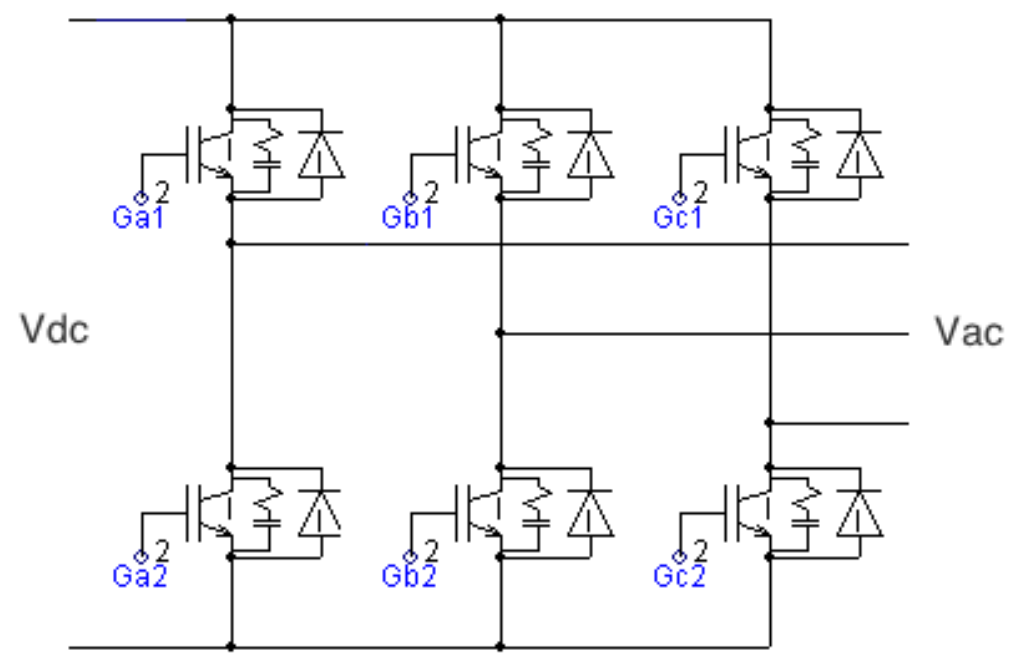

Figure 3.7: Three Phase Inverter in PSCAD with Snubber Circuits and Clamping Diodes 


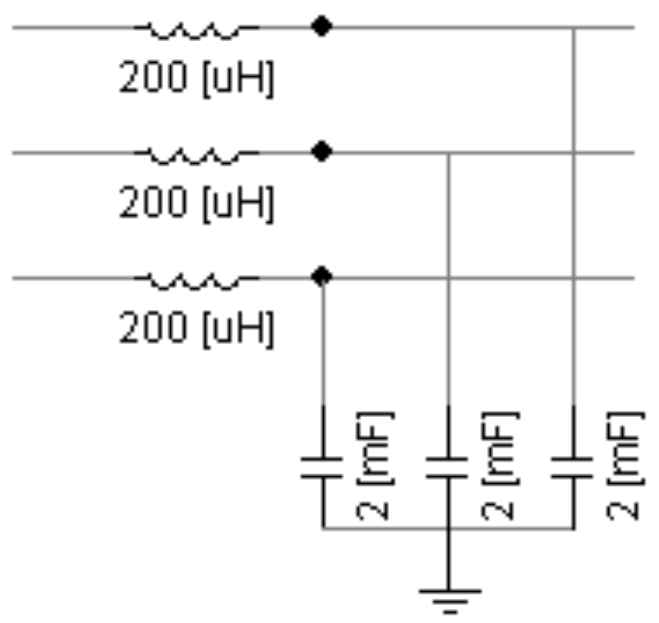

Figure 3.8: LC Output Line Filter in PSCAD

\begin{tabular}{|c|c|c|}
\hline \multicolumn{3}{|c|}{ 嚚 Power Electronic Switch } \\
\hline \multicolumn{3}{|l|}{ Main Data } \\
\hline \multicolumn{3}{|c|}{$\stackrel{\oplus}{\oplus} \mathrm{Z} \downarrow$} \\
\hline \multicolumn{3}{|l|}{$\Xi$ General } \\
\hline \multicolumn{2}{|c|}{ Thyristor ON Resistance } & 0.01 [ohm] \\
\hline \multicolumn{2}{|c|}{ Thyristor OFF Resistance } & $1.0 \mathrm{E} 6[\mathrm{ohm}]$ \\
\hline \multicolumn{2}{|c|}{ Forward Voltage Drop } & $0.0[\mathrm{kV}]$ \\
\hline \multicolumn{2}{|c|}{ Forward Breakover Voltage } & $1.0 \mathrm{E} 5[\mathrm{kV}]$ \\
\hline \multicolumn{2}{|c|}{ Reverse Withstand Voltage } & $1.0 \mathrm{E} 5[\mathrm{kV}]$ \\
\hline \multicolumn{2}{|c|}{ Minimum Extinction Time } & 0.0 [us] \\
\hline \multicolumn{2}{|c|}{ Snubber Resistance } & $5000.0[\mathrm{ohm}]$ \\
\hline \multicolumn{2}{|c|}{ Snubber Capacitance } & 0.05 [uF] \\
\hline \multicolumn{3}{|c|}{ Protected against Forward Breakover? No } \\
\hline \multicolumn{3}{|l|}{ General } \\
\hline ok & Cancel & Help... \\
\hline
\end{tabular}

Figure 3.9: Snubber Circuit Component Parameters in PSCAD

The IGBT gate signals Ga1, Ga2, etc. are shown in the inverter schematic in

Figure 3.7, these are the inputs the SPWM signals will control to turn the switches on and off as described previously. Creating the SPWM logic following Table 3.1 in PSCAD is illustrated in Figure 3.10. The Sin function block makes it extremely easy to create the needed sinusoidal reference waveforms with the ability to change the amplitude, 
frequency and phase dynamically. After creating the three reference sine waves and the triangle carrier signal they are each fed into a driving block that will finally turn on and off the IGBT's, shown in Figure 3.11.

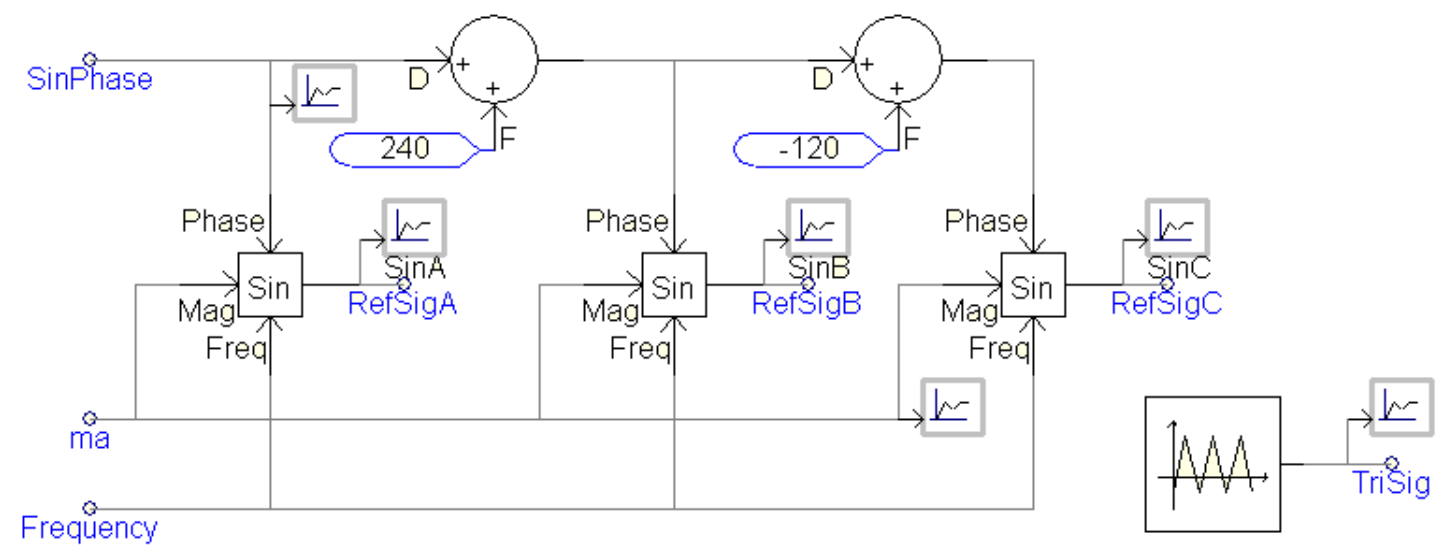

Figure 3.10: Reference Sin and Triangle Waveform Generators in PSCAD

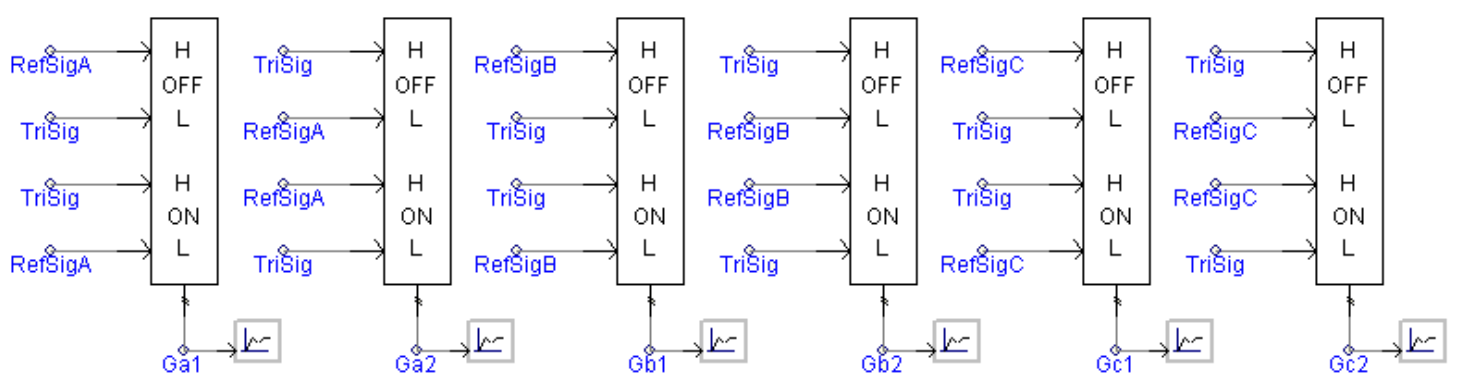

Figure 3.11: Comparators and Drivers for IGBT Gate Signals in PSCAD

\subsection{Solar PV Model}

The solar system modeled in this design is the one located at the end of one of the branches of the test circuit. The only given specifications of the solar system is the power output of approximately $2 \mathrm{MW}$ and the distribution line's nominal voltage of $12.47 \mathrm{kV}$. The rest of the solar systems parameters will be estimated and/or assumed in system modeling. 


\subsubsection{System Topology}

As solar systems grow larger and include more solar panels connected together in different arrangements various topologies for connecting inverters have arisen. A brief overview of the different types of inverter and PV panel arrangements includes: centralized, string, and multi-string. [33]. Centralized inverter systems consist of a single inverter in which all the solar panels are connected to. String inverter systems break up the solar panels into separate parallel "strings" and each string feeds their own inverter. Multi-string inverters take the concept of the string inverters one step further by incorporating an individual DC/DC converter into each string, but then all the DC/DC converters feed a single inverter similar to the centralized topology. For simplicity the centralized solar panel/inverter configuration is used to model the system studied in this thesis. Figure 3.12 shows the centralized system.

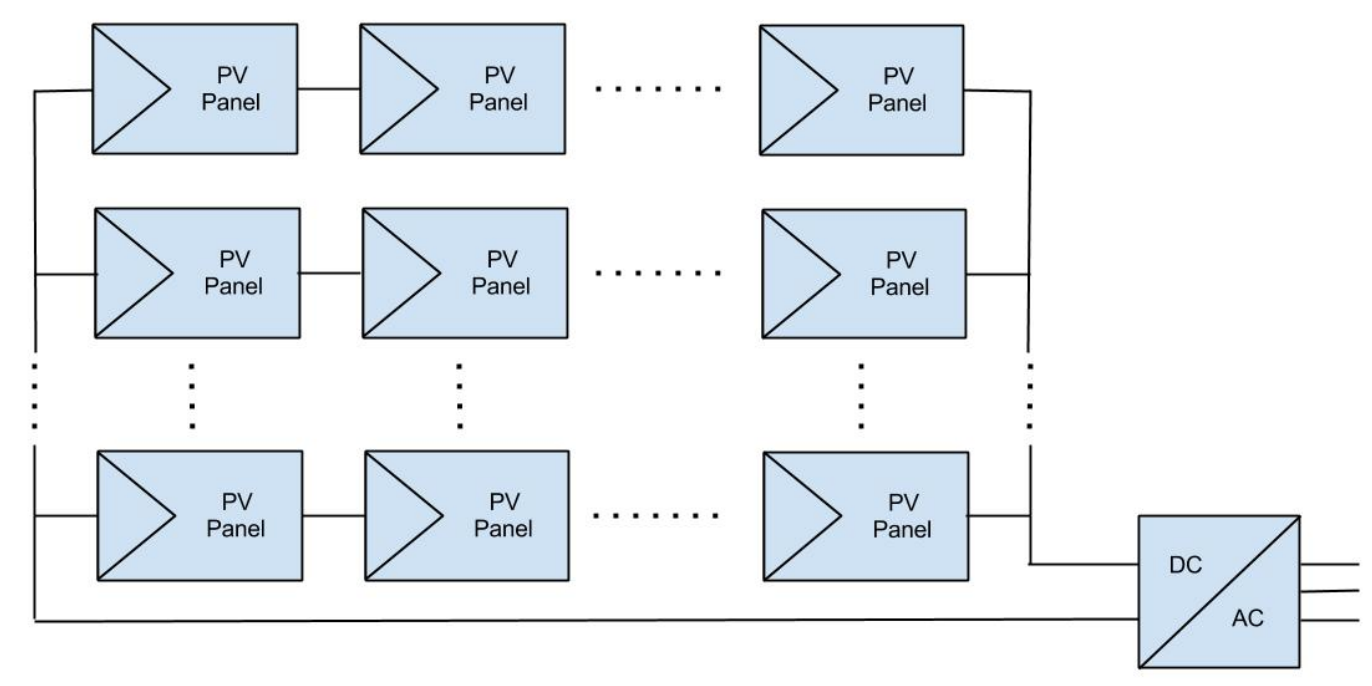

Figure 3.12: Centralized PV Inverter System Topology

\subsubsection{PV Characteristics}

In electrical engineering it is very common to model devices and their properties by developing an equivalent circuit model in order to better study and analyze them. The 
circuit model developed for a PV cell is based on a current source and is depicted in Figure 3.13.

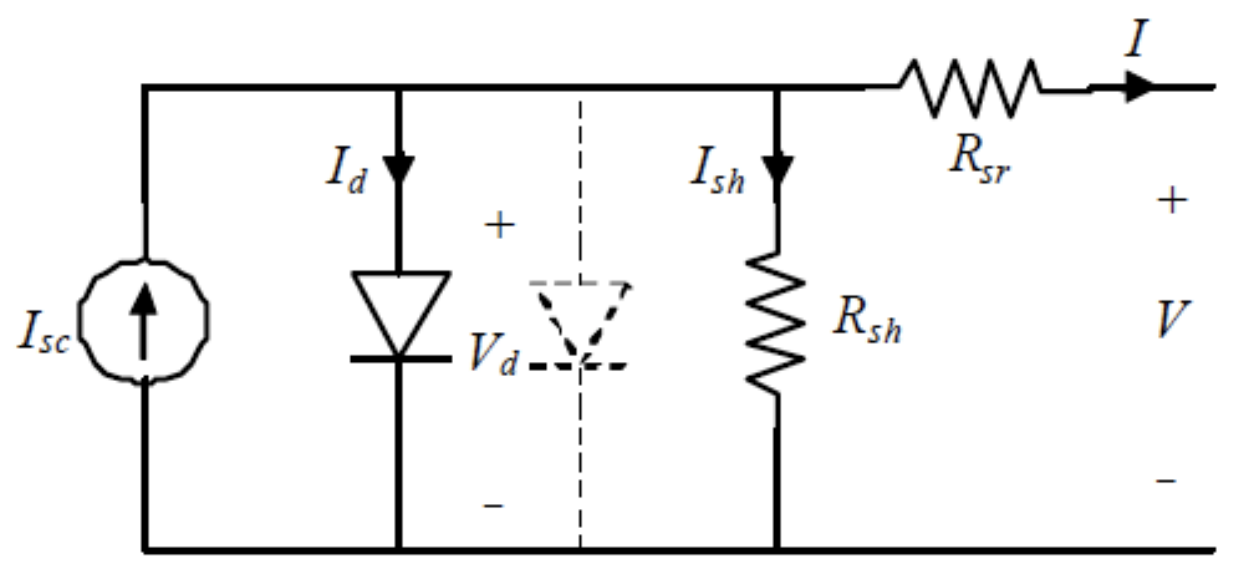

Figure 3.13: Equivalent Circuit Model of PV Cell [34]

As a solar cell is exposed to light the generated DC current is linearly proportional to the solar irradiance it is being exposed to [34]. However, the I-V characteristics of a solar cell are highly non-linear, this is primarily due to the anti-parallel diode and its current $I_{d}$. Figure 3.14 shows typical I-V operating characteristics for a solar cell with its accompanying power curve. The second diode shown dashed in the equivalent circuit model is used in more sophisticated cell models to consider the difference in current at low values due to charge recombination in the semiconductors depletion region. A single anti-parallel diode is usually sufficient enough to model a solar cell, and equations become even more complex with the addition of the second diode. 


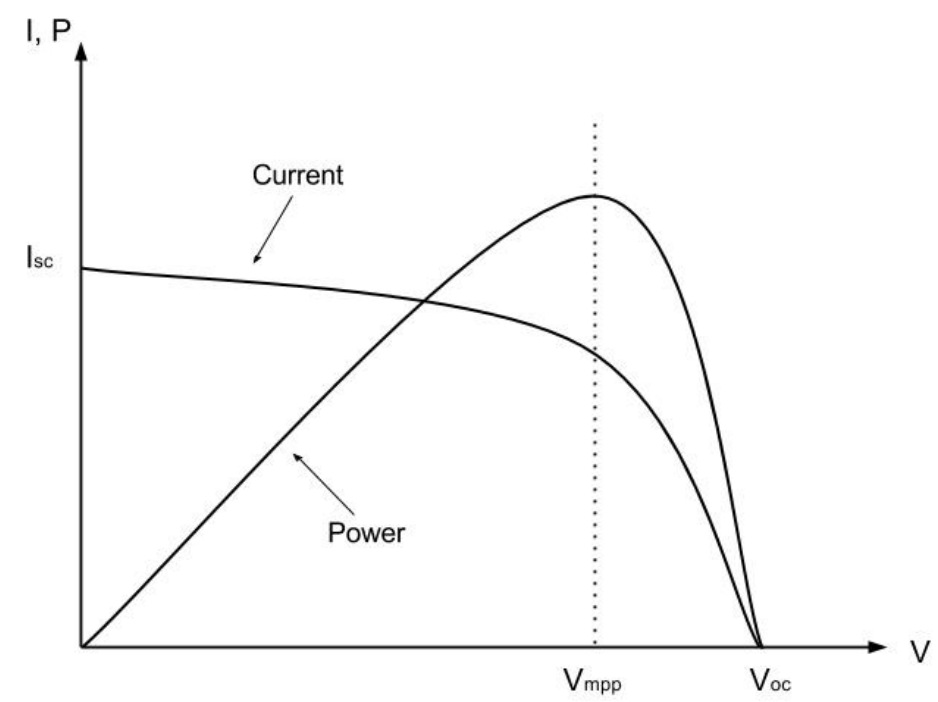

Figure 3.14: Typical I-V and Power Curves for a Solar Cell

Applying Kirchhoff's current law (KCL) to the single diode circuit model yields:

$$
I=I_{S C}-I_{d}-I_{s h}
$$

Substituting relevant expressions for the diode current and the shunt current into (3-8) gives a new expression [34]:

$$
I=I_{S C}-I_{o}\left[e^{\left(\frac{V+I R_{s r}}{n k T_{e} / q}\right)}-1\right]-\left(\frac{V+I R_{s r}}{R_{s h}}\right)
$$

where $I_{S C}$ is a function of the solar radiation on the plane of the solar cell $(\mathrm{G})$, the temperature of the cell $\left(\mathrm{T}_{\mathrm{C}}\right)$, and is referred to as the photo current. Mathematically $\mathrm{I}_{\mathrm{SC}}$ is expressed as [34]:

$$
I_{S C}=I_{S C R} \frac{G}{G_{R}}\left[1+\alpha_{T}\left(T_{C}-T_{C R}\right)\right]
$$

where $I_{s c R}$ is the reference short circuit current at the reference values for radiation, $G_{R}$, and cell temperature, $\mathrm{T}_{\mathrm{CR}}$. The variable $\alpha_{\mathrm{T}}$ is the photo currents temperature coefficient. 
Looking further at (3-9) $I_{0}$ is the cell's dark current and is strictly a function of cell temperature described by [34]:

$$
I_{o}=I_{o R} \frac{T_{C}{ }^{3}}{T_{C R}{ }^{3}}\left[e^{\left(\frac{1}{T_{C R}}-\frac{1}{T_{C}}\right) \frac{q e_{g}}{n k}}\right]
$$

$\mathrm{I}_{\mathrm{OR}}$ is the dark current at the specified reference temperature. Other parameters used in (3-9), (3-10), and (3-11) not yet explained are $\mathrm{n}$ which is the diode non-ideality factor, $\mathrm{k}$ the Boltzmann constant, $e_{\mathrm{g}}$ the band gap energy of the used solar material, and $\mathrm{q}$ the charge of an electron. By examining a solar panels specifications sheet all of the above constants can be determined [34].

The model described above is for a single solar cell. This is important because solar cells are combined in various series and parallel combinations to make up solar modules. Further, solar modules are combined in various series and parallel combinations to make up solar arrays. From this, any solar system no matter how large can be modeled as a combination of series and parallel solar cells and can be described by this solar cell model. The mathematical model for a solar cell described in this section is what will be implemented in the 2 MW solar system model for this thesis.

\subsubsection{Maximum Power Point Tracking}

Due to the non-linear I-V characteristics of a solar cell their power output varies greatly depending on the voltage in which it is operating at. This can be seen in Figure 3.14, which also shows the maximum power point occurring at the knee of the current curve. In order to fully utilize any solar system, the voltage across the solar panel terminals needs to be monitored and controlled in such a way that it is always at the maximum power point voltage. 
The two most commonly used and studied control algorithms for maximum power point tracking (MPPT) are the Perturb and Observe $(\mathrm{P} \& \mathrm{O})$ and the Incremental Conductance (IC) methods [35]. The P\&O method calculates the current output power of the solar panel. From this it "perturbs" the terminal voltage of the solar panel by incrementing or decrementing it and compares the new calculated output power to the previously calculated one. If the new value is larger, then the terminal voltage continues in the direction it was incremented or decremented. The algorithm is operated in this fashion until the maximum power point (MPP) is achieved. However, the drawback to this method is that once the MPP is reached it continues to oscillate around this point. An attempt to fix this is to make the voltage perturbation smaller but this results in slower response to rapidly changing atmospheric conditions. The IC method was created in order to provide a better alternative to the $\mathrm{P} \& \mathrm{O}$ method. The basic concept of how the IC algorithm finds the MPP is based on the slope of the power curve for a solar cell. At the MPP the slope of the power curve is zero, to the left of the MPP the slope is positive, and to the right of the MPP the slope is negative. By sampling the current and voltage of the solar cell and computing the incremental and instantaneous conductances the MPP voltage can be determined. A detailed flowchart explaining the operation of the algorithm step by step is shown in Figure 3.15. 


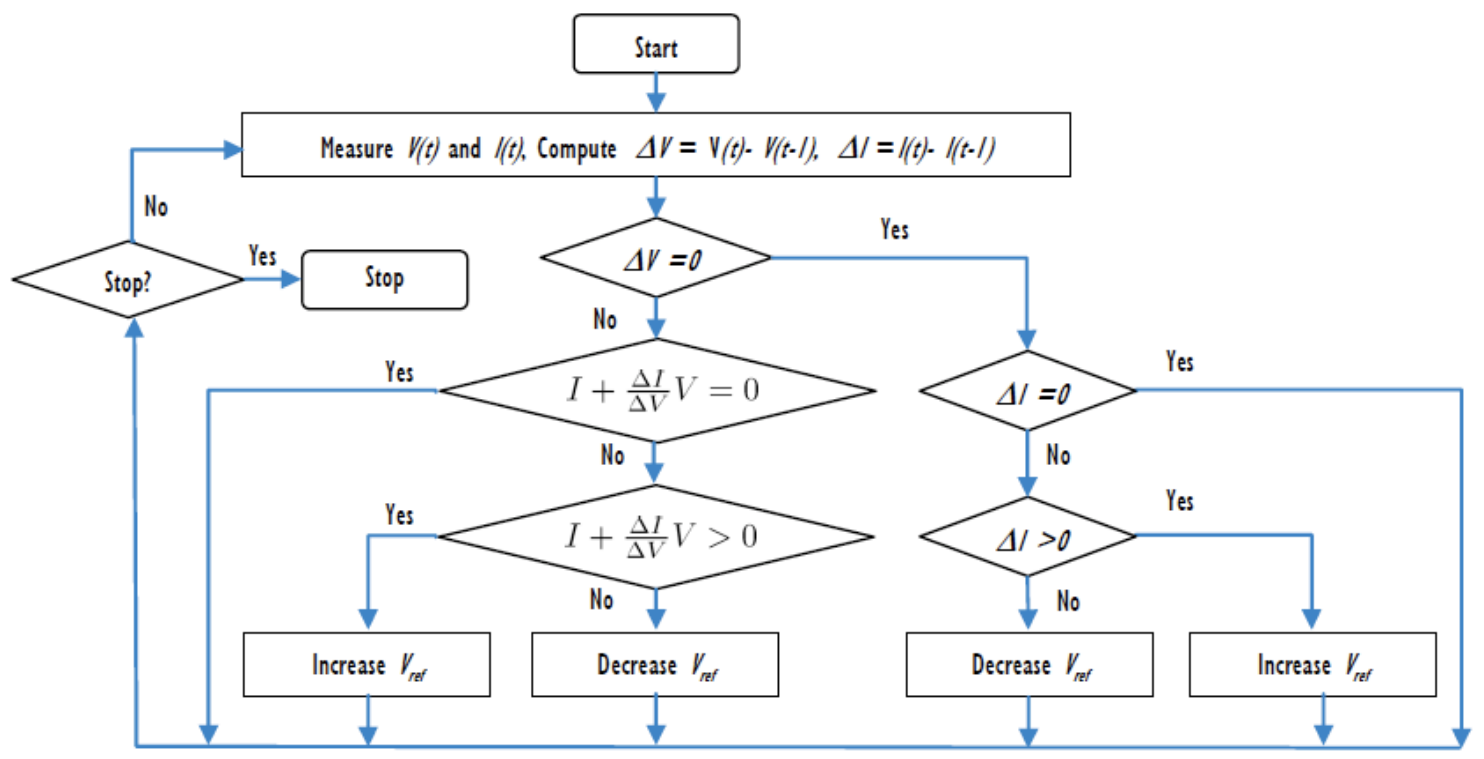

Figure 3.15: Incremental Conductance Algorithm Flowchart [34] [35]

The IC algorithm was chosen for MPPT in the design of this thesis due to its robustness over the $\mathrm{P} \& \mathrm{O}$ algorithm. The two main factors for this design choice was the IC methods ability to better adapt to rapidly changing weather conditions and its ability to find the MPP without oscillating around it.

\subsubsection{PSCAD PV Modeling}

In the latest version of PSCAD the default master library contains both a solar panel component and a maximum power point tracking component. Dr. A. D. Rajapakse developed both of these components. The solar panel model incorporates all of the PV cell characteristics mathematically described in the previous section. The MPPT model has options to run with either the P\&O or IC algorithms analyzed previously. In PSCAD the components appear as shown in Figure 3.16. 


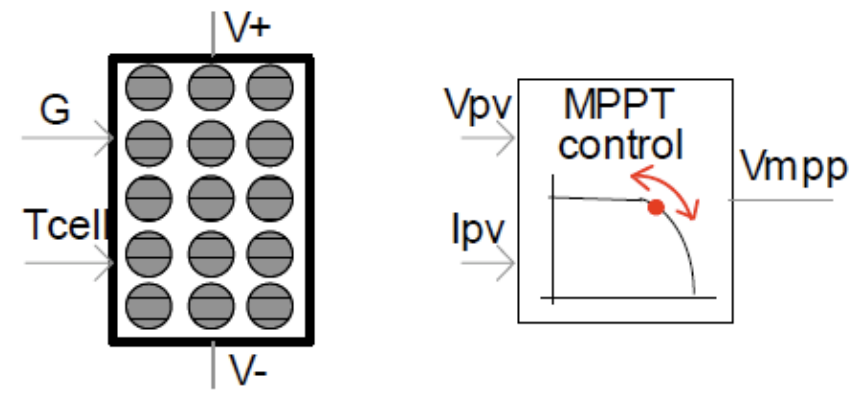

Figure 3.16: Solar Panel and MPPT PSCAD Components

The solar panel component in PSCAD is quite versatile. Upon opening the component parameter menu the PV cell and PV array properties can be edited by selecting their respective drop down menu shown in Figure 3.17.

\begin{tabular}{|c|c|c|c|c|c|c|}
\hline \multicolumn{3}{|c|}{ 国 [master:photovoltaic_source] id='374654274' } & $x$ & \multicolumn{3}{|c|}{ 国 [master:photovoltaic_source] id='374654274' } \\
\hline \multicolumn{3}{|c|}{ PV cell parameters } & $\nabla$ & \multicolumn{3}{|c|}{ PV array parameters } \\
\hline \multicolumn{4}{|c|}{ 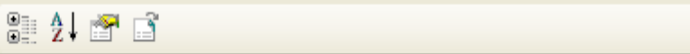 } & \multicolumn{3}{|c|}{ 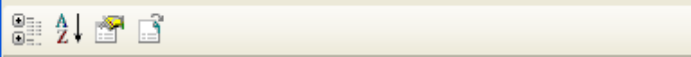 } \\
\hline \multicolumn{4}{|l|}{$\boxminus$ General } & \multicolumn{3}{|l|}{$\boxminus$ General } \\
\hline \multicolumn{2}{|c|}{ Effective area per cell } & $0.01\left[\mathrm{~m}^{\wedge} 2\right]$ & & \multicolumn{2}{|c|}{ PV array name (optional) } & PVarray1 \\
\hline \multicolumn{2}{|c|}{ Series resistance per cell } & $0.02[0 \mathrm{hm}]$ & & \multicolumn{2}{|c|}{ Number of modules connected in series per array } & 65 \\
\hline \multicolumn{2}{|c|}{ Shunt resistance per cell } & 1000 [ohm] & & \multicolumn{2}{|c|}{ Number of module strings in parallel per array } & 45 \\
\hline \multicolumn{2}{|c|}{ Diode ideality factor } & 1.5 & & \multicolumn{2}{|c|}{ Number of cells connected in series per module } & 108 \\
\hline \multicolumn{2}{|c|}{ Band gap energy } & $1.103[\mathrm{eV}]$ & & \multicolumn{2}{|c|}{ Number of cell strings in parallel per module } & 4 \\
\hline \multicolumn{2}{|c|}{ Saturation current at reference conditions per cell } & $1 \mathrm{e}-12[\mathrm{kA}]$ & & \multicolumn{2}{|c|}{ Reference irradiation } & $1000\left[W / m^{\wedge} 2\right]$ \\
\hline \multicolumn{2}{|c|}{ Short circuit current at reference conditions per cell } & $0.0025[\mathrm{kA}]$ & & \multicolumn{2}{|c|}{ Reference cell temperature } & $25[0 C]$ \\
\hline \multicolumn{2}{|c|}{ Temperature coefficient of photo current } & $0.001\left[A_{i} / K\right]$ & & \multicolumn{2}{|c|}{ Graphics Display } & industry \\
\hline \multicolumn{4}{|l|}{ General } & \multicolumn{3}{|l|}{ General } \\
\hline ok & Cancel & Help... & & ok & Cancel & Help... \\
\hline
\end{tabular}

Figure 3.17: PV Cell and Array Parameter Menus in PSCAD

Since no specific panel manufacture data was provided for the $2 \mathrm{MW}$ solar system the default solar cell parameters were used as shown in the figure. Switching from the solar cell parameters to the solar array parameters the default number of cells in series/parallel for each module, the reference solar irradiation, and the reference cell temperature were also left unchanged. Parameters that needed to be determined for this 
system were the number of modules connected in series/parallel for each array. A simple test was conducted to determine the output power of a single module with the other parameters left at their default value. It was determined that a single module produced approximately $660 \mathrm{~W}$ operating at the MPP. If $2 \mathrm{MW}$ of power capacity is desired, with 1 module producing $660 \mathrm{~W}$, the required number of modules was determined to be approximately 3000 . With these 3000 modules many combinations of parallel strings of modules in series could be used. The design choice made was to use 45 parallel strings each of 65 modules in series.

The maximum power point tracking component parameter menu requires the entry of the arrays open circuit voltage $\left(\mathrm{V}_{\mathrm{OC}}\right)$, short circuit current $\left(\mathrm{I}_{\mathrm{SC}}\right)$, sampling interval, and a starting initial value. The entered values can be seen in Figure 3.18. Running a simulation and plotting the I-V curve easily determined the $\mathrm{V}_{\mathrm{OC}}$ and $\mathrm{I}_{\mathrm{SC}}$ parameters. From the same plotted I-V curve at the reference values for solar irradiation and cell temperature the MPP was determined by observation and entered as the initial value. The default sampling interval was left unchanged. 


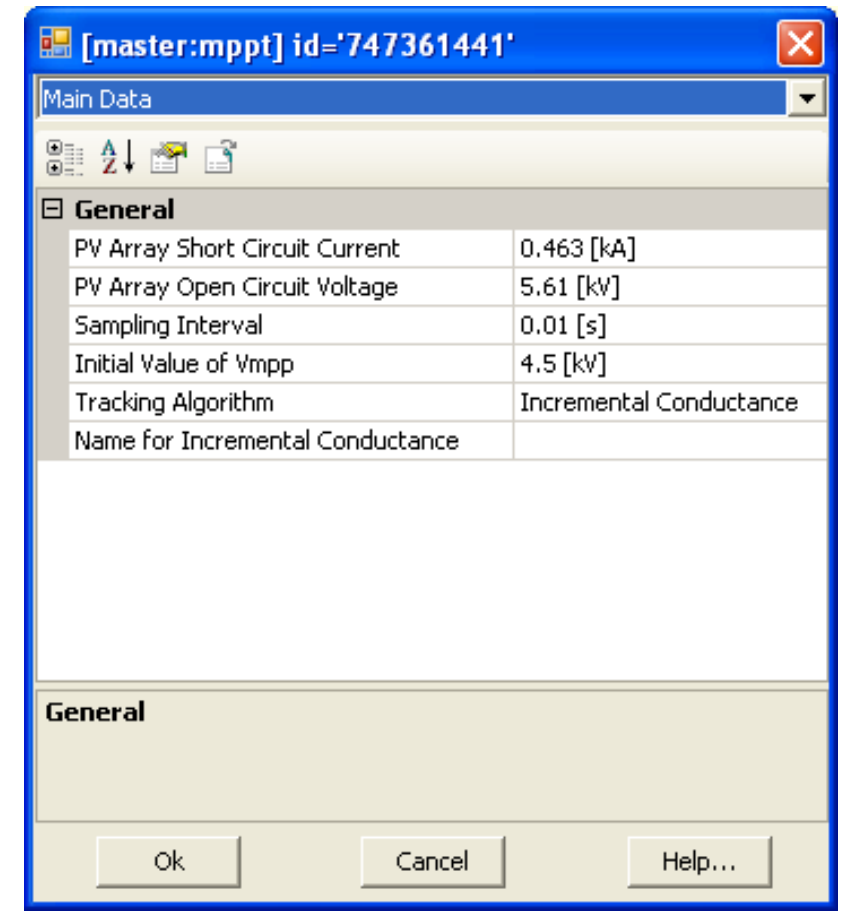

Figure 3.18: MPPT Parameter Menu in PSCAD

The PV array connected to the inverter model developed and described formerly is shown in Figure 3.19. The operation and control of the system using the MPPT block will be discussed in a following section along with the overall control scheme.

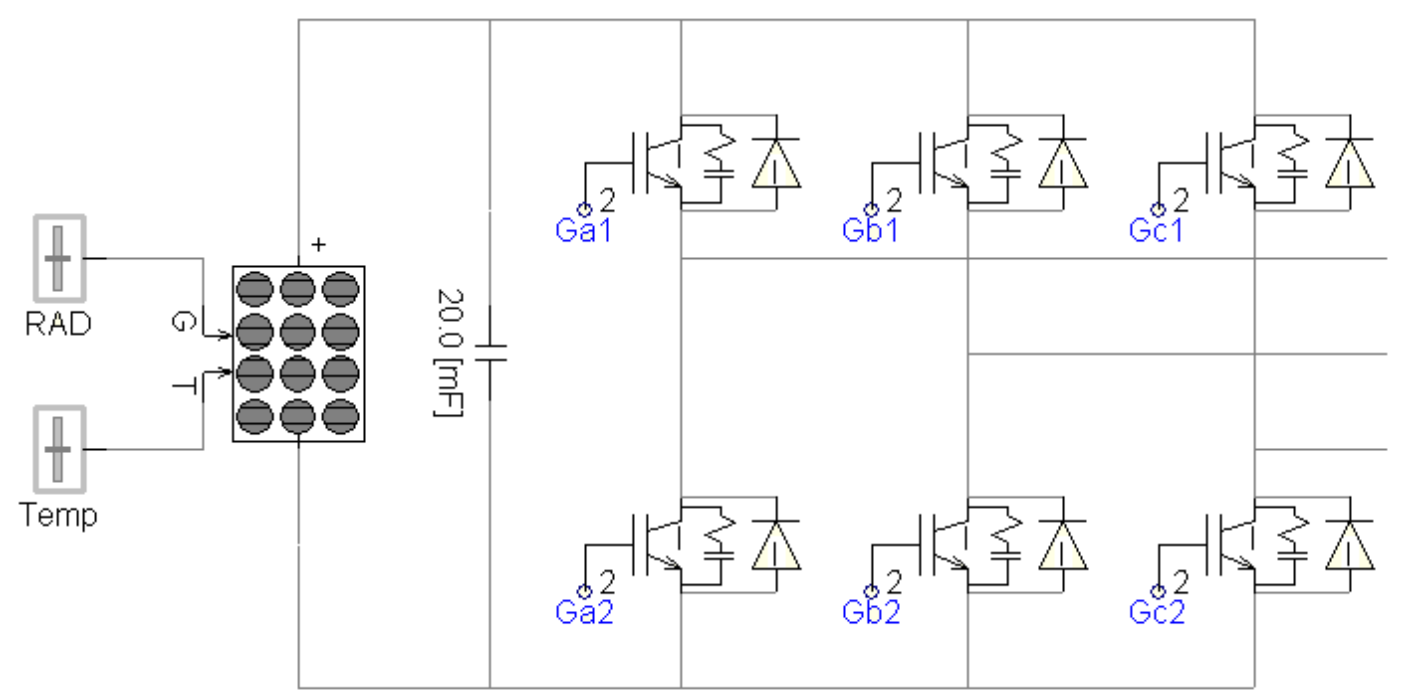

Figure 3.19: PV Inverter Modeled in PSCAD 


\subsection{Link Capacitor}

The bridge between the PV array and the inverter is the DC link capacitor graphically shown in Figure 3.19. This component is of the upmost importance as it serves three very important functions. The first function is to minimize the voltage ripple across the PV terminals and which results in a ripple of the output power [36]. Secondly, the capacitor acts as a sink and source every half cycle to help create a balance of power on the DC bus. Lastly, the capacitor is the source for reactive power generation that will be discussed in further detail in a later section.

The derivation for sizing the DC link capacitor illustrates the importance of the component due to the difference in AC output power and DC input power. Starting with equations for voltage and current for a single phase of the three phase inverter output [36] [37]:

$$
\begin{gathered}
V_{L N}=V_{p k} \sin \left(\omega_{o} t\right) \\
I_{L}=I_{p k} \sin \left(\omega_{o} t+\varphi\right)
\end{gathered}
$$

where $\varphi$ is the difference in phase between the grid voltage and inverter output voltage. This phase is equal to zero when the current and voltage are in phase. Multiplying $\mathrm{V}_{\mathrm{LN}}$ by $I_{L}$ gives the instantaneous power of a single phase. As an approximation, considering a worst case scenario, the three phase instantaneous output power of the inverter can be expressed as three times the single phase power:

$$
P_{o}=3 V_{p k} I_{p k} \sin \left(\omega_{o} t\right) \sin \left(\omega_{o} t+\varphi\right)
$$

Applying a simple trigonometric identity and assuming unity power factor operation $(\varphi$ equals zero) yields a new form of (3-14): 


$$
P_{o}=\frac{3 V_{p k} I_{p k}}{2}-\frac{3 V_{p k} I_{p k}}{2} \cos \left(2 \omega_{o} t\right)
$$

The left term on the right hand side of the equation without the cosine term is the average or DC component of the inverter output power $\mathrm{P}_{\mathrm{o}-\mathrm{AVG}}$. The right most term is the $\mathrm{AC}$ component of the output power $\mathrm{P}_{\mathrm{O}-\mathrm{AC}}$ and is twice the frequency of the grid. This equation is shown graphically in Figure 3.20. From the Figure it is evident that there are periods of time when the output power of the inverter is greater than the input PV power and also the alternate, where output power is less than the input power. In order to maintain a power balance at the DC bus, a capacitor is used to deliver and store energy when appropriate as depicted in Figure 3.20

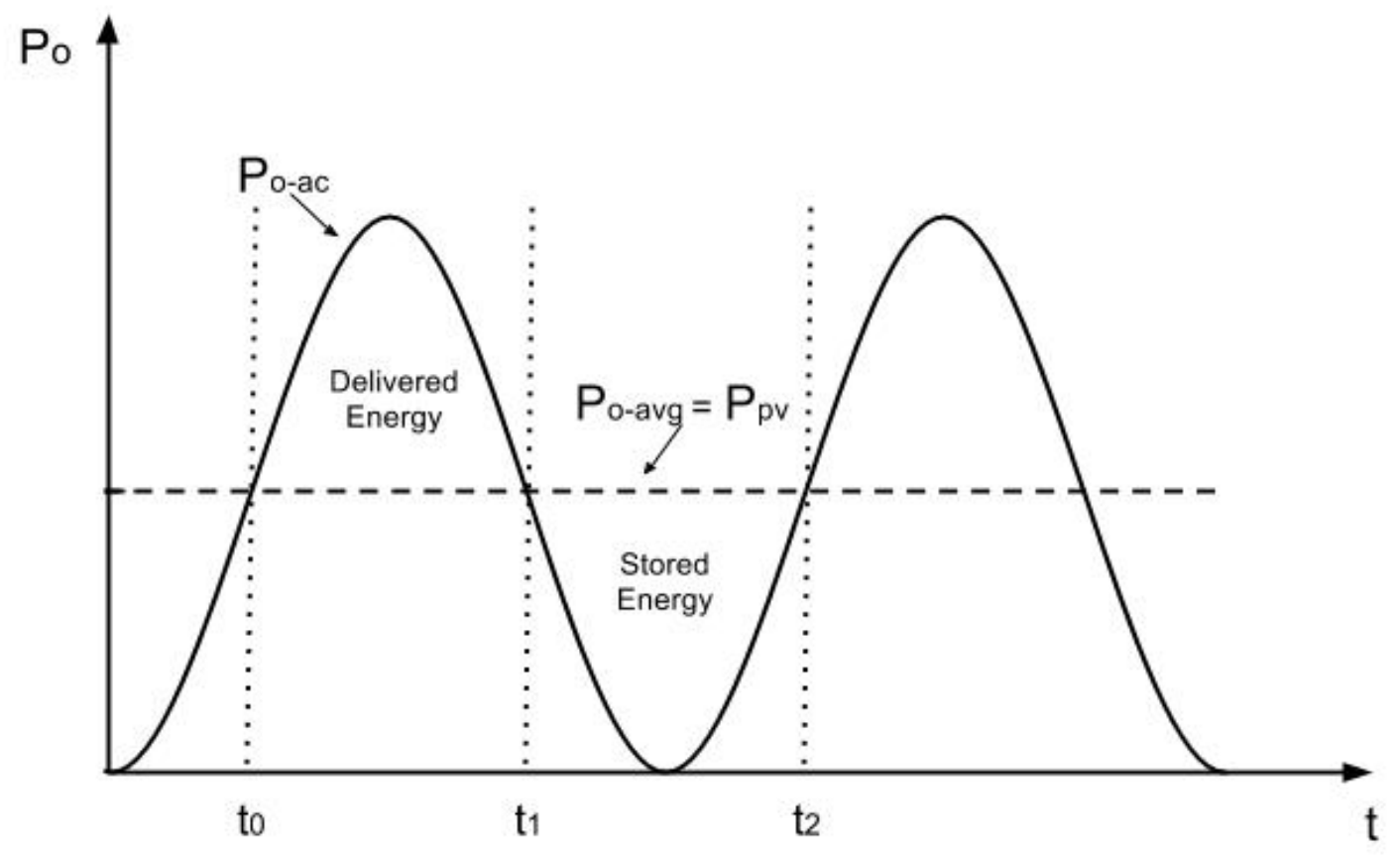

Figure 3.20: Output Power of inverter Showing AC and DC Components

As long as the inverter is operating correctly it is valid to assume the average output power of the inverter is equal to the generated PV power if losses are neglected, therefore the output power can be expressed as: 


$$
P_{o}=P_{P V}-P_{P V} \cos \left(2 \omega_{o} t\right)
$$

The net power into or out of the DC bus is described by:

$$
P_{\text {Bus }}=P_{P V}-P_{o}
$$

Combining (3-16) and (3-17) yields the instantaneous DC bus power that the capacitor will need to sink or source every half cycle:

$$
P_{B u s}=P_{P V} \cos \left(2 \omega_{o} t\right)
$$

Integrating (3-18) for one half cycle and setting it equal to the expression for energy stored in a capacitor, rearranging the result, the equation to size the input capacitor is expressed as:

$$
C=\frac{P_{P V}}{2 \pi f_{\text {grid }} V_{P V}{ }^{2}\left(\Delta V_{P V-\%}\right)}
$$

where $\Delta V_{P V}$ is the allowable ripple voltage of $V_{P V}$ expressed as a percentage. For large PV systems the voltage ripple needs to be small so the corresponding power ripple as represented in Figure 3.21 is minimal. A ripple tolerance of 1.5\% was chosen, plugging in the correct values for the system of interest into (3-19), and rounding to a typical value the DC link capacitor was sized to be $20 \mathrm{mF}$. 


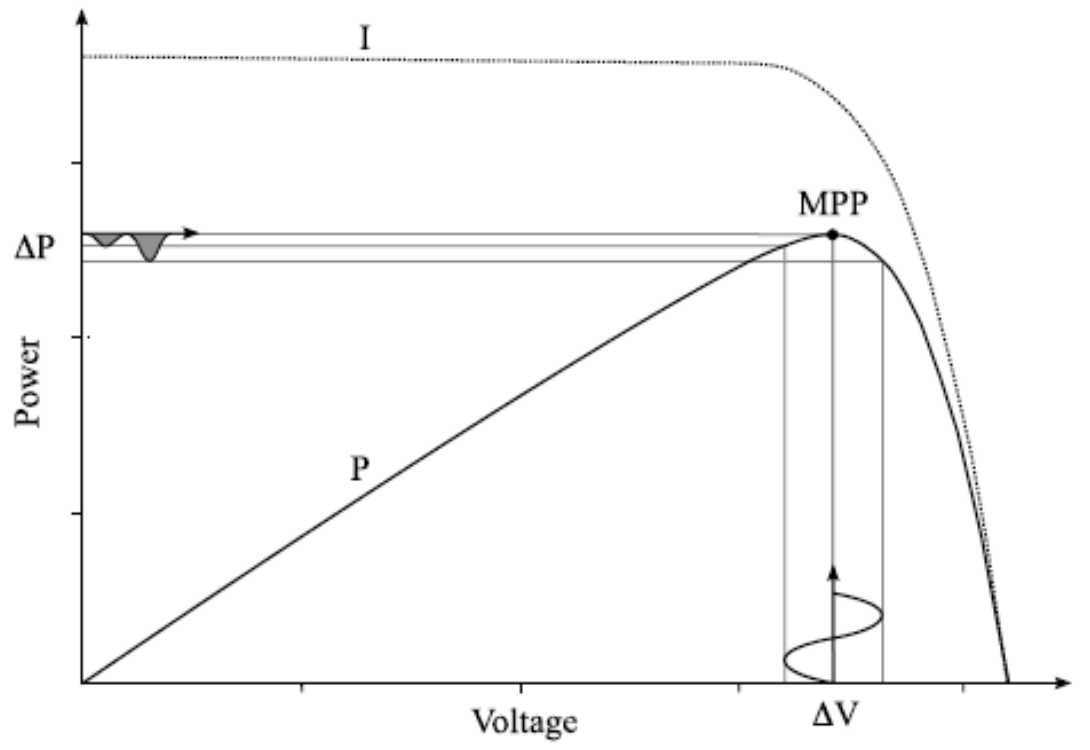

Figure 3.21: Output Power Ripple Due to Voltage Ripple [36]

\subsection{The Transformer}

In selecting the transformer to step up the filtered inverter voltage to the $12.47 \mathrm{kV}$ distribution line several items were taken into consideration. Minimally, the transformer needed a power rating, a suitable turns ratio, primary winding type, and secondary winding type to be selected. The MVA rating of the transformer was based on the MW capacity of the solar array whose generated power it is transferring to the power grid. Since the solar system has a peak generation of $2 \mathrm{MW}$, and the inverter has additional reactive power generation or absorption capability the rating of the transformer was selected to be 3MVA.

\subsubsection{Winding Connection Type}

Of the four types of transformer winding connection types (wye-wye, wye-delta, delta-wye, and delta-delta) the delta-wye winding connection type was chosen. In addition to the winding type selection, the wye side of a transformer can be ungrounded, 
grounded through impedance, or solidly grounded. The wye side was chosen to be solidly grounded which is typical and helps reduce the insulation requirements on the high voltage side [9]. The delta side is connected to the inverter after the output filter and the wye side is connected to the distribution network. Delta-wye is the most common connection type for transformers connecting large generators to transmission systems [9]. Since this PV system is of relatively large size in terms of its power generating capacity choosing the transformer that would be used if a standard synchronous generator of similar size were being connected is fitting.

Another benefit of choosing the delta-wye transformer is the added harmonic suppression [9]. Without providing a detailed background on sequence components in power systems that can be studied in detail in [9], zero sequence currents are trapped by the delta connection in the transformer. So instead of the zero sequence current being able to flow through the transformer as it would if it were wye-wye connected, they instead flow in a circle contained in the delta connected windings. The presence of zero sequence current introduces triple frequency $(180 \mathrm{~Hz}, 360 \mathrm{~Hz}, 540 \mathrm{~Hz}$, etc.) harmonics in the power system [22]. Harmonics are not desired in power systems because they degrade the quality of the voltage and current waveforms present and can cause conductors to overheat.

\subsubsection{Primary and Secondary Winding Voltages}

In order to determine the turns ratio, or primary and secondary voltages, of the transformer the output of the inverter voltage after it has been filtered needs to be considered. Since the wye side of the transformer is connected to the $12.47 \mathrm{kV}$ 
transmission system its winding voltage will also be $12.47 \mathrm{kV}$. For the delta side voltage winding its selection is slightly more difficult.

Recall equation (3-6) that shows the inverter filtered RMS line to line output voltage as a function of the input PV voltage and control signal $m a$. In order for the inverter to operate with ancillary services, as will be discussed in detail in the section following, the secondary winding voltage needs to be selected so that under normal condition the modulation index control signal is between zero and one with room to increase or decrease slightly while still staying away from its lower and outer bounds of zero and one. Standard operation for this model is based on the default solar irradiation and cell temperature input to the PSCAD solar array model. With default values of 1000 $\frac{w}{m^{2}}$ and $50^{\circ} \mathrm{C}$ for solar irradiation and cell temperature respectively, the solar array produces power with the MPP voltage occurring at $4.5 \mathrm{kV}$. Given the MPP voltage under normal operation, the DC voltage at the input of the inverter can be assumed to be the same for use in calculations. Further analyzing equation (3-6), fixing $\mathrm{V}_{\mathrm{DC}}$ to $4.5 \mathrm{kV}$, and taking into consideration the fact that transformer winding voltages come in discrete values, the delta side voltage winding was determined to be $2 \mathrm{kV}$. To give insight on this value and how it corresponds to the modulation index $m a$, under normal PV voltage output with the injected voltage controlled to perfectly match the grid voltage in magnitude, $m a$ would need to be equal 0.726 .

\subsubsection{PSCAD Transformer Modeling}

The transformer model in PSCAD can be as simple or complex as desired based on the selected input parameters in the transformer input parameter menu. The transformer in a single line view is presented in Figure 3.22. An ideal transformer model 
was used in this design for simplicity since the goal of this study can be completed without the addition of a more complex model. Since the transformer was assumed to be ideal only basic parameters needed to be entered, these parameters are illustrated in Figure 3.23.

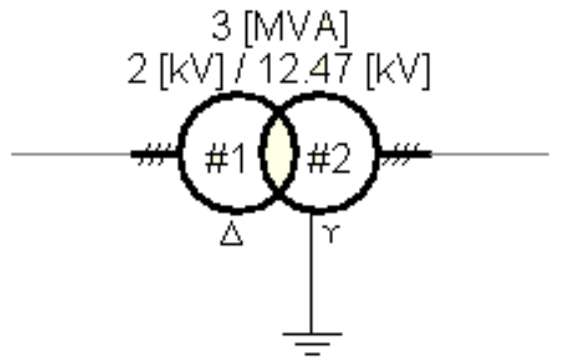

Figure 3.22: Single Line Diagram of Three Phase Delta-Wye Transformer Model in PSCAD

\begin{tabular}{|c|c|}
\hline 嚚 3 Phase 2 Winding Transformer & $x$ \\
\hline \multicolumn{2}{|l|}{ Configuration } \\
\hline \multicolumn{2}{|l|}{ (9-1) $\mathrm{A} \downarrow$} \\
\hline \multicolumn{2}{|l|}{$\boxminus$ General } \\
\hline \multicolumn{2}{|l|}{ Transformer Name } \\
\hline 3 Phase Transformer MVA & 3 [MVA] \\
\hline Base operation frequency & $60.0[\mathrm{~Hz}]$ \\
\hline Winding \#1 Type & Delta \\
\hline Winding \#2 Type & $Y$ \\
\hline Delta Lags or Leads Y & Lags \\
\hline Positive sequence leakage reactance & $0.1[\mathrm{pu}]$ \\
\hline Ideal Transformer Model & Yes \\
\hline No load losses & 0 [pu] \\
\hline Copper losses & 0 [pu] \\
\hline Tap changer on winding & None \\
\hline Graphics Display & Single line (circles) \\
\hline Display Details? & Yes \\
\hline \multicolumn{2}{|l|}{ General } \\
\hline Cancel & Help... \\
\hline
\end{tabular}

Figure 3.23: Transformer Input Parameter Menu PSCAD 


\subsection{Complete System and Control}

The design and control of this grid tied inverter system was derived from basic power flow equations, PWM inverter controls, and a single stage MPPT algorithm. The control is rather novel, however the scheme allows the inverter to operate with the ancillary services formerly defined. The complete power stage of the system in PSCAD is shown in Figure 3.24. The model developed in this thesis is similar to the PV grid tied inverter presented in [34] where the PV modeling tools were developed. A useful component used from this model was the DC link capacitor pre-charging circuit which greatly reduced simulation time.

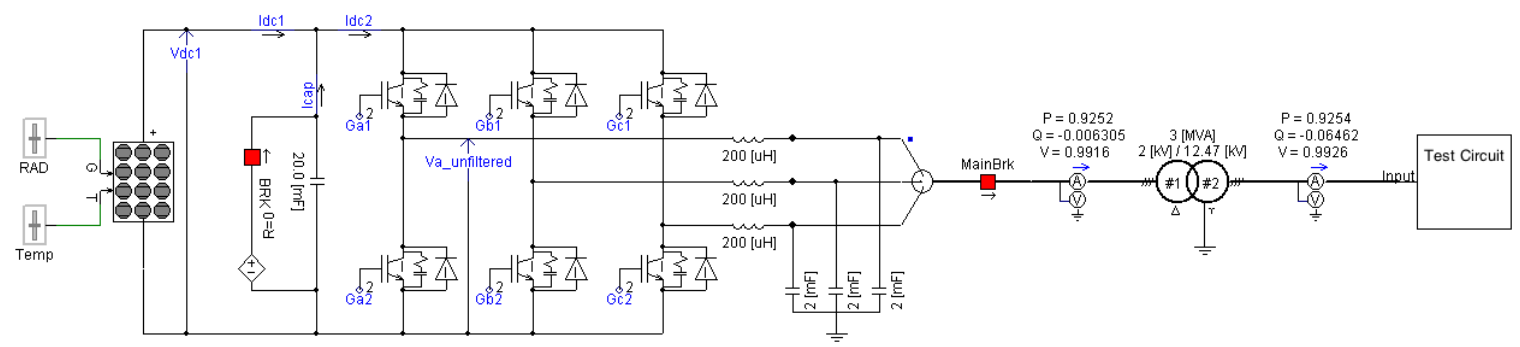

Figure 3.24: Complete Grid Tied PV Inverter Power Stage Modeled in PSCAD

\subsubsection{Active Power Control}

The power produced by the $2 \mathrm{MW}$ solar array is in a DC form before it is inverted and filtered into an $\mathrm{AC}$ grid injectable form. Controls need to be considered so that all of the power generated, minus loss across the inverter, is transferred through the system and into the power network. This control is modeled around the basic real power flow equation for a two-port network:

$$
P_{12}=\frac{V_{1} V_{2}}{X_{12}} \sin \delta
$$

where $\mathrm{P}_{12}$ is the power flowing from port one to port two shown in Figure 3.25. The voltages $V_{1}$ and $V_{2}$ are the magnitudes of the terminal voltages of the two-port network. 
$\mathrm{X}_{12}$ is the equivalent system impedance between the two voltages. And delta, $\delta$, is the phase angle difference between $V_{1}$ and $V_{2}$.

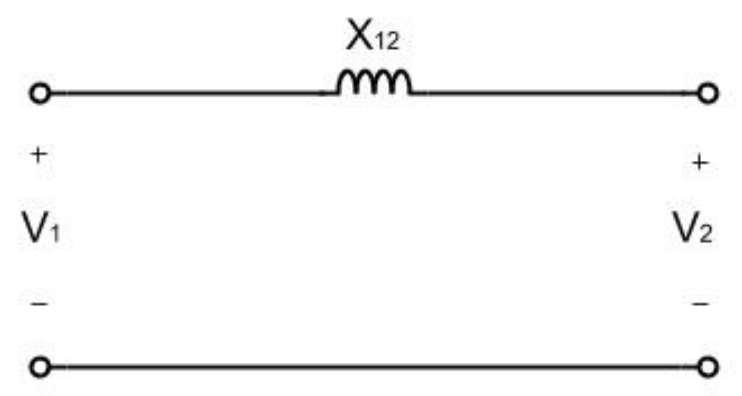

Figure 3.25: Simple Two-Port Network

The equation (3-20) assumes the equivalent system impedance has a high reactance to resistance ratio. This assumption is valid for the system of interest because the power flow equation is being applied across the grid-coupling transformer and a natural characteristic of transformers is to have very high $\mathrm{X} / \mathrm{R}$ ratios. Analyzing the variables in (3-20), the reactance $X_{12}$ is a fixed parameter and does not change. $V_{2}$ is the grid voltage and is usually considered "stiff" or not easily changed from its nominal value. And $V_{1}$ is the inverter produced voltage which is controllable but doesn't vary far above or below its nominal value. This leaves the last variable delta, also known as the power angle, the dominating variable in the equation. Delta is the phase difference between voltages across the transformer referred to one side in order to neglect the inherent delta-wye thirty degree phase shift. Since the power systems phase is a stiff quantity controlling the power angle, and hence the power delivered to the grid, is easily achieved by adjusting the phase input signal applied to the PWM reference sine waveforms. With the real power now controllable, how to control/set the power angle needs to be determined.

Ideally, the power angle needs to adjust so the power delivered to the grid is equal to the PV generated power minus loss. When these two powers are equal the voltage at 
the DC bus, across the DC link capacitor and the PV array terminals, is constant and at the MPP of the PV array. If the power angle is too large the controller is effectively trying to send more power than is available and the DC bus voltage decreases/collapses because the required PV operating point is not on its operating curve. The DC link capacitor prevents this from happening rapidly by supplying supplemental energy as it discharges when demand is greater than generation, but this can only be maintained briefly. If the power angle is too small, the system is not making efficient use of the PV system because it is not operating at the MPP voltage. In order to realize the required control action, the difference between the measured PV voltage and the calculated maximum power point voltage is fed through a proportional integral (PI) controller and the output is the phase applied to the PWM reference sine waves. This control scheme, shown in Figure 3.26, forces the power angle to modulate until both the grid injected power is equal (minus loss) to the PV array and the array is operating at is MPP.

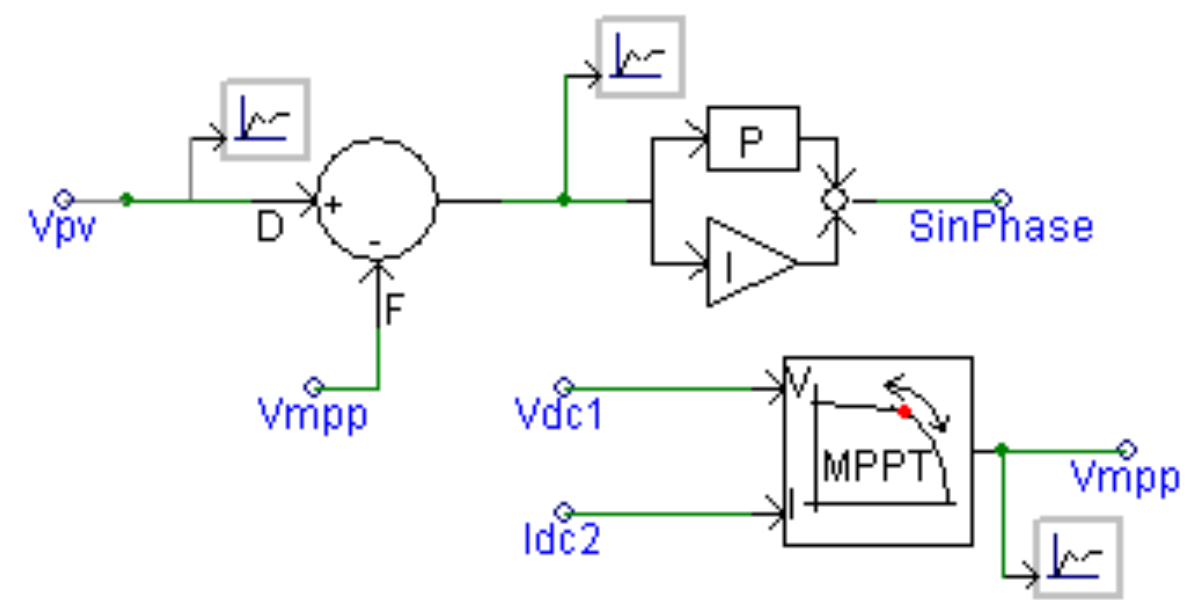

Figure 3.26: Real Power, Power Angle, and MPPT Control Modeled in PSCAD

\subsubsection{Reactive Power Control}

The control method for the voltage output of the inverter and effectively the reactive power generated or absorbed is based on a simple reactive power flow equation 
just as in the real power control method. Referring back to the two-port network of Figure 3.25, the reactive power flowing from port one to port two can be described by:

$$
Q_{12}=\frac{V_{1} V_{2}}{X_{12}} \cos \delta-\frac{V_{2}^{2}}{X_{12}}
$$

The same analysis applied for (3-20) to justify the validity of the equation can be applied to (3-21). In (3-21) it becomes apparent that delta is not the most influential variable for the resulting reactive power but instead it is the inverter generated voltage $V_{1}$ since $V_{2}$ is fixed at the grid voltage. So by controlling the inverter output voltage, the reactive power can be controlled.

Since most inverters are required to operate at unity power factor, that mode of operation will be discussed first and considered standard operation. Recall (3-6), showing the inverter generated voltage as a function of $m a$ and the DC input voltage. Assuming the PV voltage to be fairly constant under normal operation the inverter voltage is linearly proportional to $m a$. Therefore, adjusting the modulation index of the PWM reference sine waves can control the inverter voltage and consequently the reactive power output. The control is realized by subtracting the measured reactive power from a set point of zero and sending the difference through a PI controller which outputs the $m a$ signal to be input to the PWM reference sine waves. This control scheme is shown in Figure 3.27. 


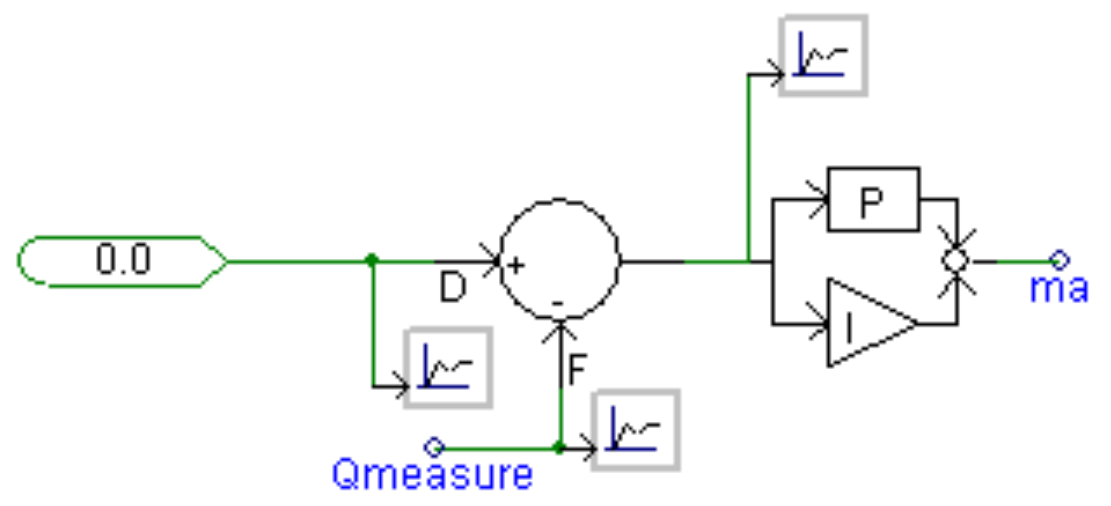

Figure 3.27: Reactive Power, Voltage, and Modulation Index Control Modeled in PSCAD

\subsubsection{Voltage Regulation and Ride Through}

Modifying the control scheme to change from unity power factor operation to provide the necessary reactive power for active voltage regulation is rather easily accomplished. Instead of creating the error signal by subtracting the measured reactive power from zero, the measured reactive power is replaced with the measured PCC terminal voltage and the zero set point is replaced with the nominal $12.47 \mathrm{kV}$ voltage. This new error signal is applied to the PI controller and its output, $m a$, adjusts which in turn changes the generated inverter voltage, which finally sends or absorbs reactive power to or from the power system and successfully regulates its terminal voltage at the PCC to the set point value of $12.47 \mathrm{kV}$. The voltage regulating control loop is illustrated in Figure 3.28. 


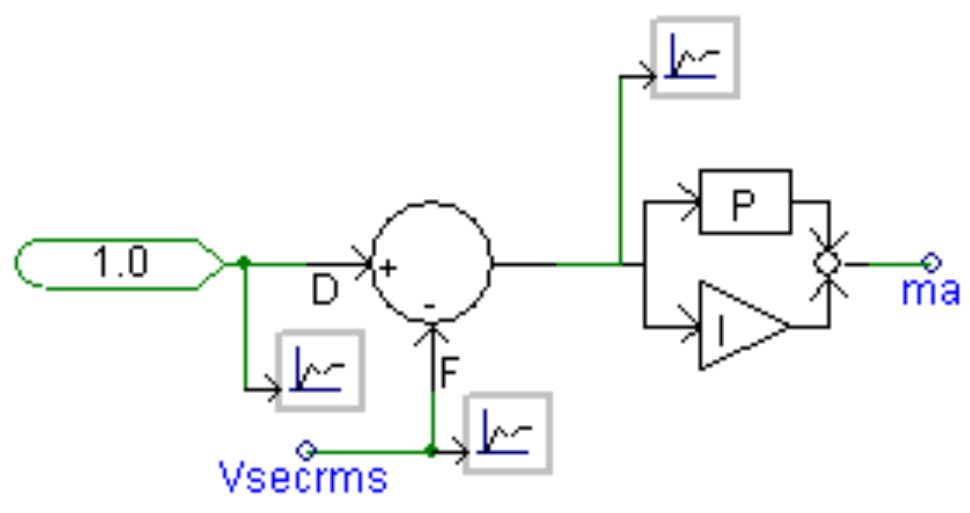

Figure 3.28: Voltage Regulation Control

In order to be able to run the inverter in both modes of operation based on operator selection a switch was added. The switch selects which parameter's error signal the PI controller's output forces to zero. Figure 3.30 shows the voltage control scheme with selectable modes of operation.

\subsubsection{Frequency Response}

For power systems to operate normally at sixty hertz with very stringent tolerances the instantaneous power generated must equal the instantaneous power demanded. When generation exceeds demand frequency rises, and when demand exceeds generation frequency droops. A control strategy based on this phenomena can be created by measuring the grid frequency and curtailing or increasing the power being generated by the inverter to help match the current demand and in essence maintain the grid at its nominal frequency.

In order to generate the required control in PSCAD another simple control loop was created. This control loop finds the difference between the nominal grid frequency and the measured grid frequency at the PCC and the error signal is passed through a PI 
controller that realizes the required phase to send to the PWM reference sine wave until the frequency is fixed back to its nominal value.

This method of control needs only to be activated if the frequency is sensed to be outside of a specified window. To make this happen, the frequency is measured and compared with upper and lower adjustable tolerance bounds, if the frequency is beyond either of the bounds the frequency mode of control is switched on and maintained until the frequency is held at its nominal value for an adjustable off delay.

Another consideration discovered during testing is how the inverter should switch back to normal operation seamlessly when the frequency has been held at nominal value for the adjustable off delay. The nature of the PI controller is to change its output rapidly when the input error signal is large. This quick response is desirable during the transition of the frequency mode from off to on in order to change the inverters output real power quick enough to help match the new demand and stabilize the system frequency. However, in the on to off transition having too quick of a response results in a rapid output power change and causes the frequency to become unstable. The solution to this problem was to create logic that limited the rate of change of output power $\left(\frac{d P}{d t}\right)$ during the frequency mode transition from on to off. The complete control loop with the required logic and normal MPPT operation mode is shown in Figure 3.29.

\subsubsection{Remote Curtailment and Ramping}

The last smart function desirable of the inverter is to have complete remote control by an operator to adjust the real and reactive power levels as desired. This is accomplished by adding additional switches that override other control methods and strictly control the real and reactive power output. Similar to the other control loops, the 
error signal is generated by finding the difference between a set point and a measured value, it is then fed into a PI controller, and the output adjusts the reference sine waves parameters accordingly as with the other control methods described. The integration of this mode of operation into the existing controls is presented in Figure 3.29 and Figure 3.30 .

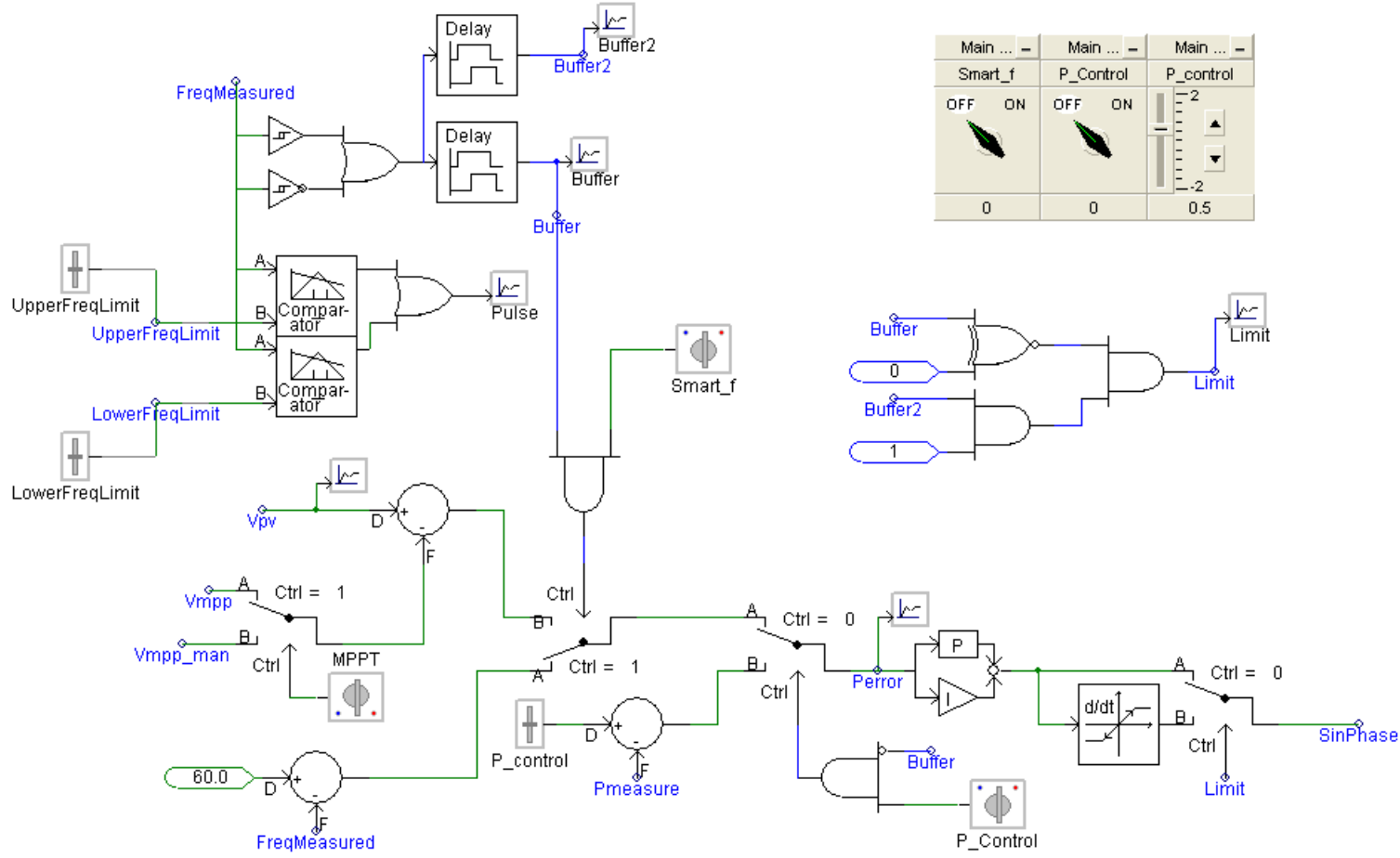

Figure 3.29: Complete Active Power Control Scheme 


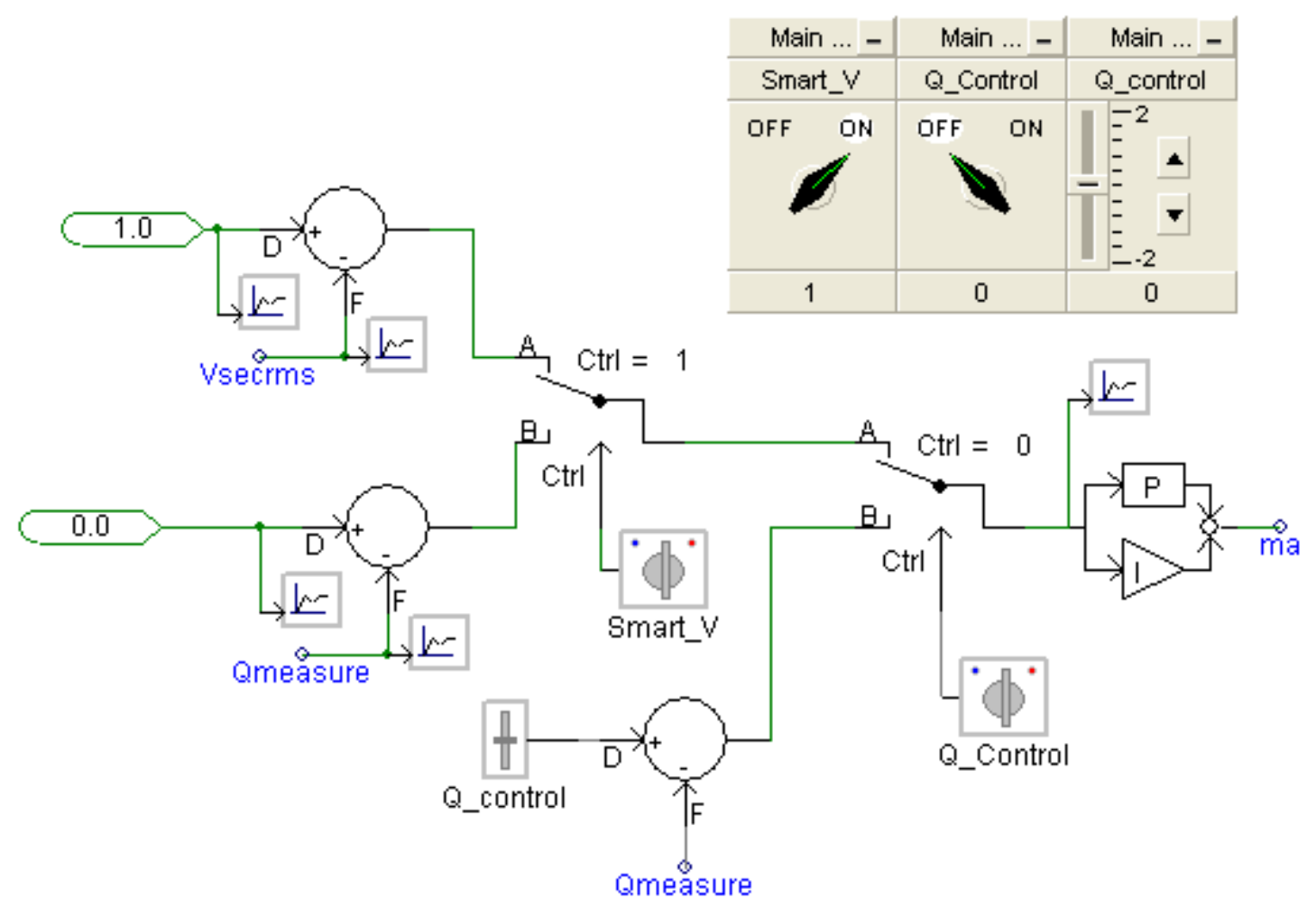

Figure 3.30: Complete Reactive Power Control Scheme

\section{9 $\quad$ PSCAD Test Setup}

Due to the complex solar PV model and high switching frequency of the PWM inverter the simulations in PSCAD must be run with a small solution time step in order to achieve satisfactory results. Because of the required small simulation time step the duration of real time required to complete several seconds of simulation can take hours. In order to reduce the run time the snapshot feature of PSCAD was utilized. This allows a simulation to be started from an initialized state. This was highly beneficial because the inverter simulation takes a large amount of time just to reach steady state, and analysis cannot be performed until steady state is reached. Therefore, in some of the PSCAD graphs shown in the following section the inverter was started from an initialized state, so transient startup is ignored. 
The module at the end of the inverter system in Figure 3.24 is the one line diagram of test circuit modeled in PSCAD. This is the electric power system in which the inverter is connected to and will be used during testing to provide data for analysis on the inverter's performance. Figure 3.31 shows the inside the test circuit module.

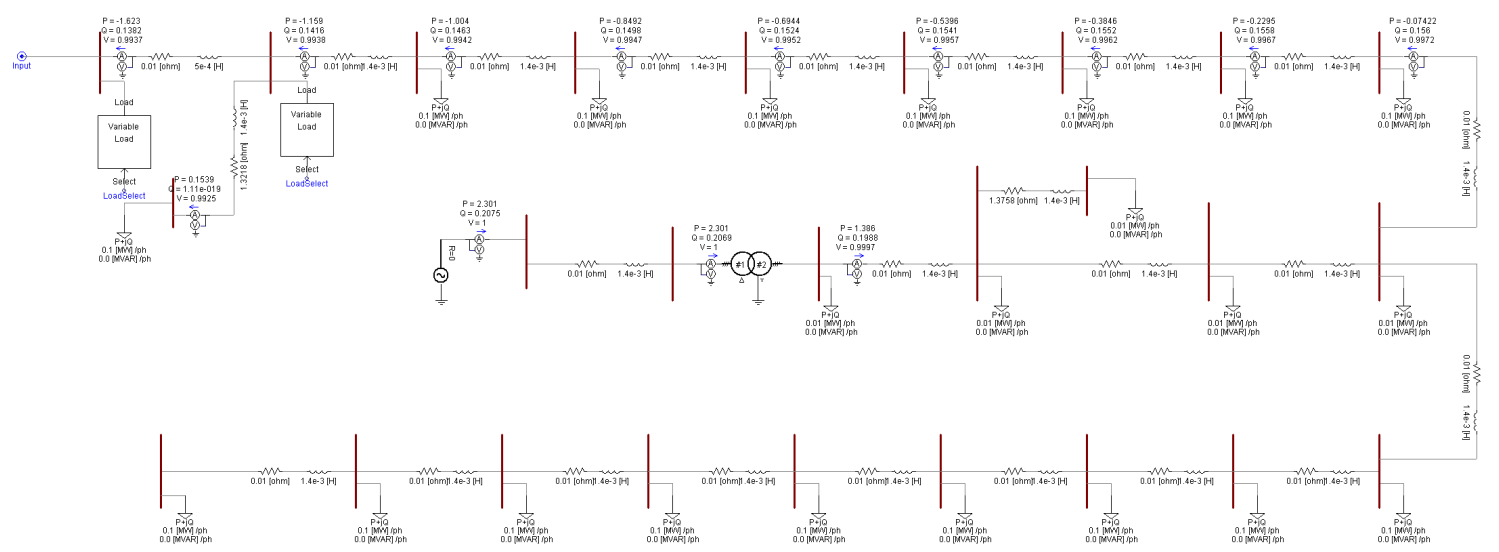

Figure 3.31: One Line Diagram of Test Circuit Modeled in PSCAD

Most of the measurements taken to capture and plot results in PSCAD were through the use of the three phase multimeter tools, which can be seen before and after the grid coupling transformer in Figure 3.24. The multimeters provide basic measurement of voltage, current, real power, reactive power, and the voltage phase angle. PSCAD has the ability to use the per unit system to display values and the base apparent power and voltages can be set in the multimeters options. Numerous graphs of different parameters in the following section are expressed in per unit. The system's base values selected for this study are presented in Table 3.6. 


\begin{tabular}{|c|c|c|}
\hline & Inverter Side & Grid Side \\
\hline $\mathbf{S}_{\text {base }}-$ Chosen & $2 \mathrm{MVA}$ & $2 \mathrm{MVA}$ \\
\hline $\mathbf{V}_{\text {base }}-$ Chosen & $2 \mathrm{kV}$ & $12.47 \mathrm{kV}$ \\
\hline $\mathbf{I}_{\text {base }}-$ Calculated & $577.35 \mathrm{~A}$ & $92.598 \mathrm{~A}$ \\
\hline $\mathbf{Z}_{\text {base }}-$ Calculated & $2 \Omega$ & $77.75 \Omega$ \\
\hline
\end{tabular}

Besides basic PSCAD equipment found in the default master library, an additional module was created to aid in testing the inverter functions. In order to switch the static load real and reactive power at a specified time a variable load module was created. The model takes in an array of signals and based on the inputs can vary the real and reactive power of the load over time switching on or off the appropriate circuit breakers. The variable load module and its interconnections are illustrated in Figure 3.32 and Figure 3.33 .

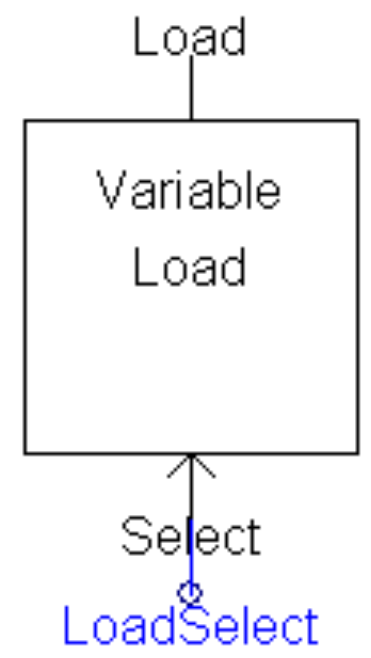

Figure 3.32: Variable Load Module 

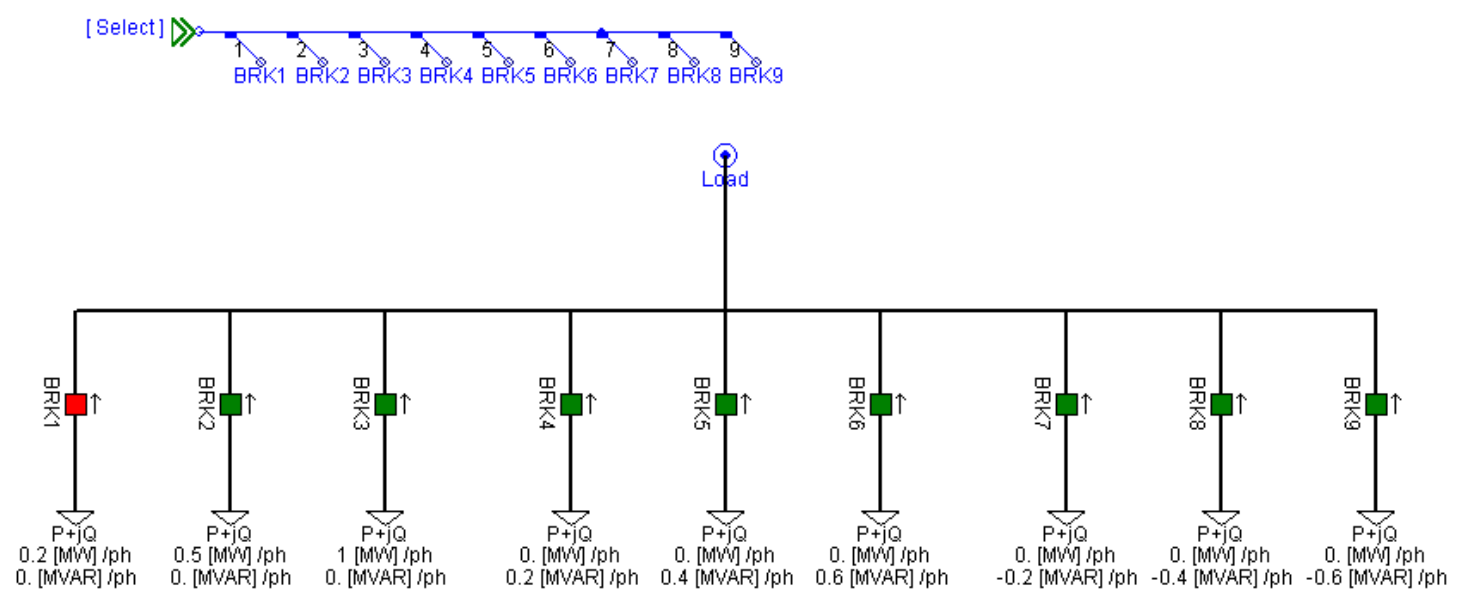

Figure 3.33: Variable Load Module Interconnectings

To perform the harmonic analysis on the inverter of this thesis the PSCAD measurement circuitry created can be seen in Figure 3.34 and Figure 3.35. The math performed in front of the FFT blocks in Figure 3.35 ensures the output harmonics will be in a percent of the rated current and voltage values.
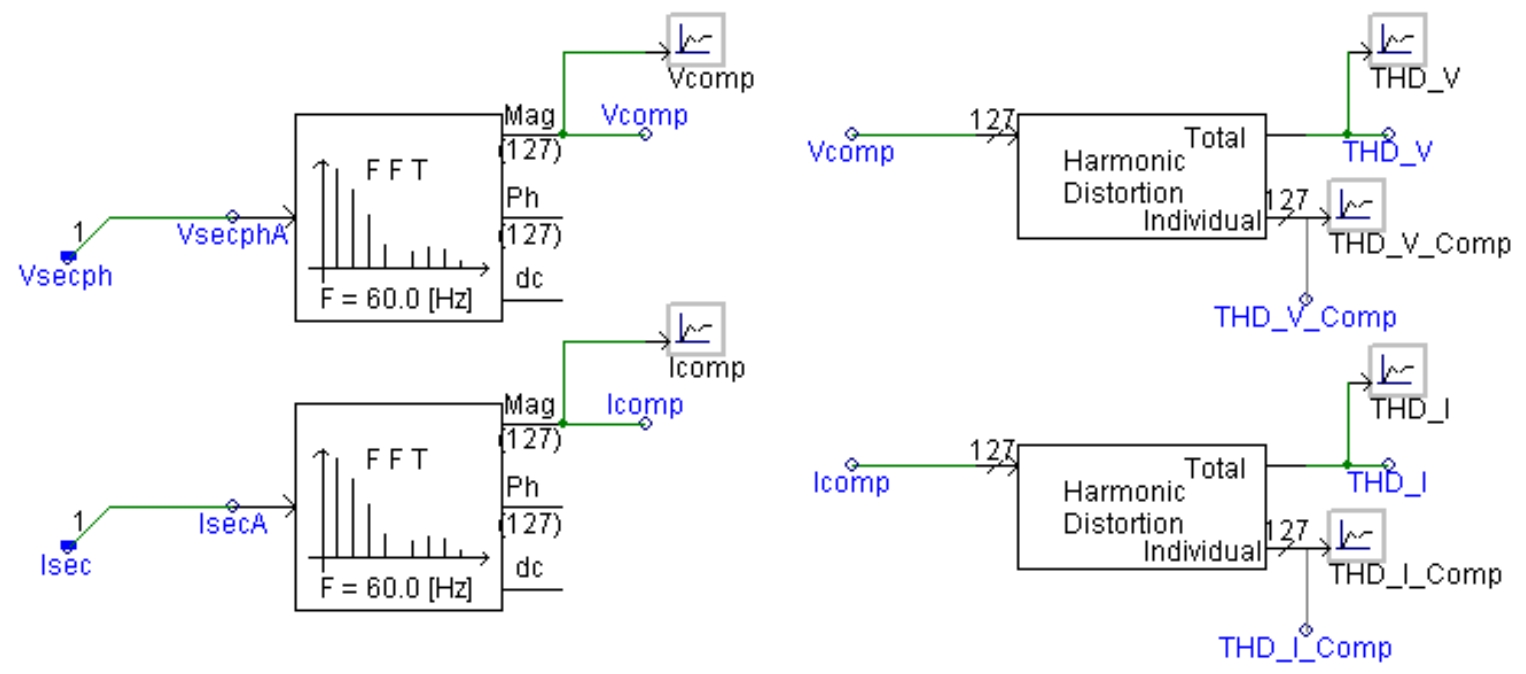

Figure 3.34: FFT and THD Blocks in PSCAD 


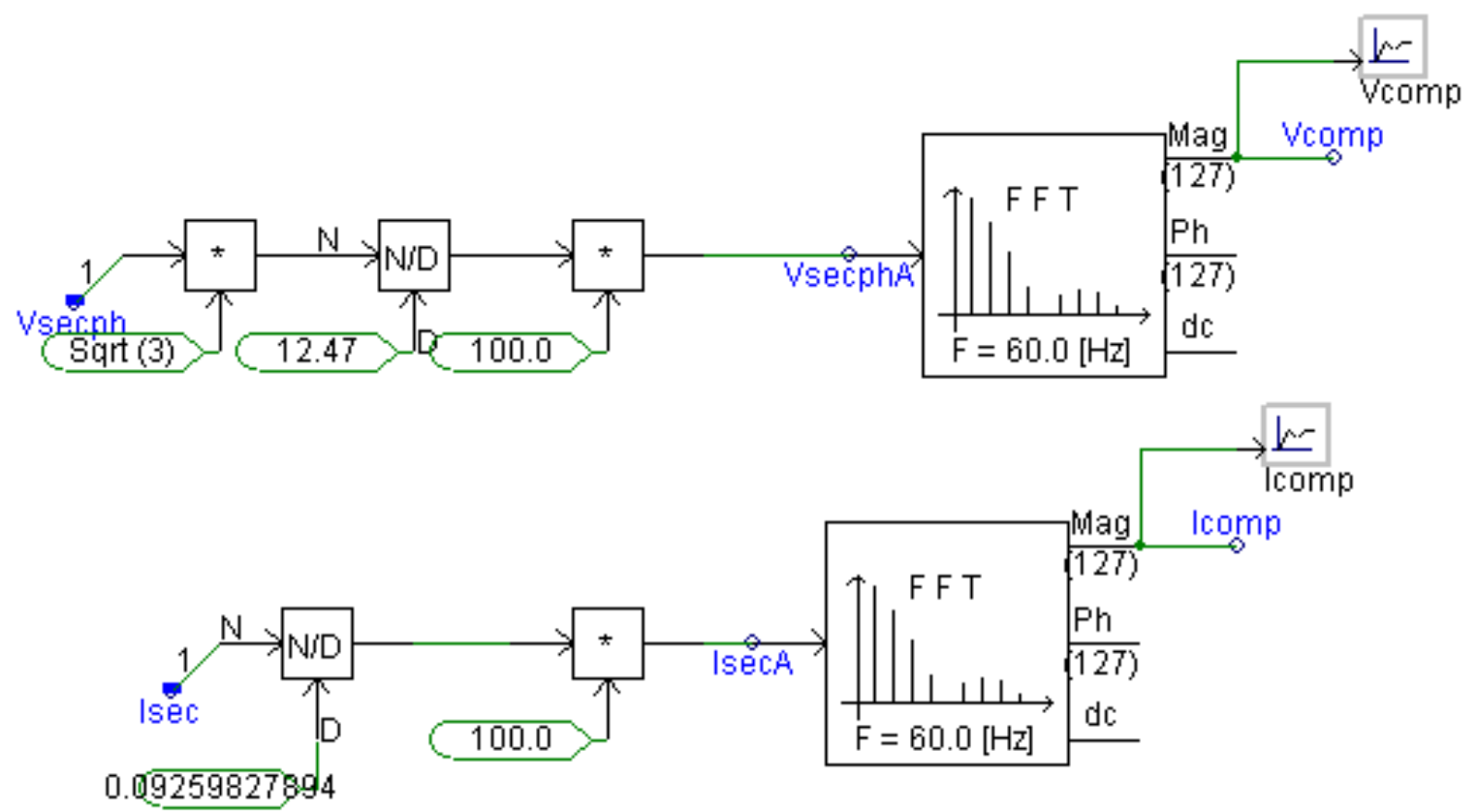

Figure 3.35: Voltage and Current Harmonic Amplitudes in \% of Rated Value 


\section{$4 \quad$ Tests and Results}

In order to demonstrate the effectiveness of the inverter's added support functions, several test cases were developed in the PSCAD simulation environment. In addition to the voltage and frequency regulating capabilities, and remote curtailment/ramping capabilities, basic inverter function operating at steady state and the corresponding power quality will be analyzed.

\subsection{Steady State Operation}

Before the smart functions of the inverter operating in response to disturbances are validated the inverter will be operated with the smart functions disabled. The ability for the inverter to track the MPP of the solar array, operate within specified current and voltage distortion limits, and inject the appropriate power to the test circuit successfully are all defined as basic inverter functions.

\subsubsection{Basic Operation and MPPT}

To test the inverters basic functions after the inverter is brought to steady state the solar irradiance and cell temperature parameters are varied to modify the PV array's IV curve, and hence the panels MPP. The test conditions are outlined in Table 4.1.

Table 4.1: PV Input Parameters For Basic Functionality Test

\begin{tabular}{|c|c|c|}
\hline Time (s) & Solar Irradiance $\left(\frac{w}{m^{2}}\right)$ & Cell Temperature $\left({ }^{\circ} \mathbf{C}\right)$ \\
\hline $\mathbf{t}<\mathbf{2}$ & 1000 & 50 \\
\hline $\mathbf{2}<\mathbf{t}<\mathbf{4}$ & 800 & 40 \\
\hline $\mathbf{4}<\mathbf{t}<\mathbf{6}$ & 600 & 30 \\
\hline $\mathbf{6}<\mathbf{t}<\mathbf{8}$ & 500 & 20 \\
\hline $\mathbf{8}<\mathbf{t}<\mathbf{1 0}$ & 1200 & 60 \\
\hline
\end{tabular}


The PV systems voltage, current, and power are illustrated in Figure 4.1 and the inverters active power, reactive power, power angle, and modulation index are shown in Figure 4.2. With the applied time varying irradiance and temperature parameters the inverter successfully tracked the changing maximum power point to ensure the maximum power was constantly being supplied to the test circuit. As the PV output changed, the controllers modulated the PWM reference sine waves phase and amplitude in order to ensure the inverter output the maximum possible power and held the reactive power to zero since unity power factor operation was selected during the simulation run. This is illustrated by the changing delta and modulation index signals. Some overshoot in the inverter response is noticeable when the PV power is instantaneously changed, however a small amount of overshoot is necessary to provide a fast response to the step input. 


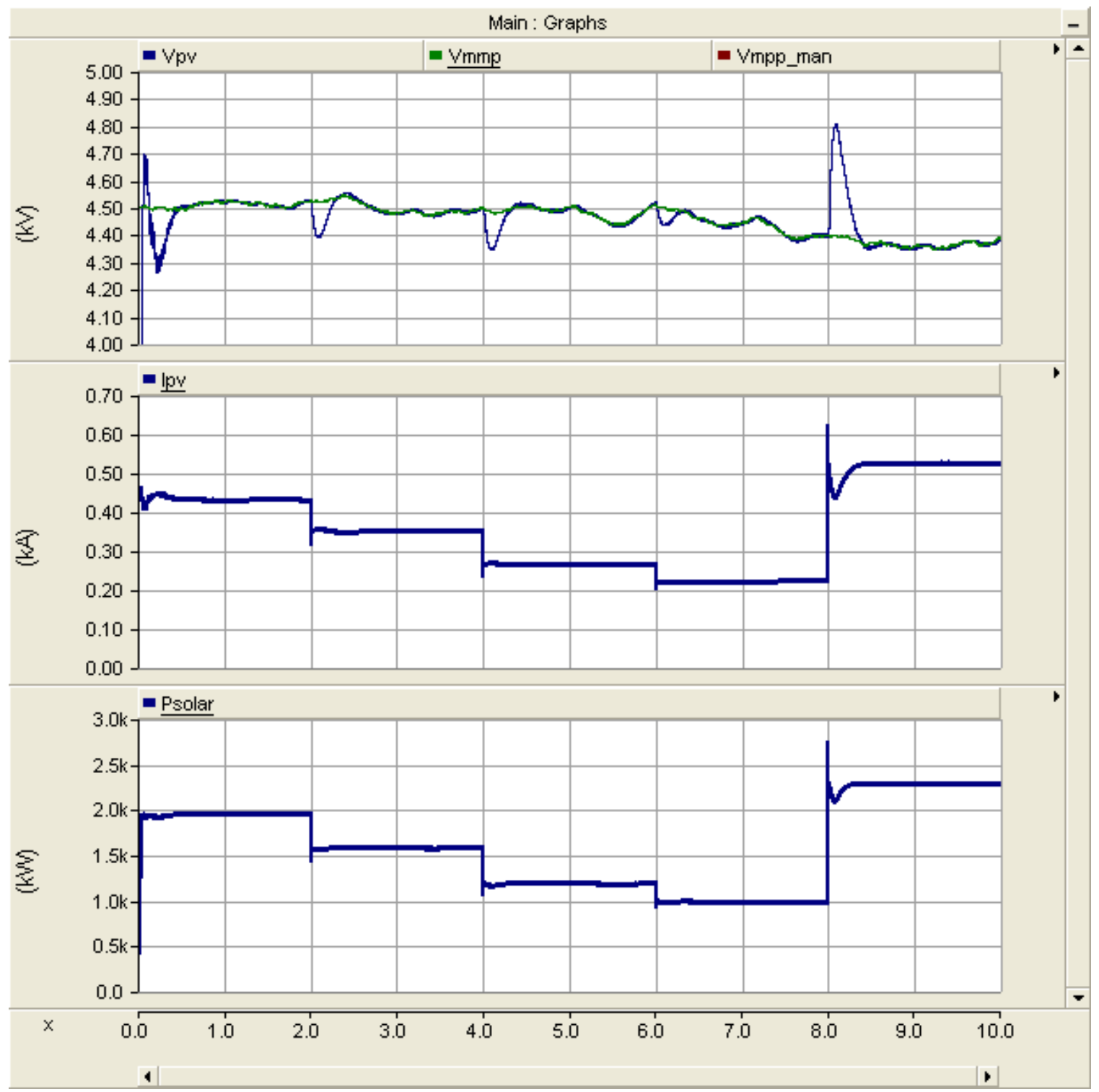

Figure 4.1: PV Array Voltage, Current, and Power with Varying Irradiance and Temperature 


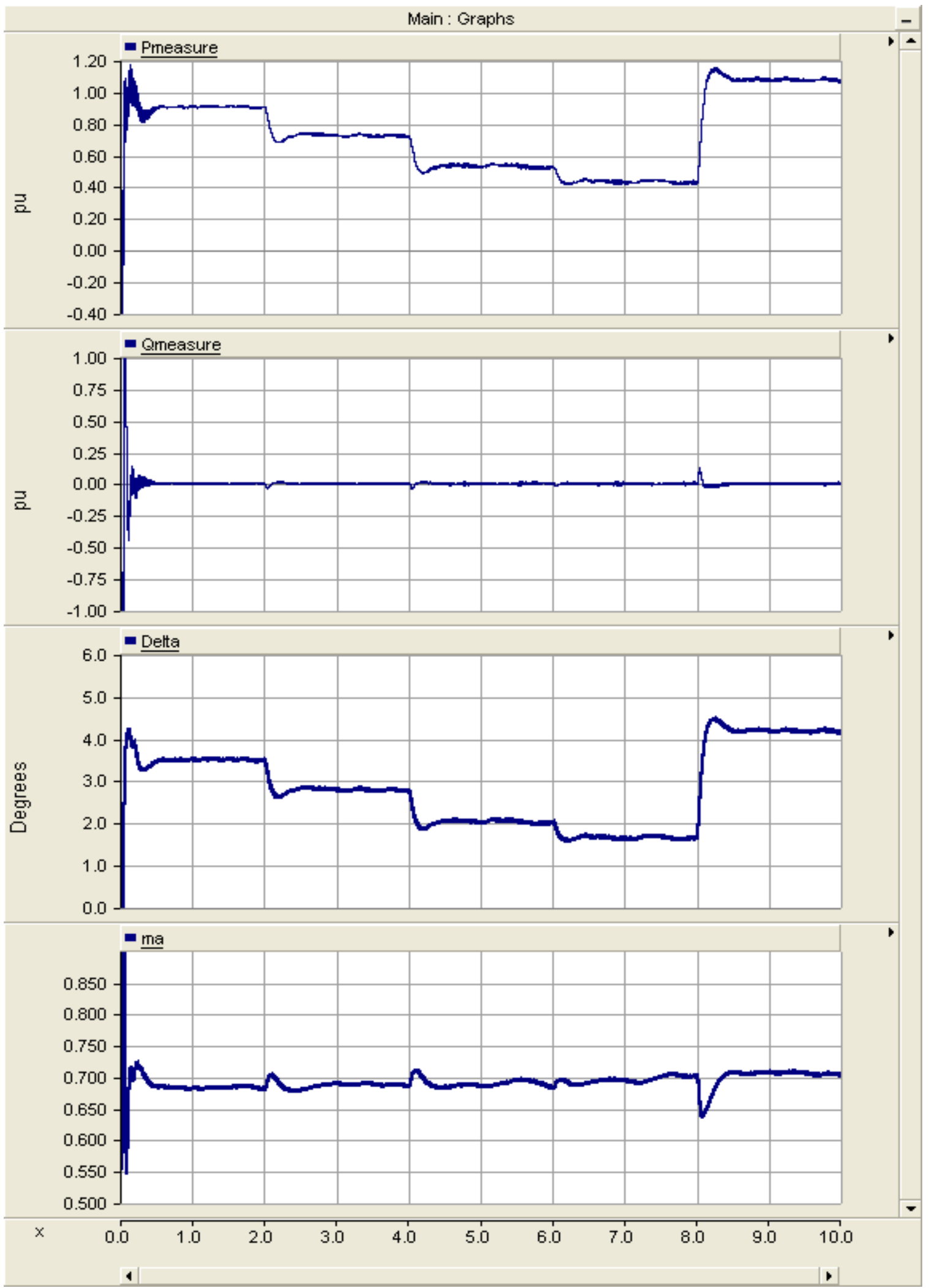

Figure 4.2: Inverter Real and Reactive Output Power, Power Angle, and Modulation Index Under Varied Solar Irradiance and Temperature 


\subsubsection{Harmonic Analysis}

From the same steady state test started from a snapshot taken during the run,

Figure 4.3 and Figure 4.4 respectively show the instantaneous voltage and current waveforms and their corresponding THD levels at the PCC for a short time segment during the run. The voltage THD level is under the maximum limit specified in Table

\section{4 .}

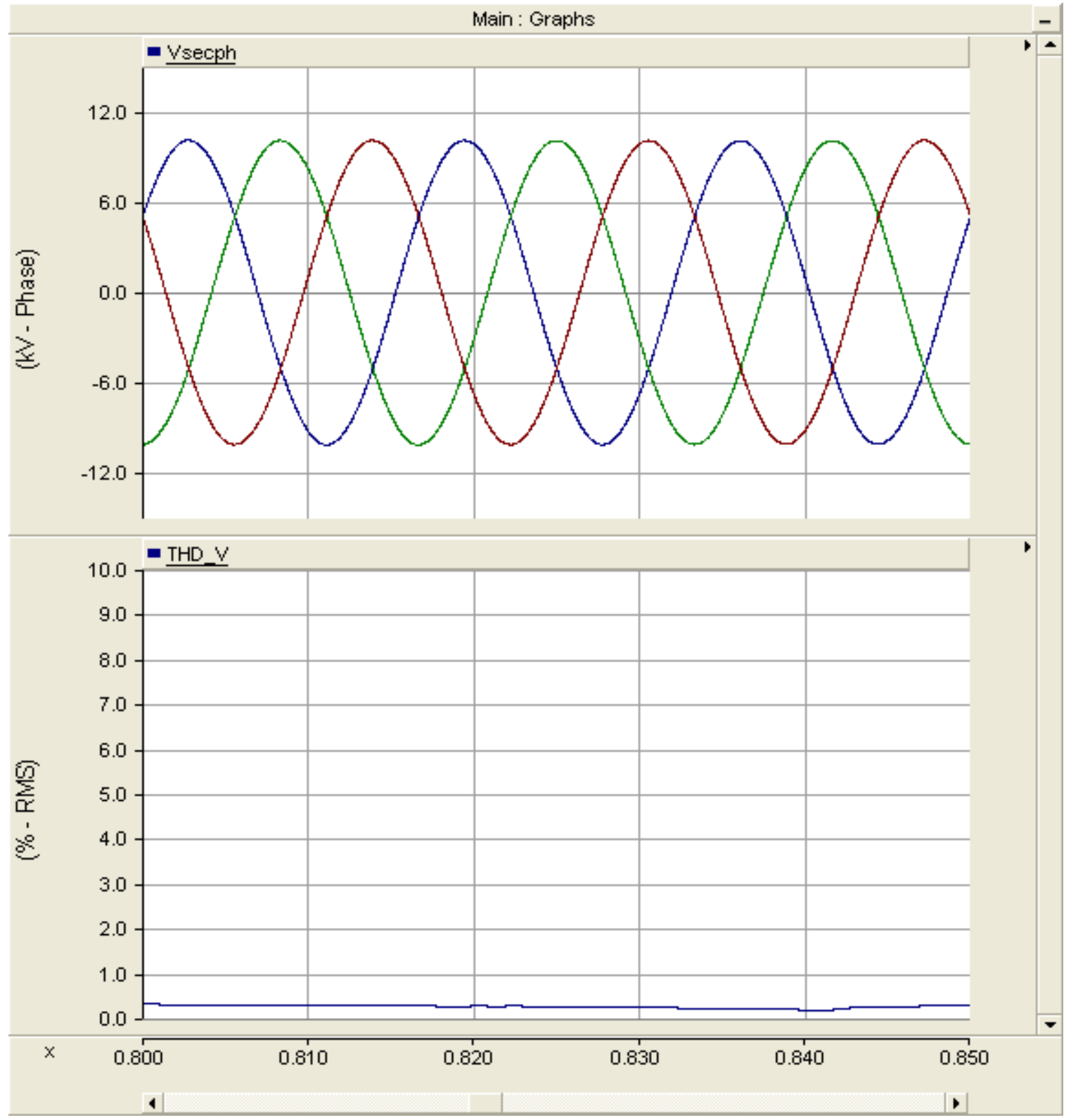

Figure 4.3: Injected Voltage at The PCC and Corresponding THD 


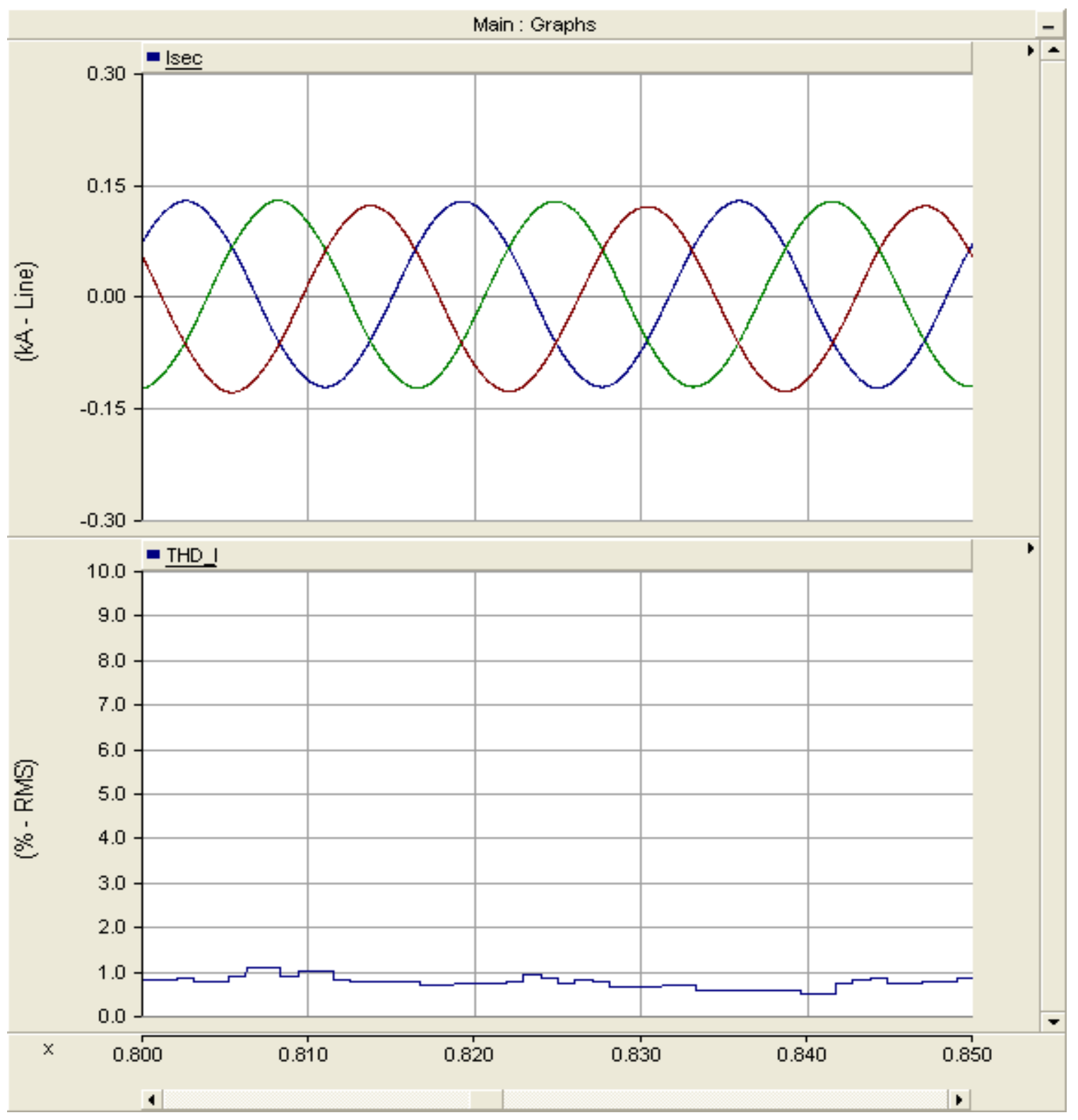

Figure 4.4: Injected Current at The PCC and Corresponding THD

Figure 4.5 and Figure 4.6 provide further analysis of the injected harmonic content and their locations, the measurements agree with theoretical predictions from equation (3-7) for the PWM scheme used. 


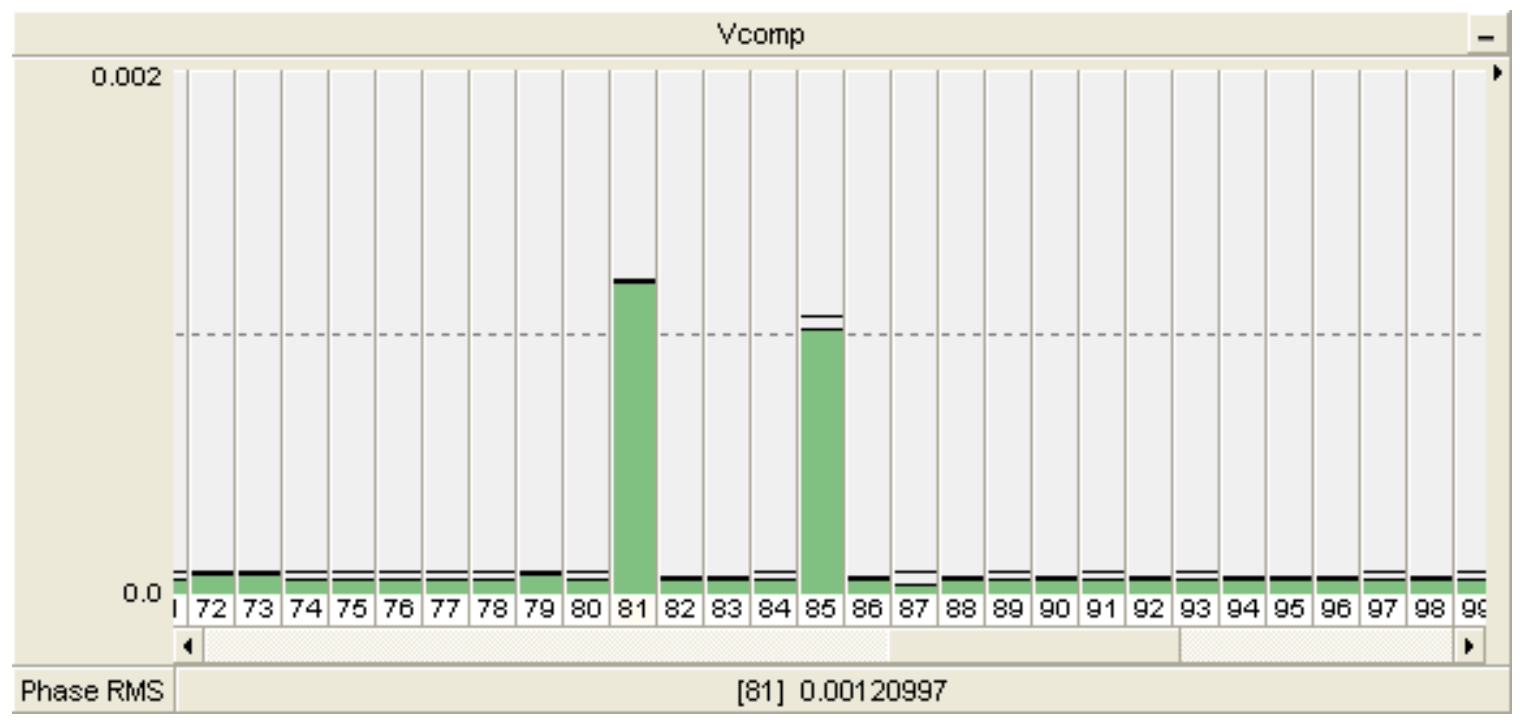

Figure 4.5: Voltage Harmonic Content and Location

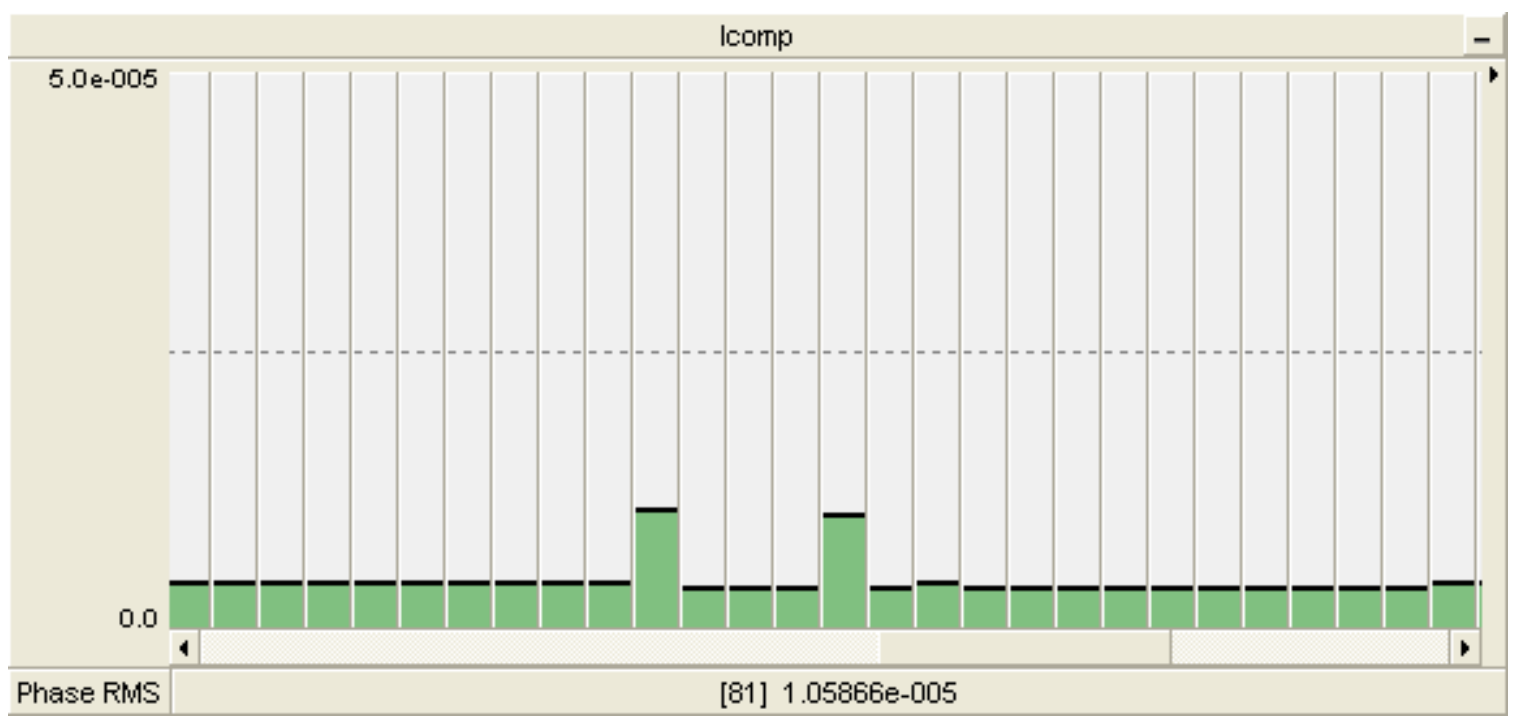

Figure 4.6: Current Harmonic Content and Location

Using the setup from Figure 3.35 data were collected to determine if the allowable injected current harmonic amplitudes and TDD from Table 3.3 and individual voltage harmonic magnitudes from Table 3.4 were exceeded. The measured harmonics expressed as a percent of the rated current and voltage are shown in Figure 4.7 and Figure 4.8 . 


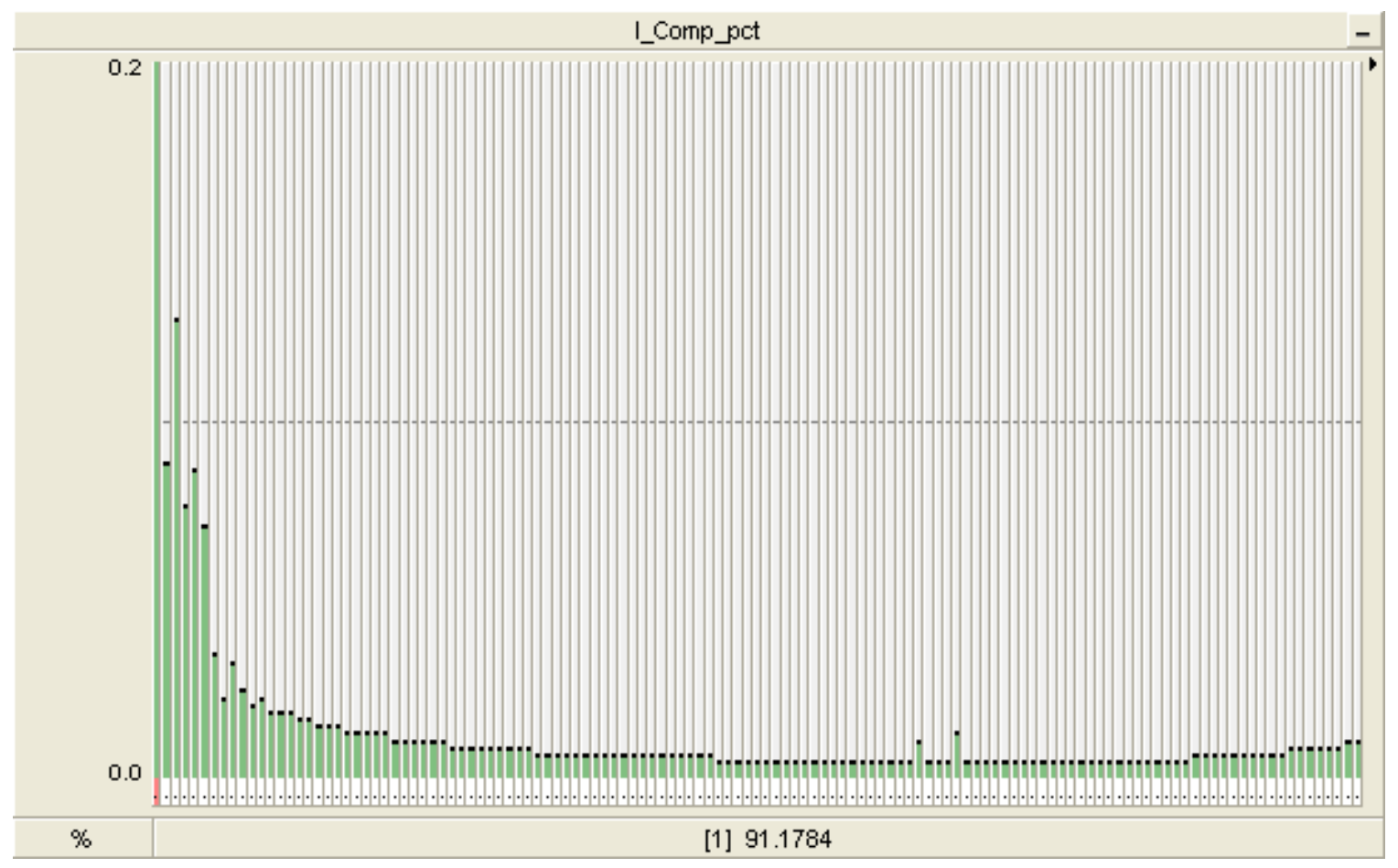

Figure 4.7: Current Harmonic Amplitudes Expressed as \% of Rated Current

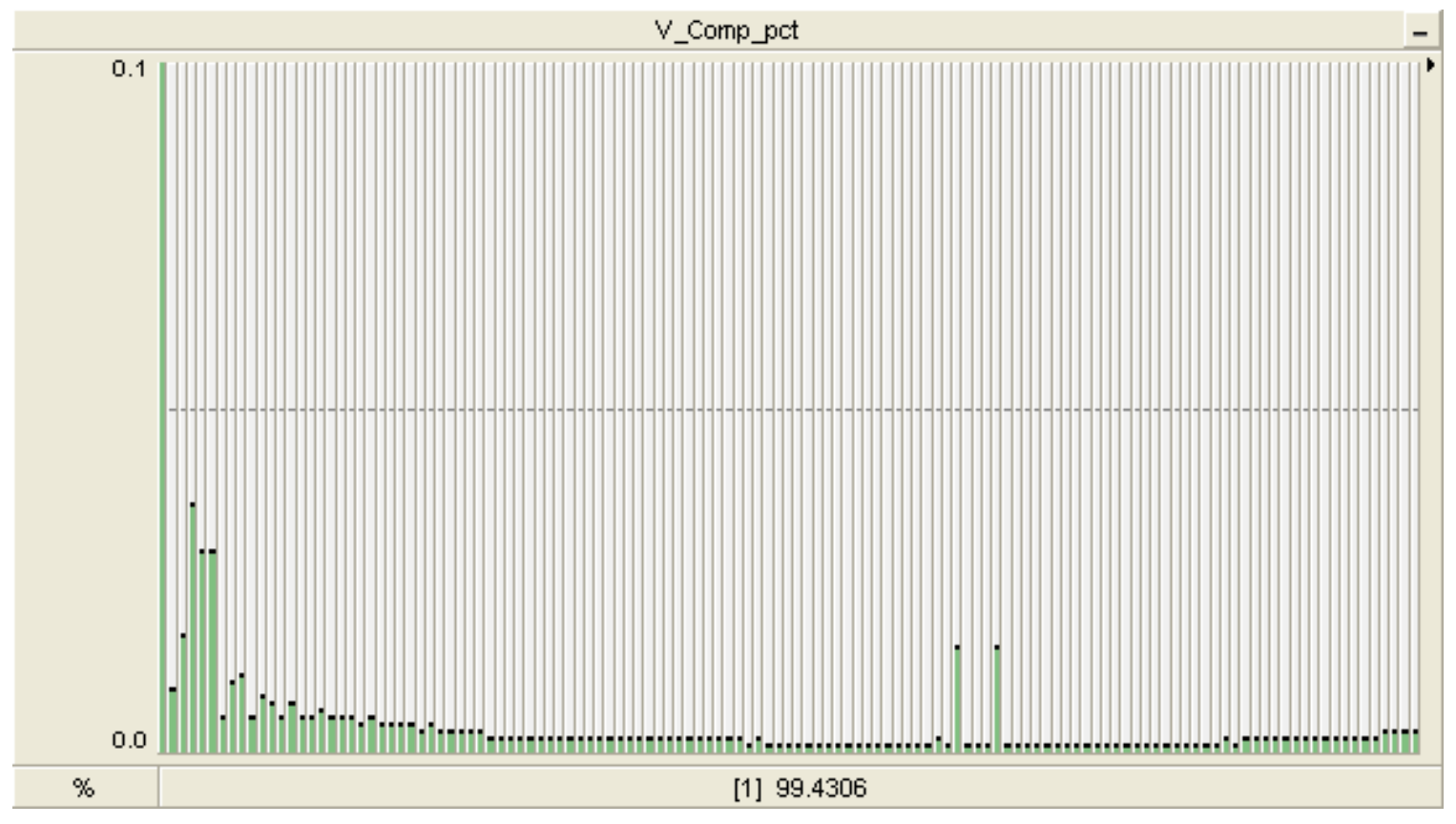

Figure 4.8: Voltage Harmonic Amplitudes Expressed as \% of Rated Voltage 
The scales used to display Figure 4.7 and Figure 4.8 can be hard to understand at first glance but the height of each of the harmonics is in a percent of the rated current (92.6 A) and rated voltage $(12.47 \mathrm{kV})$ respectively. On the plots, the fundamental component is selected and its value (\%) is shown which is far out of the selected viewable window scale. The fundamental voltage component is $99.3406 \%$ of the rated $12.47 \mathrm{kV}$ and this is sensible because the inverter is operating at unity power factor. The fundamental current component is only $91.1784 \%$ of the rated $92.6 \mathrm{~A}$ and this is rational since the power being delivered by the inverter is slightly less than the $2 \mathrm{MW}$ power rating. All of the voltage and current harmonic components from the figures expressed in actual RMS values and in percentages of the ratings can be seen in Appendix A. It should be noted that when analyzing the individual voltage harmonic magnitude limits of Table 3.4 the voltage limits are expressed in terms of the fundamental component not the voltage rating of $12.47 \mathrm{kV}$. However, from the results it can be seen that the fundamental component is extremely close to the rating of $12.47 \mathrm{kV}$ so the rating can be used as an approximation for the fundamental. Based on this assumption, Figure 4.7 and Figure 4.8 visibly show that the harmonic content is far from exceeding the IEEE 519-1992 limits based on the vertical axis scale. Table 4.2 and Table 4.3 have been created which show the voltage and current harmonics generated by the PV inverter and the maximum allowable limits.

Table 4.2: Comparison of Applicable Voltage Distortion Limits and Measured Harmonic Content *See Appendix A

\begin{tabular}{|c|c|cc|c|}
\hline PCC Voltage & $\begin{array}{c}\text { Individual } \\
\text { Harmonic } \\
\text { Magnitude } \\
\text { Limit (\%) }\end{array}$ & $\begin{array}{c}\text { THD } \\
\text { Limit } \\
(\%)\end{array}$ & $\begin{array}{c}\text { Individual } \\
\text { Harmonic } \\
\text { Magnitude } \\
\text { Measured (\%) }\end{array}$ & $\begin{array}{c}\text { THD } \\
\text { Measured } \\
(\%)\end{array}$ \\
\hline $\mathbf{V} \leq \mathbf{6 9} \mathbf{~ k V}$ & 3 & 5 & All $<3^{*}$ & 0.078 \\
\hline
\end{tabular}


Table 4.3: Comparison of Applicable of Current Distortion Limits and Measured Harmonic Content

*See Appendix A

\begin{tabular}{|c|c|c|c|c|c|c|}
\hline $\begin{array}{c}\text { Harmonic } \\
\text { Range }\end{array}$ & $\mathrm{n}<11$ & $11 \leq \mathrm{n}<17$ & $17 \leq \mathrm{n}<23$ & $23 \leq \mathrm{n}<35$ & $35 \leq \mathrm{n}$ & TDD \\
\hline $\begin{array}{c}\text { \% Rated } \\
\text { Current Limit }\end{array}$ & 4 & 2 & 1.5 & 0.6 & 0.3 & 5 \\
\hline $\begin{array}{c}\text { \% Rated } \\
\begin{array}{c}\text { Current } \\
\text { Measured }\end{array}\end{array}$ & All $<4^{*}$ & All $<2 *$ & All $<1.5^{*}$ & All $<0.6^{*}$ & All $<0.3^{*}$ & 0.21 \\
\hline
\end{tabular}

\subsection{Voltage Regulation}

The goal of the voltage regulation test of the smart inverter is to demonstrate how the inverter can regulate the voltage at the PCC by providing or consuming reactive power. In order to create voltage levels at the PCC above and below acceptable levels to test the inverter static loads capable of operating with various leading and lagging VAR levels were added at the end of the feeder near the PV connection. This was chosen to simulate the effects of over generation as well as sagging conditions which could arise for numerous reasons. In the PSCAD model creating over generation and its voltage effects on the feeder could not be simulated because when more power was delivered by the PV inverter the source modeling the substation in the test circuit either decreased its output power or complete power flow reversal occurred and it consumed the extra power.

To generate a sagging voltage condition the static loads were set to consume reactive power (reactive), and to generate a swelling voltage the static loads were set to provide reactive power (capacitive). In order to switch the static load reactive power at a specified time the variable load module discussed previously was used. To test the inverters voltage regulating capability Table 4.4 summarizes the sequence of two 
switched reactive loads that were applied over a run. The location of the loads being varied can be seen in the picture of the test circuit in Figure 3.31.

Table 4.4: Voltage Regulation Test Conditions

\begin{tabular}{|c|c|}
\hline Time $(\mathrm{s})$ & $\begin{array}{c}\text { Net Reactive Power (MVAR/phase/load) } \\
(+=\text { Reactive) }\end{array}$ \\
\hline $\mathbf{t}<\mathbf{2}$ & 0 \\
\hline $\mathbf{2}<\mathbf{t}<\mathbf{4}$ & 0.6 \\
\hline $\mathbf{4}<\mathbf{t}<\mathbf{6}$ & 0 \\
\hline $\mathbf{6}<\mathbf{t}<\mathbf{8}$ & -0.4 \\
\hline $\mathbf{8}<\mathbf{t}<\mathbf{1 0}$ & 0 \\
\hline $\mathbf{1 0}<\mathbf{t}<\mathbf{1 2}$ & 0.6 \\
\hline $\mathbf{1 2}<\mathbf{t}<\mathbf{1 4}$ & 0 \\
\hline
\end{tabular}

The conditions of Table 4.4 were applied to the inverter operating with and without its smart capabilities so a comparison could be made. The corresponding voltages at the PCC when the inverter is operating in its respective modes can be seen in Figure 4.9 and Figure 4.10. Additionally, the corresponding real and reactive power output, power angle, and modulation index plots for each case are shown in Figure 4.11 and Figure 4.12 . 


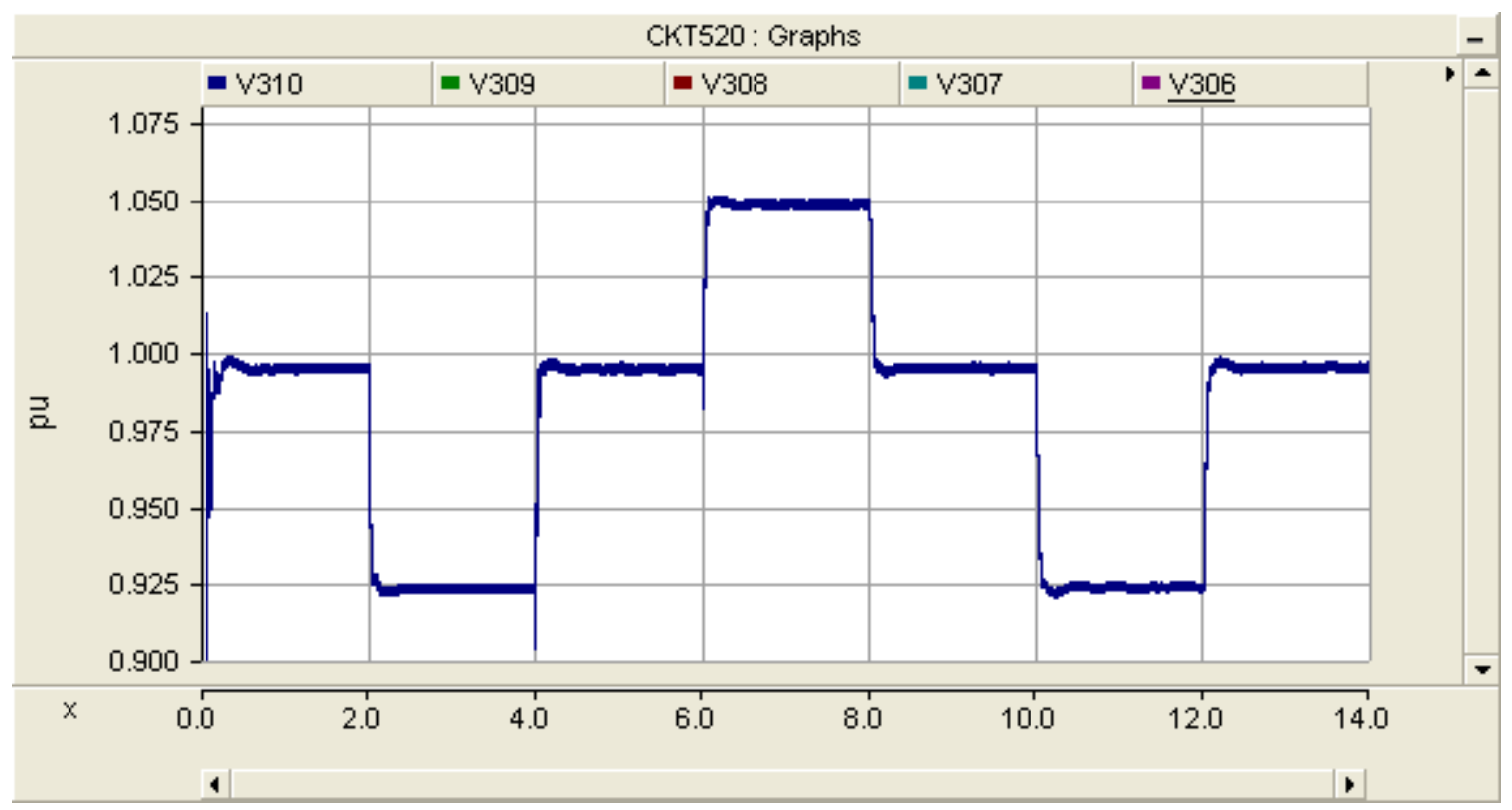

Figure 4.9: PCC Bus Voltage With Inverter Operating at Unity Power Factor

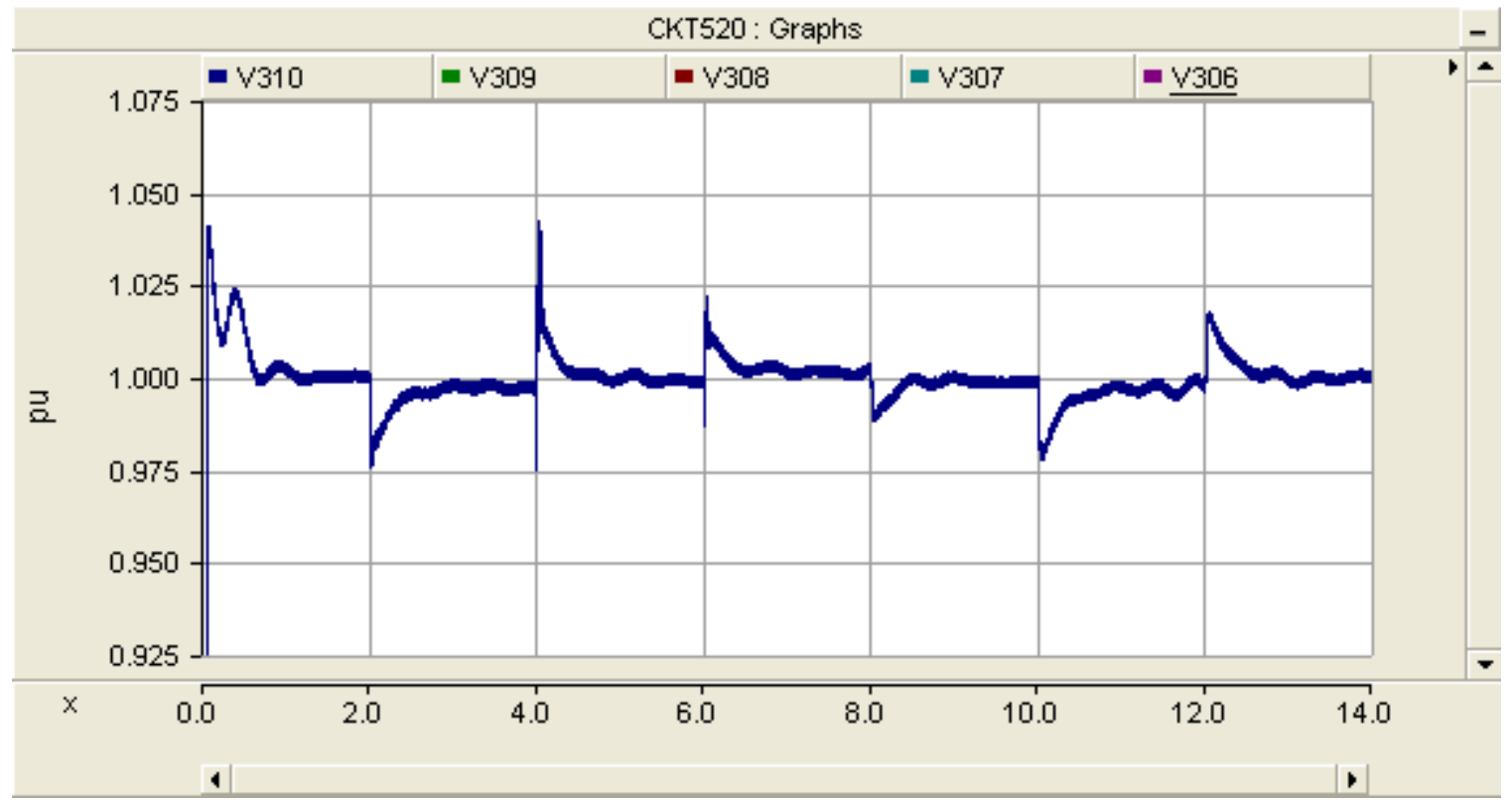

Figure 4.10: PCC Bus Voltage With Voltage Regulating Capability Enabled 


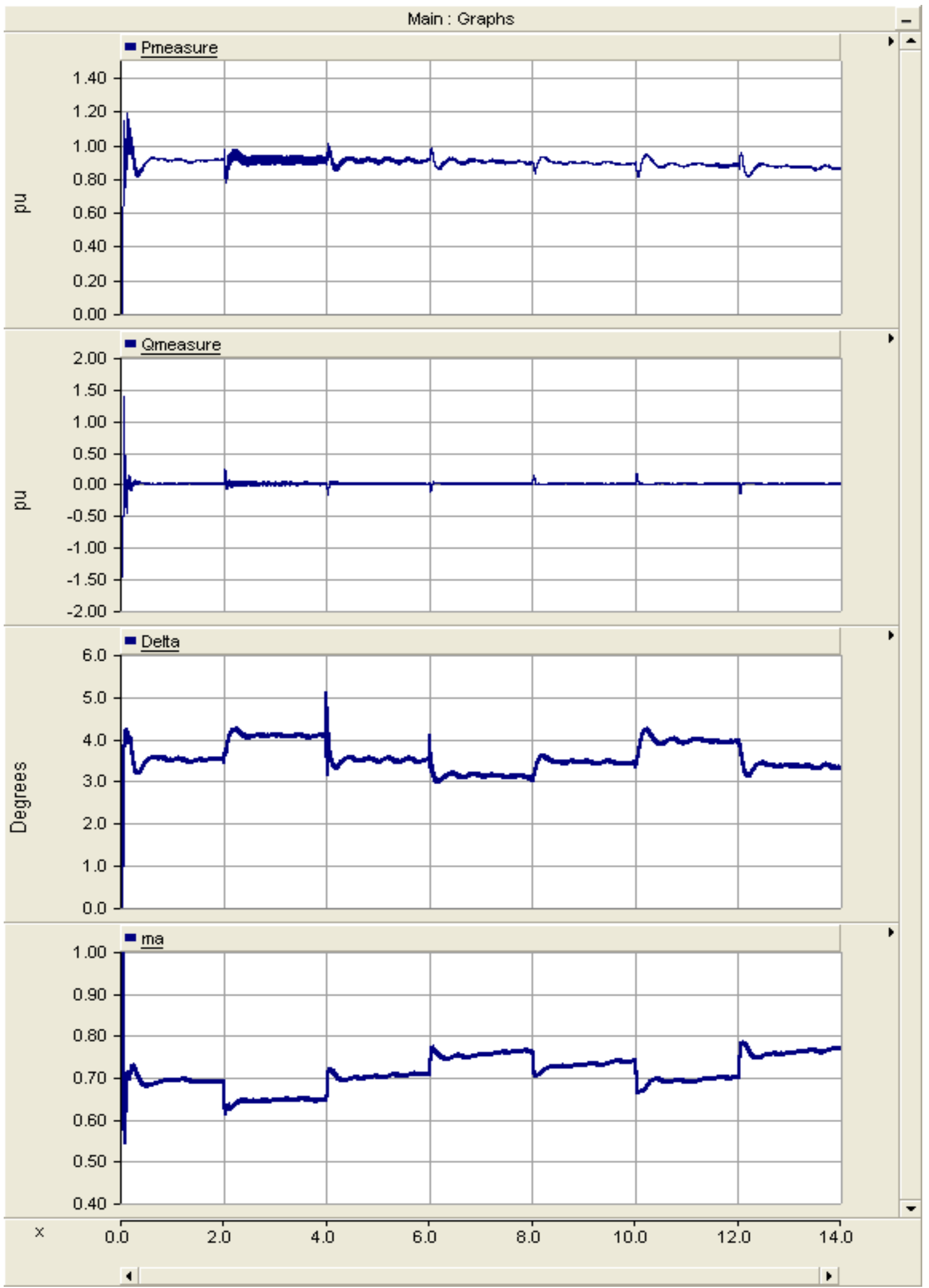

Figure 4.11: Inverter Real and Reactive Output Power, Power Angle, and Modulation Index Operating at Unity Power Factor 


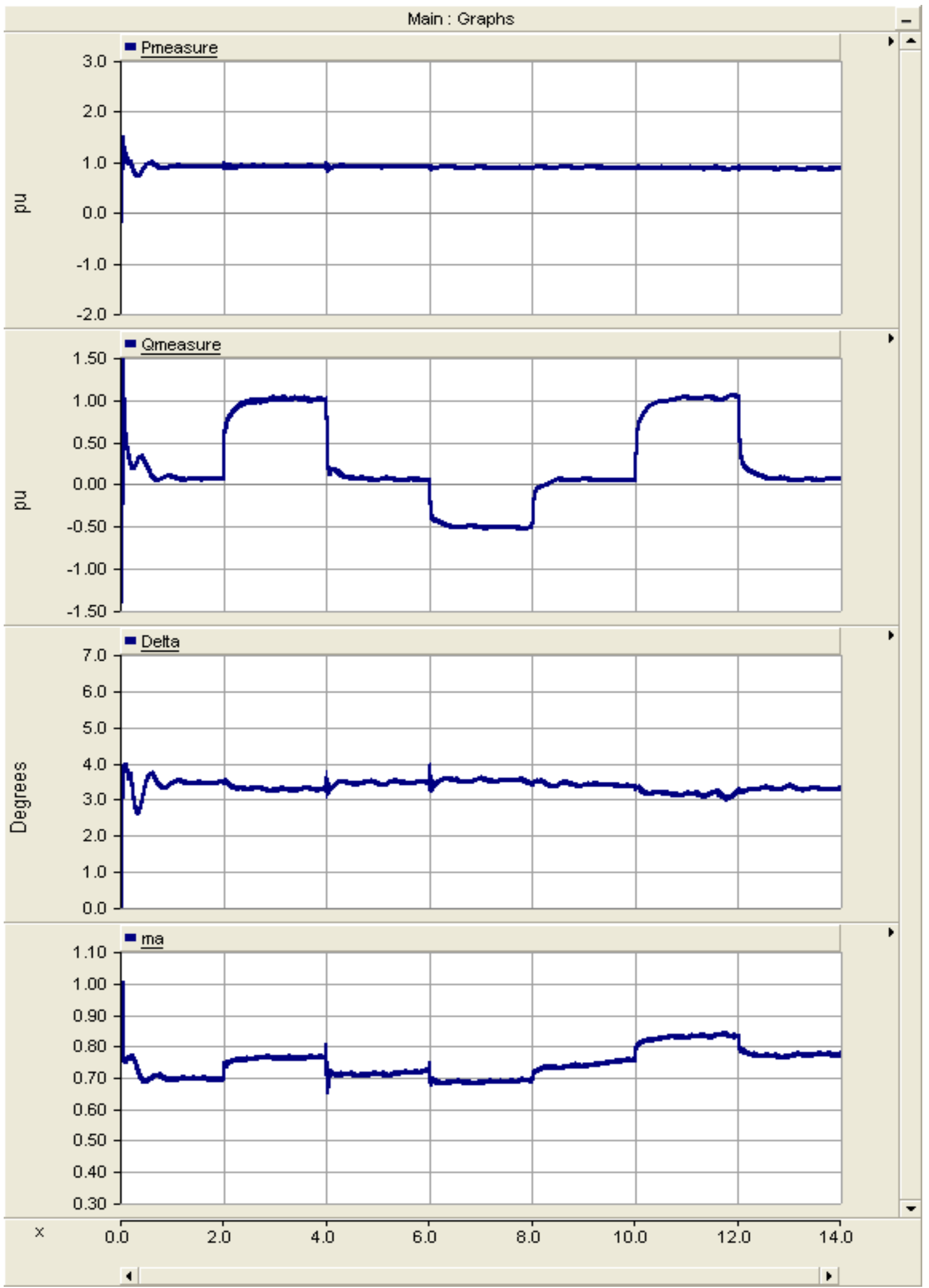

Figure 4.12: Inverter Real and Reactive Output Power, Power Angle, and Modulation Index Operating with Voltage Regulating Capability Enabled 
The difference in voltage at the end of the feeder is quite drastic between modes of operation. With the inverter set to operate at unity power factor the voltage swings up and down outside of tolerable limits and the reactive power remains at zero. With the voltage regulating mode enabled, the required reactive power is supplied or consumed by the inverter in order to keep the voltage at 1 per unit. Although the test scenario is extreme, it serves to prove the inverters ability to hold the voltage at its nominal value.

\subsection{Frequency Response}

Testing the inverters ability to maintain a stable grid frequency by adjusting its real output power was accomplished similarly to how the voltage regulation mode was tested. Two variable load modules were used again except active power static loads were switched instead of reactive ones.

By bringing the inverter to a steady state operating point and then suddenly switching on or off a large MW load a droop or rise in the system frequency is observed. Normally, the source in the test circuit modeling the substation adjusts its generation in order to match the new demand. However, this can take time, and the inverter can react quickly enough to help supplement the other sources load balancing act by increasing or decreasing its generation to match the demand and maintain the frequency. Table 4.5 summaries the sequence of switched active power loads that were applied over the two runs.

Table 4.5: Frequency Response Test Conditions * $(+=$ Switched on $)$

\begin{tabular}{|c|c|c|}
\multicolumn{1}{c|}{ Run \# } & \multicolumn{1}{c}{ Time (s) } & $\begin{array}{c}\text { Net Active Load Power } \\
\text { (MW/Phase/Load)* }\end{array}$ \\
\cline { 2 - 3 } \multirow{2}{*}{1} & $\mathrm{t}<0.05$ & 0 \\
\hline \multirow{2}{*}{2} & $\mathrm{t} \geq 0.05$ & -0.5 \\
\cline { 2 - 3 } & $\mathrm{t}<0.05$ & 0 \\
\hline
\end{tabular}


Several figures were captured to help explain the results of this simulation. For Run \#1 the simulation was brought to steady state with the net $3 \mathrm{MW}$ load connected to the system, and then at the time indicated in the table it was disconnected via a three phase circuit breaker. The resulting system frequency and control signals can be seen in Figure 4.13. The subsequent active and reactive power, power angle, and modulation index are shown in Figure 4.14.

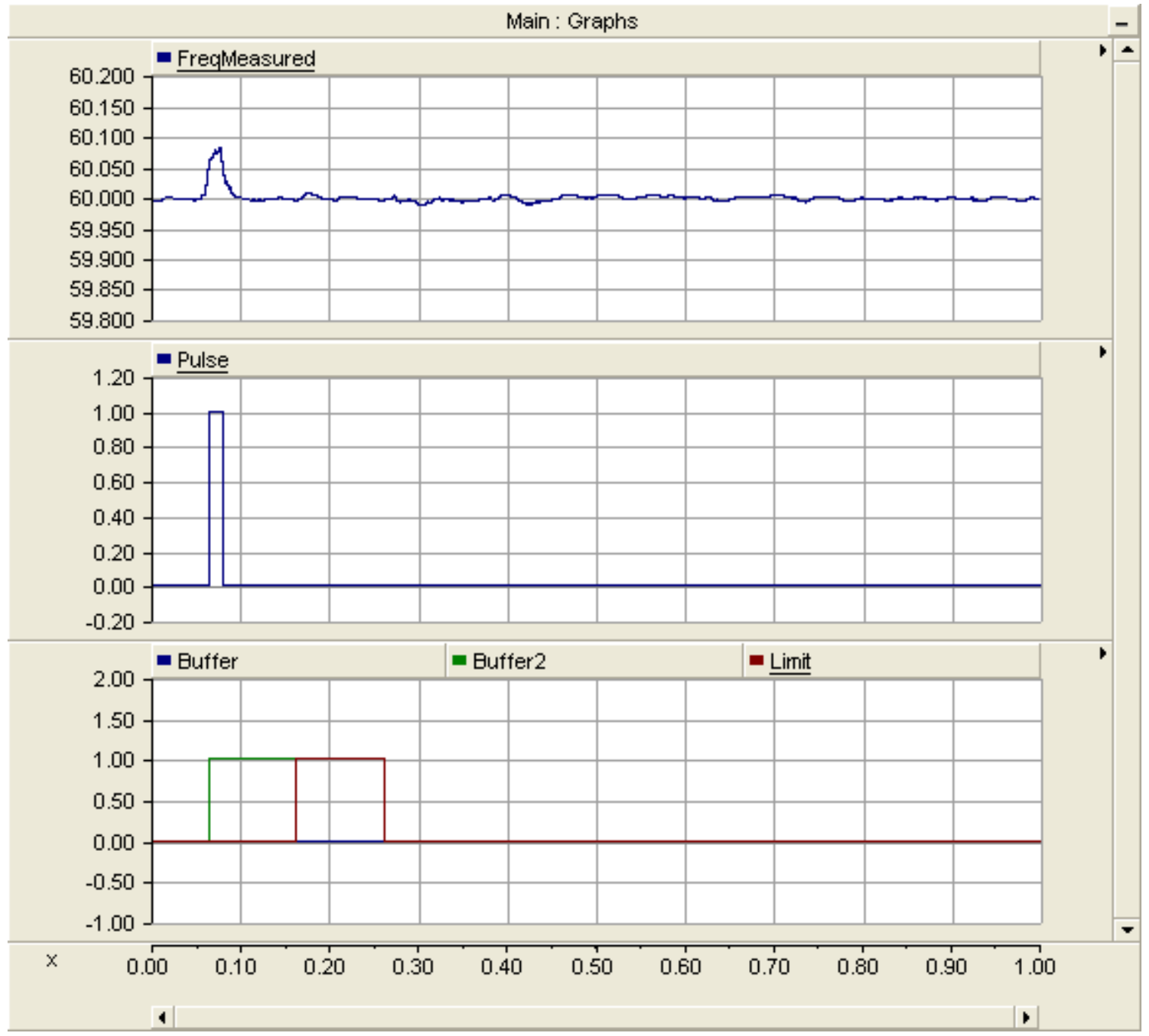

Figure 4.13: System Frequency for Run \#1 


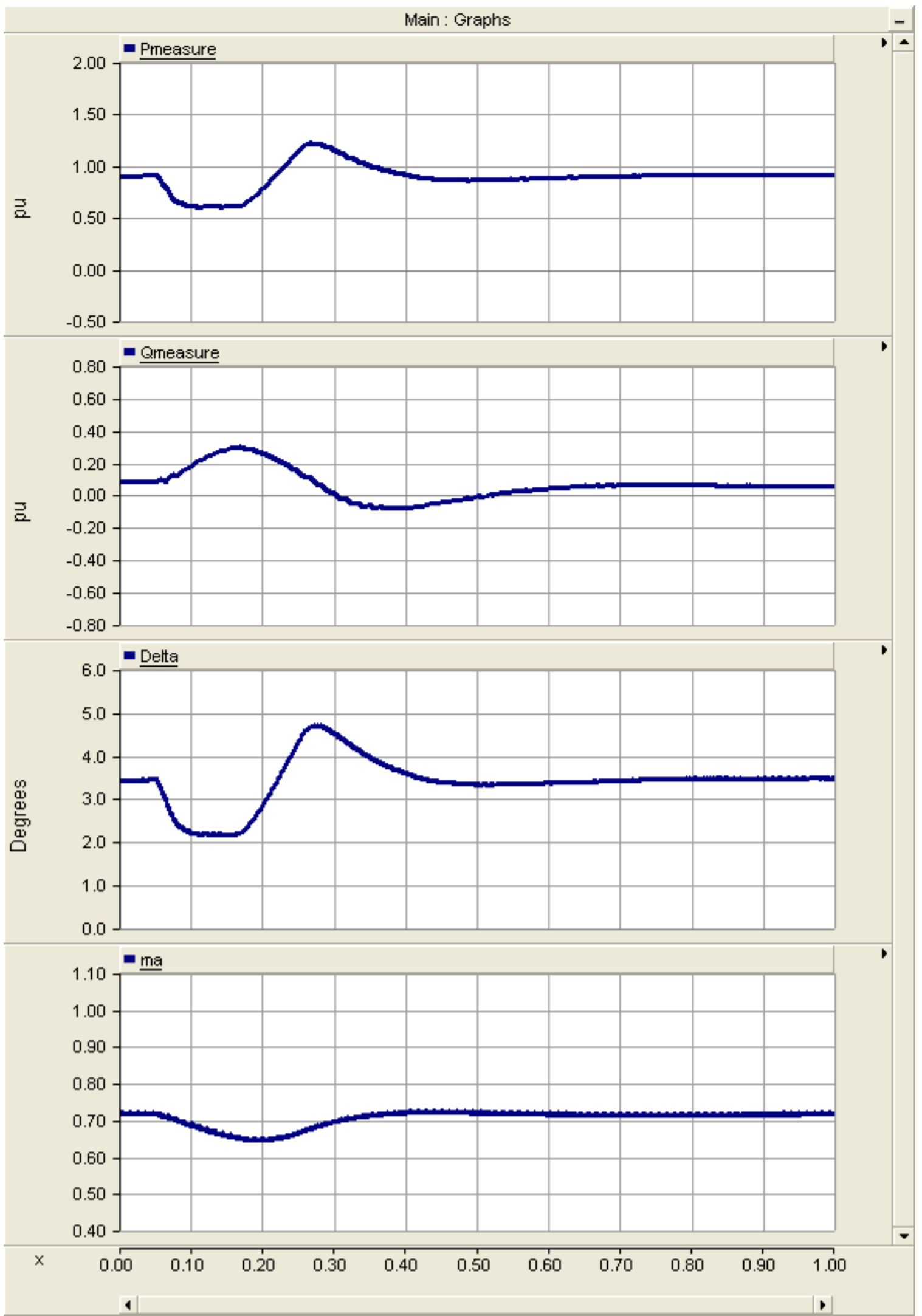

Figure 4.14: Active and Reactive Powers, Power Angle, and Modulation Index for Run \#1 


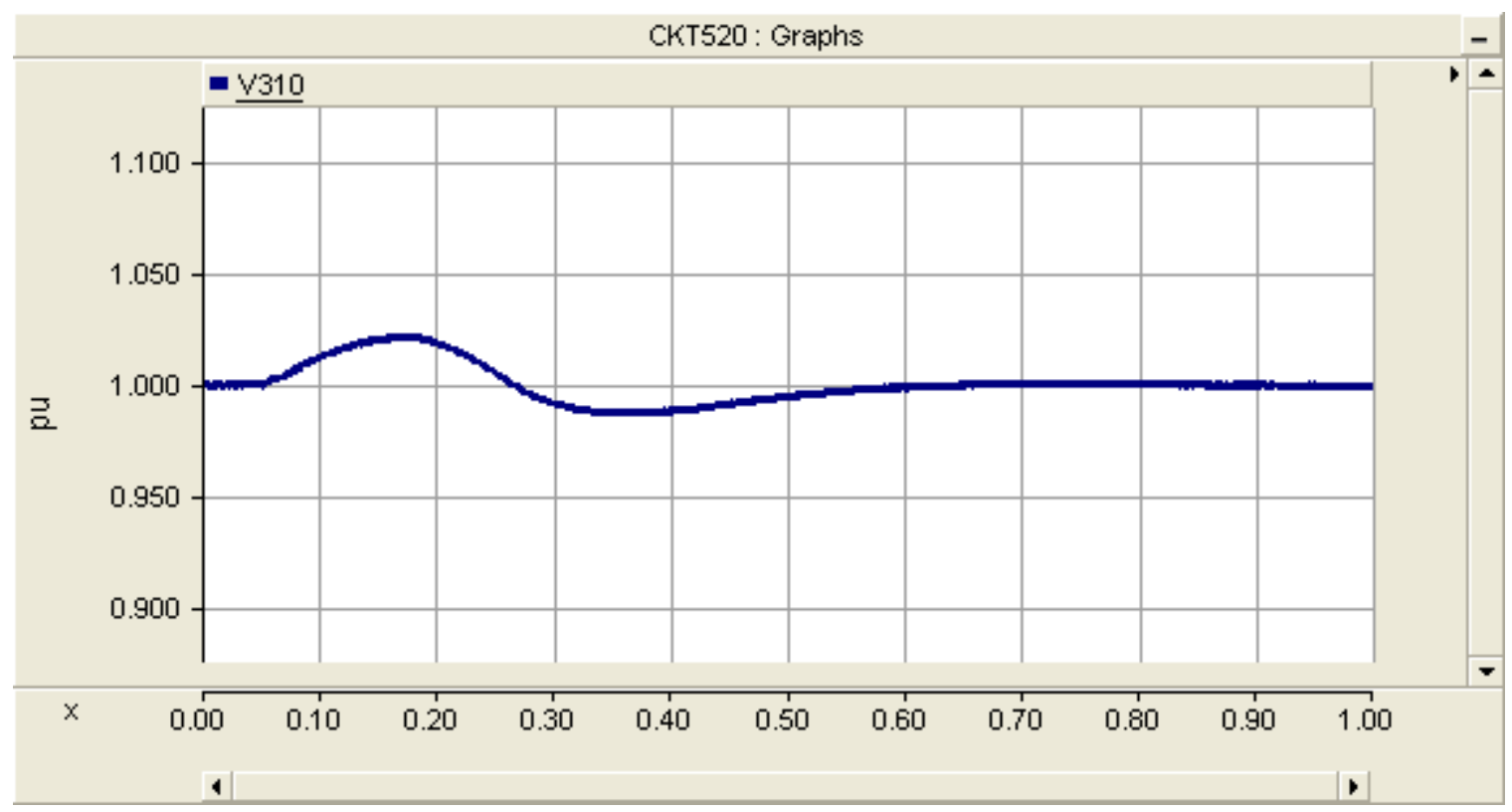

Figure 4.15: PCC Voltage for Run \#1

Once the frequency was sensed above the upper limit the inverters frequency mode control was activated. Shown in Figure 4.14 the inverters output power decreased promptly until the nominal system frequency of $60 \mathrm{~Hz}$ was maintained. Once the frequency was steady for the off delay the frequency mode control was disabled and the inverters output power ramped back to full power with some overshoot. The slope of the power vs. time curve is important to note in Figure 4.14 because if it is too steep the frequency of the system will not be maintained at $60 \mathrm{~Hz}$. The rate limiting block used in the control scheme ensures the time rate of change of the output power is not to large. Since only an active power load is being switched during the run the change in system voltage and the inverters output reactive power is small but the controller responds quickly to restore the voltage to its nominal value.

Run \#1 assumed the inverter was operating at full power when the load was disconnected and it rapidly decreased its output power to compensate. If a load was brought on, not switched off, during the Run \#1 the inverter would not have had any extra 
power it could inject. However, if the inverter was operating with some reserve, meaning not at full capacity, then if a load was brought on it could tap into the reserve to provide power for frequency compensation. This may not seem economical (for the PV array to not be operating the MPP) but the power system stability receives value from operating with a reserve. In Run $\# 2$ the simulation is brought to steady state with the inverter providing $0.5 \mathrm{pu}$ real power with the static loads not connected at the end of the test circuit. At the time indicated in Table 4.5 the three phase breaker is closed and the load is suddenly connected. The system frequency was recorded for this run and can be seen in Figure 4.16 along with the appropriate control signals. Just as in the other run the active and reactive powers, power angle, and modulation index are plotted in Figure 4.17. 


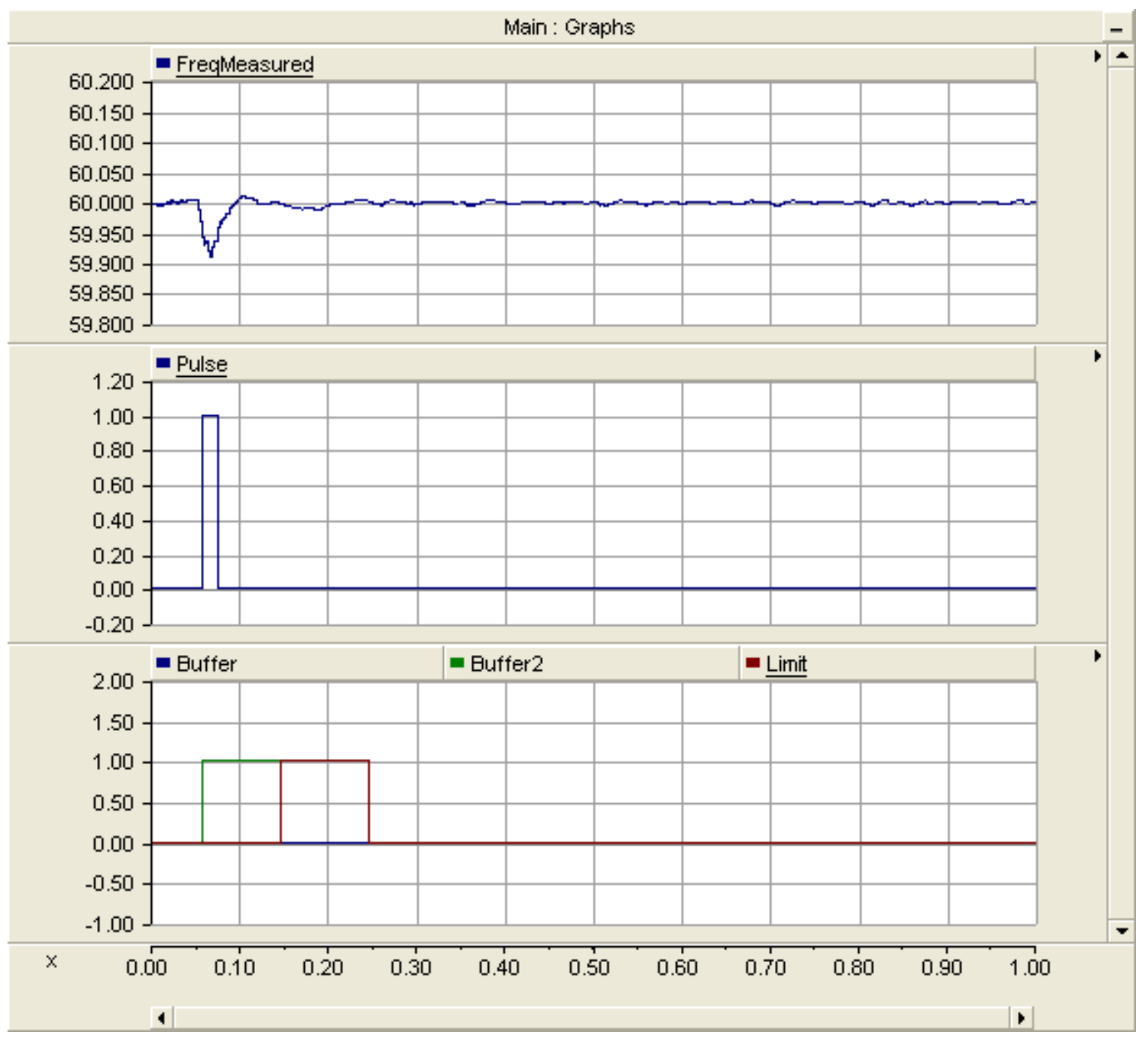

Figure 4.16: System Frequency for Frequency Response Run \#2 


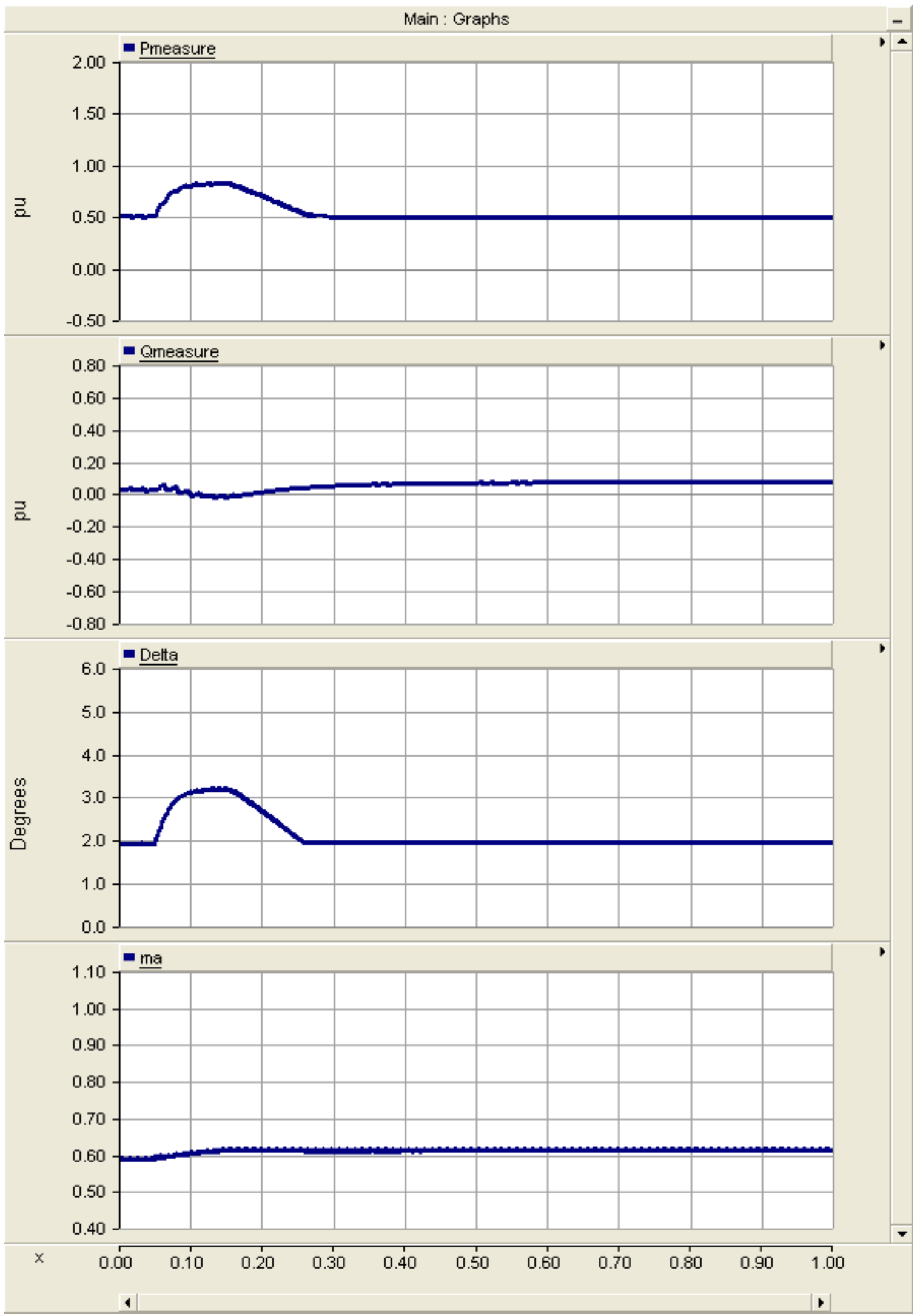

Figure 4.17: Active and Reactive Powers, Power Angle, and Modulation Index for Run \#2 


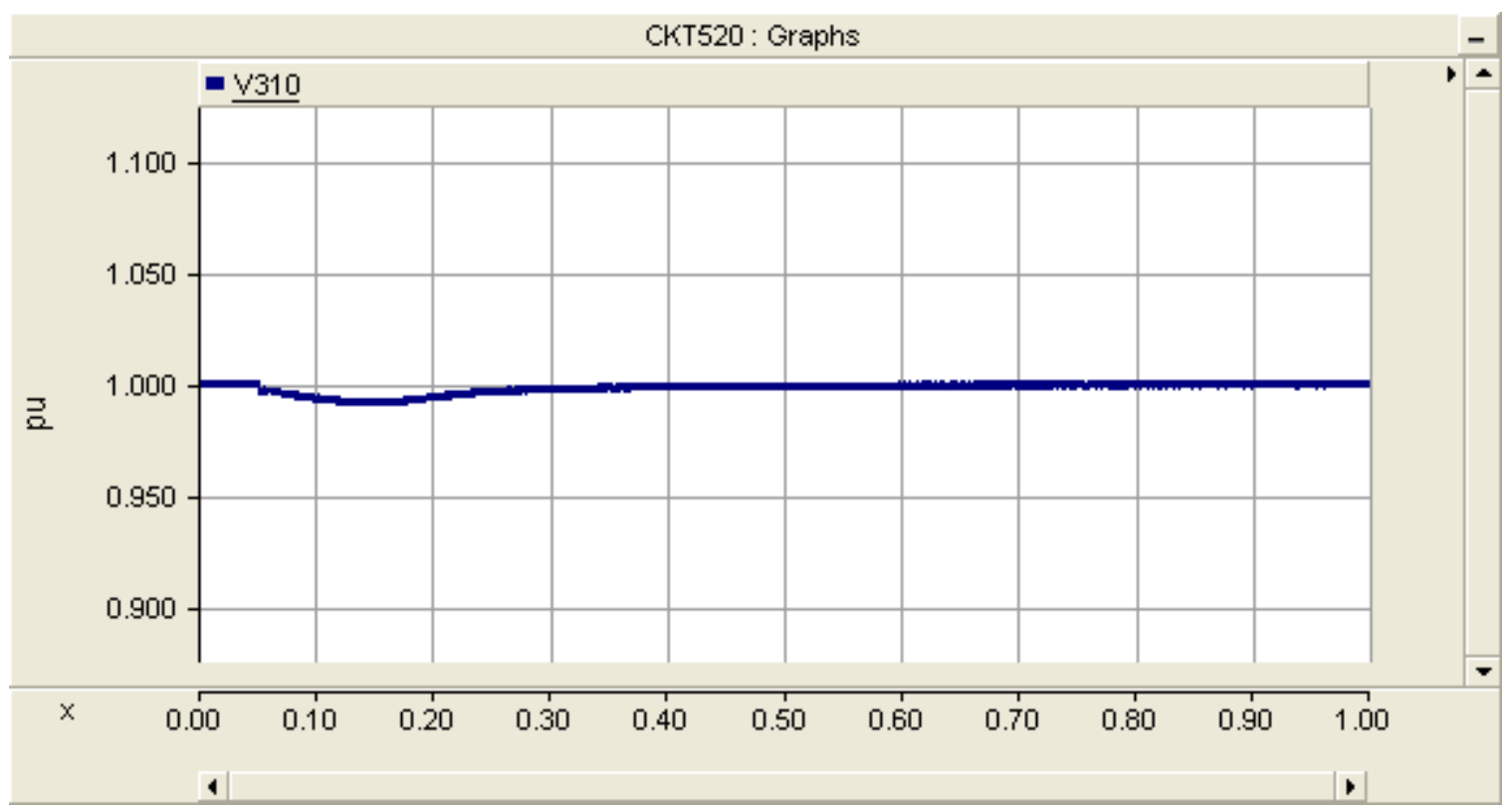

Figure 4.18: PCC Voltage for Frequency Response Run \#2

For Run \#2 as the MW load is switched on the frequency drops and the control scheme acts as designed and described previously to increase the inverters real output power. When the frequency mode is switched off the output power rate of change is limited to make sure the system frequency remains stable. The limit is seen by the constant sloping real power curve, the PI controller is trying to change it faster than the maximum allowable rate of change. Since the inverter was operating with some reserve during the run the change in system voltage and the inverters output reactive power is minimal.

\subsection{Remote Curtailment and Ramping}

The last operating mode covers the event in which the inverters injected real and reactive power levels are desired to be set at fixed levels by an operator. In the PSCAD model adjusting the appropriate switches for P and Q control and setting the sliders to the desired levels in per unit accomplish this. To test this control, the desired levels of real and reactive power were varied over time shown in Table 4.6. 
Table 4.6: Remote Curtailment/Ramping Test Conditions

\begin{tabular}{|c|c|c|}
\hline Time (s) & Real Power (pu) & Reactive Power (pu) \\
$\mathbf{t}<\mathbf{1 . 5}$ & 0.4 & 0 \\
\hline $\mathbf{1 . 5}<\mathbf{t}<\mathbf{2 . 5}$ & 0.4 & +0.5 \\
\hline $\mathbf{2 . 5}<\mathbf{t}<\mathbf{3 . 5}$ & 0.6 & +0.5 \\
\hline $\mathbf{3 . 5}<\mathbf{t}<\mathbf{4 . 5}$ & 0.6 & +0.75 \\
\hline $\mathbf{4 . 5}<\mathbf{t}<\mathbf{5 . 5}$ & 0.8 & +0.75 \\
\hline $\mathbf{5 . 5}<\mathbf{t}<\mathbf{6 . 5}$ & 0.8 & +0.5 \\
\hline $\mathbf{6 . 5}<\mathbf{t}<\mathbf{7 . 5}$ & 0.4 & +0.5 \\
\hline $\mathbf{7 . 5}<\mathbf{t}<\mathbf{8 . 5}$ & 0.4 & 0 \\
\hline $\mathbf{8 . 5}<\mathbf{t}<\mathbf{9 . 5}$ & 0.6 & -0.5 \\
\hline $\mathbf{9 . 5}<\mathbf{t}<\mathbf{1 0 . 5}$ & 0.6 & -0.5 \\
\hline $\mathbf{1 0 . 5}<\mathbf{t}<\mathbf{1 1 . 5}$ & 0.8 & -0.75 \\
\hline $\mathbf{1 1 . 5}<\mathbf{t}<\mathbf{1 2 . 5}$ & 0.8 & -0.75 \\
\hline $\mathbf{1 2 . 5}<\mathbf{t}<\mathbf{1 3 . 5}$ & 0.6 & -0.5 \\
\hline $\mathbf{1 3 . 5}<\mathbf{t}<\mathbf{1 4 . 5}$ & 0.6 & -0.5 \\
\hline $\mathbf{1 4 . 5}<\mathbf{t}<\mathbf{1 5 . 5}$ & 0.4 & 0 \\
\hline $\mathbf{t}>\mathbf{1 5 . 5}$ & 0.4 & \\
\hline
\end{tabular}

Figure 4.19 demonstrates the ability of the inverter to provide output capable of tracking the desired inputs for $\mathrm{P}$ and $\mathrm{Q}$. The green curves show the reference value the operator has selected and the blue curves are the measured output. The response of the controller is relatively fast with minimal overshoot. Some spikes occur when the reference reactive power is changed but they are quickly stabilized. The plotted delta and $m a$ in this figure epitomize the created control philosophy of the inverter in this thesis. That is, delta predominantly controls the real power and $m a$ predominantly controls the reactive power. As the real and reactive power references are adjusted this is depicted. However, the real and reactive power equations (3-20) and (3-21) are coupled, meaning an increase in delta is not a pure change in real power but also results in a slight change in the reactive power as well. The same is true for a change in $m a$ and how it slightly affects the real power and not purely just the reactive power. The coupled nature of the power equations is seen in Figure 4.19 when during a transition where only the $\mathrm{Q}$ 
reference is increased and $\mathrm{P}$ is held constant. The modulation index adjusts accordingly to realize the new desired reactive power, but the power angle changes slightly as well.

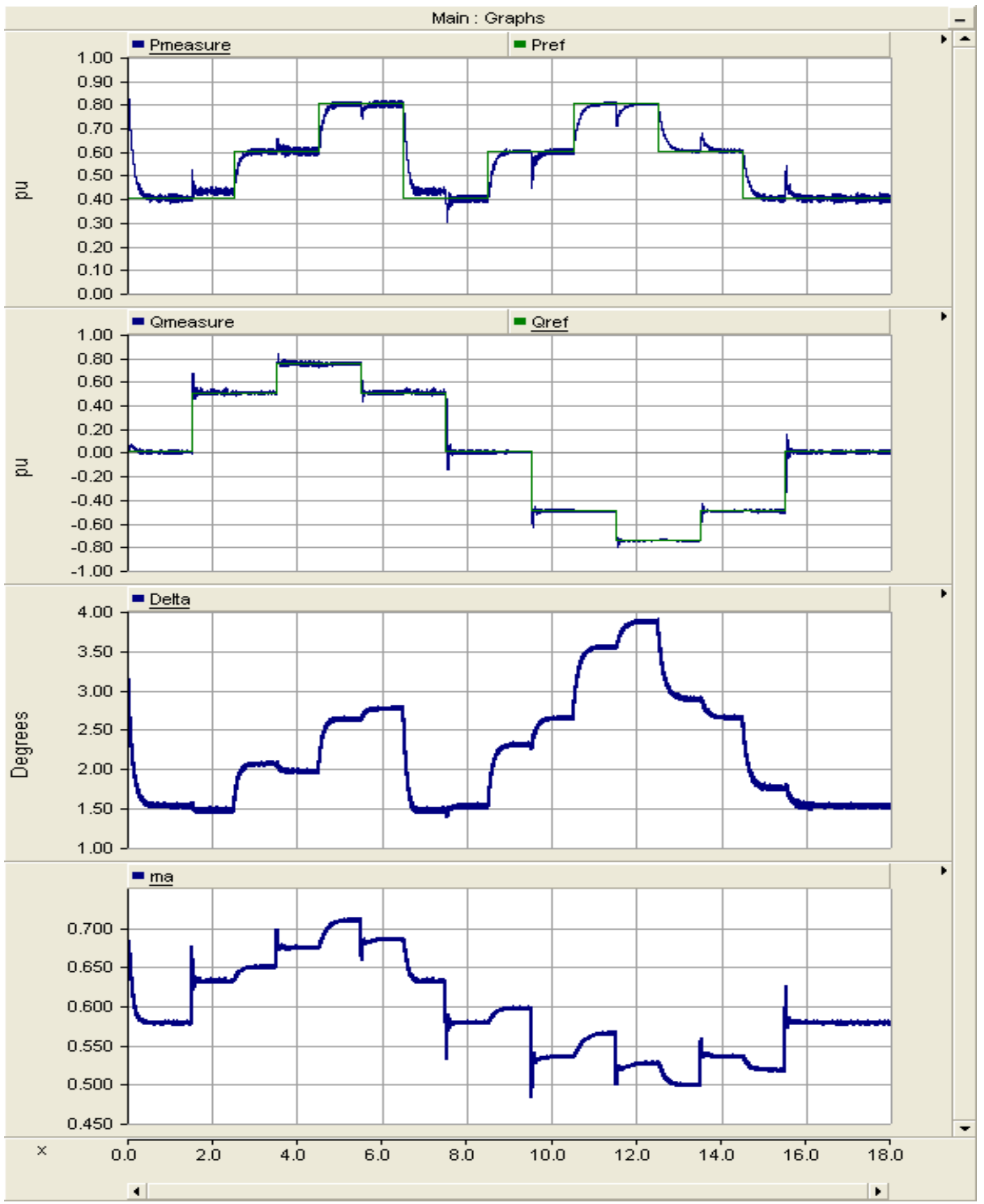

Figure 4.19: Inverter Real and Reactive Output Power, Power Angle, and Modulation Index Operating Based on Reference Values 
The PCC voltage is presented in Figure 4.20. The resulting increasing and decreasing voltage is similar to that of the voltage regulating test case. As the reactive power output of the inverter is adjusted the corresponding voltage is produced at the connection. The effect of reactive powers ability to change the voltage if it is supplied in large enough quantities is further proven by the figure.

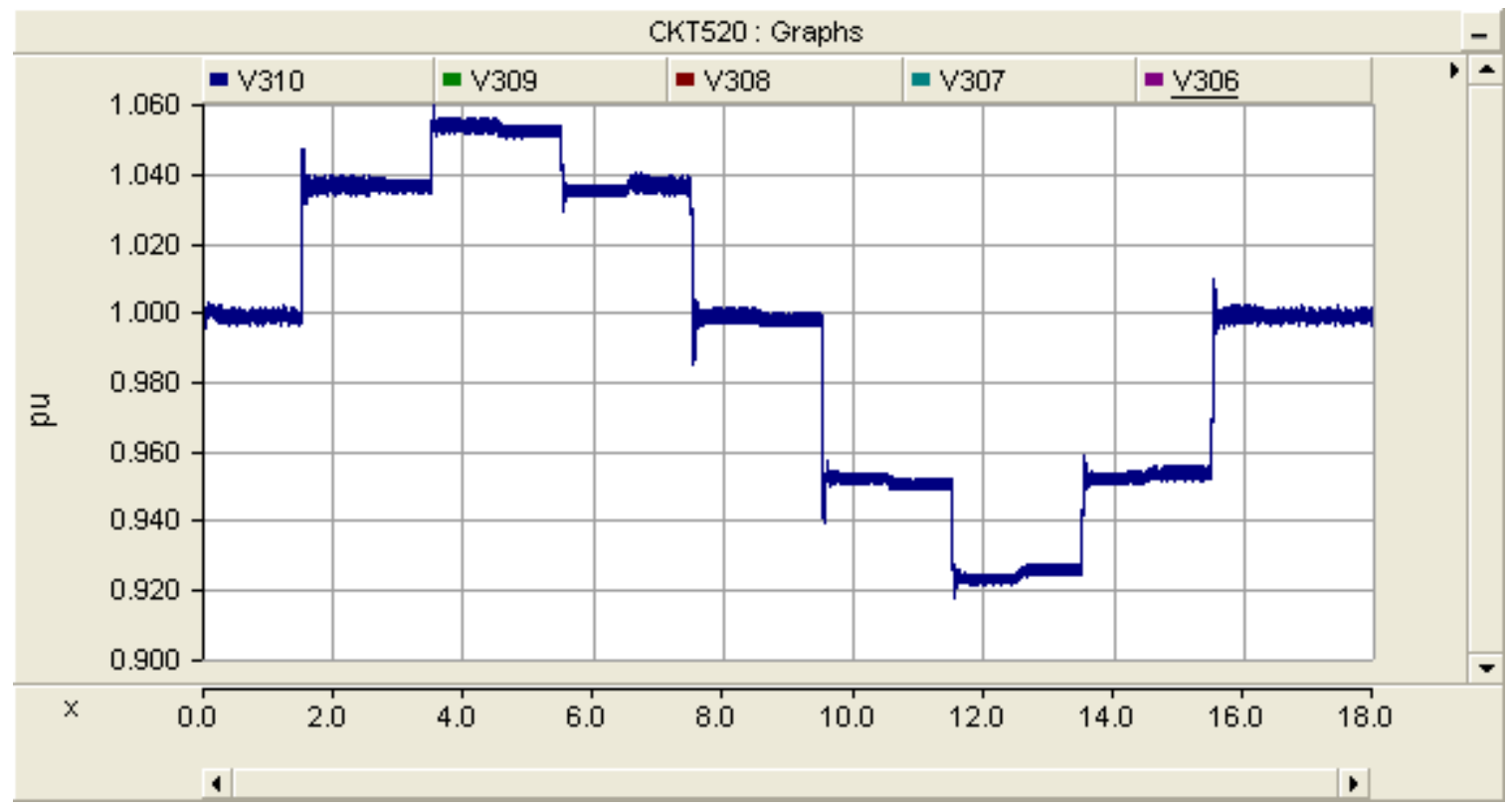

Figure 4.20: PCC Voltage with Inverter Operating in Remote Curtailment/Ramping Mode The last result presented from the remote curtailment/ramping test case is the PV voltage, current, and power outputs from Figure 4.21. Analyzing the figure, the PV arrays terminal voltage and hence power is adjusted by the inverters desired output power level because it sets the DC bus voltage. The drawback of this, sending the requested $\mathrm{P}$ and $\mathrm{Q}$ of an operator, is that the solar panel is forced to leave its maximum power point operating voltage. Further analyzing the figure, it is only the real power output by the inverter that changes the voltage of the PV array. Some voltage spikes occur when the reactive power is adjusted but they quickly diminish. Characterized by the figure, when 
the power demanded is maximum the PV voltage is lowest, which is when it is closer to its maximum power point of approximately $4.5 \mathrm{kV}$.

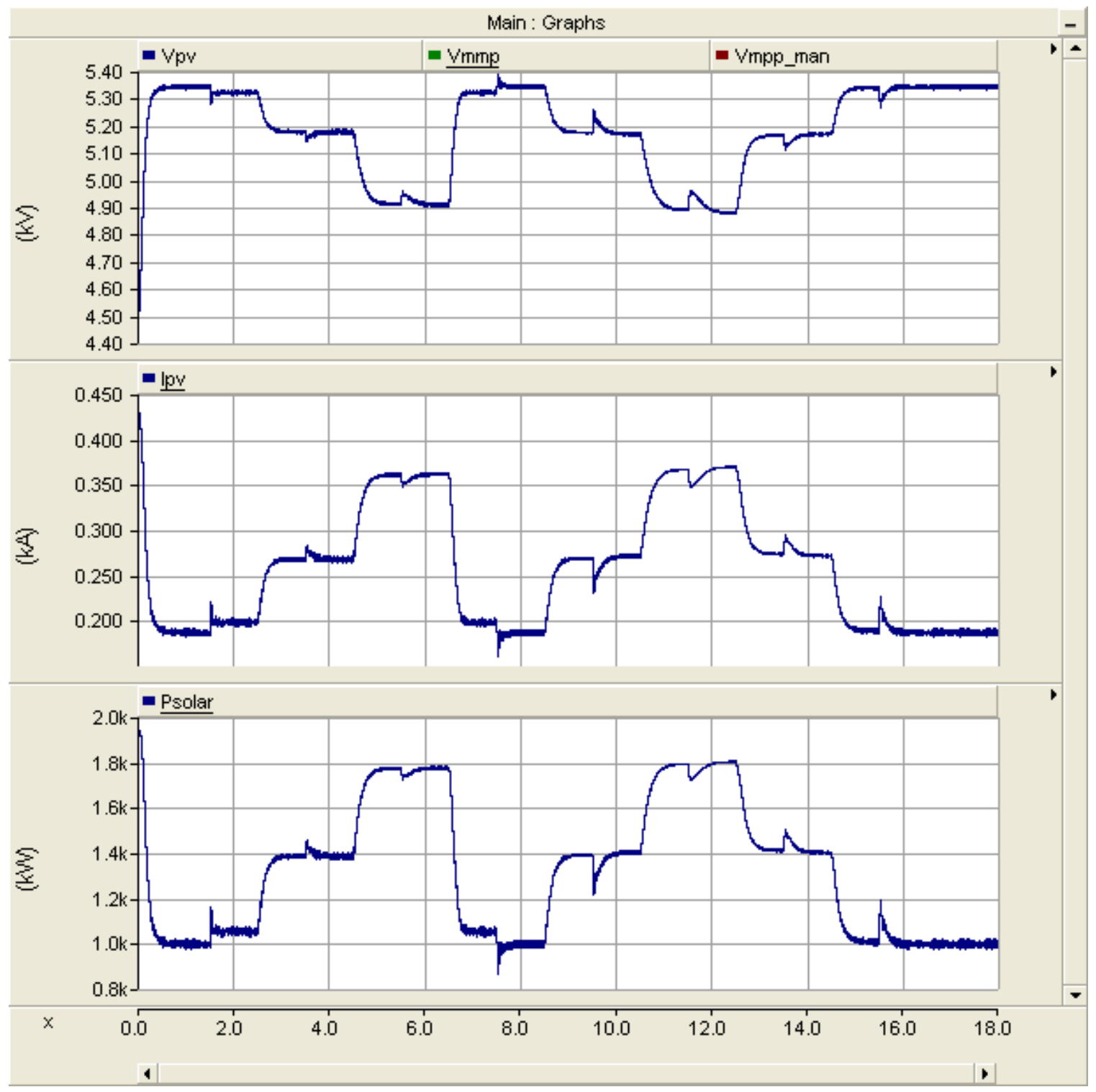

Figure 4.21: PV Array Voltage, Current. and Power with Inverter Operating in Remote Curtailment/Ramping Mode 


\section{Future Work}

To further advance this study in its analysis of a smart inverters grid support functions, several areas of new research could be explored and applied to the existing model. The model created and analyzed only encompasses a novel approach in its methods and schemes chosen to provide the inverter with the required ancillary services this thesis focuses on.

\subsection{Battery Energy Storage System}

The scope of this thesis in demonstrating the new support features added to the inverter primarily assumed the input power from the PV array was constant. As real and reactive power loads were switched on and off during the various tests scenarios, and as reference values for $\mathrm{P}$ and $\mathrm{Q}$ were tracked during the remote curtailment test, the intermittent nature of the solar resource was not introduced in the analysis.

To further the study, a battery energy storage system could be introduced in parallel with the PV array. This study might analyze the same test cases as this thesis but also vary the solar irradiation and cell temperature parameters during the tests as well to see if the battery system can smooth out the output power due solar intermittency while the inverter provides the necessary real and reactive power as required to support an abnormal grid condition.

In this thesis design the inverters output power regulated the DC bus voltage at the solar systems maximum power point. As rapid changes in real and/or reactive power were required the bus voltage fluctuated at times in response to the power demands. When the bus voltage fluctuates the PV array is no longer operating at its maximum power point. The addition of a battery energy storage system could indefinitely keep the 
DC bus voltage more stable and in essence achieve a more efficient use of the solar system.

\subsection{Multi-string Inverter/PV Configuration}

A topology to connect solar panels with inverters gaining recent popularity is a multi-string multi-inverter approach. The merits of the multi-string configuration are increased reliability with multiple parallel branches, reduced power loss, and scalability of the PV plant [33]. How each inverter would be controlled so the net real and reactive power injected into the grid would be controllable as in the central inverter design of this thesis would be interesting. This study assumed a single centralized inverter for simplicity in system modeling because only a single inverter was used. Having one higher level in PSCAD consisting of several inverters and solar arrays connected to the grid would result in a much more complex model. A possible issue with this approach is the node limit for PSCAD would most likely be reached if only an education license is being used because a single inverter module contains very many nodes.

\subsection{Two Stage Maximum Power Point Tracking}

A more common MPPT scheme than the one used in this thesis is a two-stage approach. The extra stage is a DC to DC converter, such as a buck or boost circuit, inserted between the PV system and the inverter and its sole function is to ensure the voltage across the PV array terminals is the maximum power point voltage.

Adding this stage to the existing model could also aid in maintaining the PV voltage at its maximum power point while allowing the input voltage to the inverter to fluctuate. The fluctuations, as described earlier, occur when quick demands for real and reactive power are present. The two stage MPPT scheme in conjunction with a battery 
energy storage system could improve overall inverter stability, and enhance the existing smart inverter model.

\subsection{Decoupled Controls}

The fundamentals of the control scheme developed for this model are based on the basic power flow equations for real and reactive power. The drawback with controlling $\mathrm{P}$ and $\mathrm{Q}$ based on measured voltages and the power angle is that $\mathrm{P}$ is not only a function of the power angle and Q is not only a function of the voltage magnitudes. Therefore the real and reactive power cannot be controlled independently from the basic power flow equations by only controlling the power angle and inverter output voltage.

In order to decouple the controls and effectively control the real and reactive powers independently a mathematical transformation known as the parks transformation can be applied. The parks transformation transforms three time varying phasors (phases $\mathrm{A}, \mathrm{B}$, and $\mathrm{C}$ ) to a two dimensional rotating reference frame known as the DQ0. The DQ0 reference is considered two dimensional because the 0 is the zero sequence component and is equal to zero for balanced systems. By implementing this mathematical model into the controller, measurements can be transformed to the DQ0 reference frame, control actions implemented while in the DQ0, and then transformed back to the $\mathrm{ABC}$ reference and used to control the real and reactive powers independently. Ideally, the response time should be decreased and the controller will be more robust with the addition of decoupled controls. 


\section{Conclusion}

The general trends in the past decade of increasing solar cell efficiency, decreasing PV system costs, increasing government incentive programs, and several other factors have all combined synergistically to reduce the barriers of entry for PV systems to enter the market and expand their contribution to the global energy portfolio. The increase in economic feasibility could not come at a better time to provide a clean solution for generating energy to meet the rapidly rising demand. However, the price paid for tapping into the free resource is its intermittent nature and the problems discovered when integrating the resource into electrical power systems. The problems continue to grow as a larger percent of generation is coming from renewable sources.

In an attempt to help mitigate some of the problems produced by PV systems, rather then installing additional equipment along a feeder, this thesis presents a solution by modifying the controls of the inverter to eliminate the problems. The additional control features designed, modeled, and analyzed in the PSCAD simulation environment are voltage regulation, frequency response, and remote curtailment and ramping capabilities. The results from simulation show that by modifying simple control parameters the inverter is able to detect abnormal voltages and frequencies in the power system and increase or curtail its real and reactive power output to bring the system back to a normal state. In addition to the implemented control features, a power quality analysis was performed based on applicable IEEE standards. Voltage and current harmonics were maintained below maximum acceptable levels.

Current PV grid tied inverters, which are static, non-sensing, and disconnect during the presence of disturbances may not be of great concern today because solar 
power is only a small fraction of the total electrical power generation. As PV system penetration continues to increase even faster over the next decade, smart inverter controls are imperative to the utility network in order to keep the vital resources connected to the grid during disturbances when they are needed most. 


\section{Bibliography}

[1] "Solar Photovoltaics: Status, Costs, and Trends," EPRI, Palo Alto, 1015804, 2009.

[2] "Renewables 2012: Global Status Report," REN21, 2012.

[3] Roger A Messenger and Jerry Ventre, "Photovoltaic Systems Engineering," 2010.

[4] Governor Schwarzenegger Advances State's Renewable Energy Development. (2008, November) California Governor's Executive Order S-14-08. [Online]. http://gov38.ca.gov/index.php?/executive-order/11072/

[5] U.S. Department of Energy, "2010 Solar Technologies Market Report,".

[6] First Solar. [Online]. http://www.firstsolar.com/Projects/Topaz-Solar-Farm

[7] U.S. Department of Energy, "2008 Solar Technologies Market Report,".

[8] "The Smart Grid: An Introduction," Department of Energy,.

[9] J. Duncan Glover, Mulukutla S Sarma, and Thomas J Overbye, Power System Analysis and Design, 5th ed. CT, USA: Cengage Learning, 2012.

[10] Qiuye Sun, Zhongxu Li, and Huaguang Zhang, "Impact of Distributed Generation on Voltage Profile in Distribution System," in International Joint Conference on Computational Sciences and Optimization, 2009.

[11] S. A. Pourmousavi, A. S. Cifala, and M. H. Nehrir, "Impact of High Penetration of PV Generation on Frequency and Voltage in a Distribution Feeder," IEEE, 2012.

[12] Masato Oshiro, Kosuke Uchida, Tomonobu Senjyu, and Atsushi Yona, "Voltage Control in Distribution Systems Considered Reactive Power Output Sharing in Smart Grid," in International Conference on Electric Machines and Systems, 2010, 
pp. $458-463$.

[13] Edward J Coster, Johanna A Myrzik, Bas Kruimer, and Wil L Kling, "Integration Issues of Distributed Generation in Distribution Grids," IEEE, vol. 99, January 2011.

[14] John D Kueck, Brendan J Kirby, Leon M Tolbert, and D Tom Rizy, "Tapping Distributed Energy Resources," Public Utilities Fortnightly, September 2004.

[15] Y Liu, J Bebic, B Kroposki, J de Bedout, and W Ren, "Distribution System Voltage Performance Analysis for High-Penetration PV," , November 2008.

[16] C. Debruyne et al., "Preventing overvoltages in PV grids by integration of small storage capacity,".

[17] Tom Verschueren et al., "Assessment and mitigation of voltage violations by solar panels in a residential distribution grid," IEEE, 2011.

[18] Harsha Ravindra et al., "Dynamic Interactions Between Distribution Network Voltage Regulators for Large and Distributed PV Plants,".

[19] Leo F. Casey and Colin Schauder, "Advanced Inverters Facilitate High Penetration Of Renewable Generation On Medium Voltage Feeders - Impact And Benefits For the Utility,".

[20] Cody A. Hill, Matthew Clayton Such, Dongmei Chen, Juan Gonzalez, and W. Mack Grady, "Battery Energy Storage for Enabling Integration of Distributed Solar Power Generation," IEEE Transactions on Smart Grid, vol. 3, no. 2, June 2012.

[21] Tom E Jauch, "Possible Effects of Smart Grid Functions on LTC Transformers," IEEE TRANSACTIONS ON INDUSTRY APPLICATIONS, vol. 47, no. 2, March/April 2011. 
[22] Taufik, Advanced Power Electronics, 6th ed., 2013.

[23] Ping Yan and Arun Sekar, "Analysis of Radial Distribution Systems With Embedded Series FACTS Devices Using a Fast Line Flow-Based Algorithm," IEEE

Transactions on Power Systems, vol. 20, no. 4, November 2005.

[24] Mehrdad Ahmadi Kamarposhti and Hamid Lesani, "Comparison between Parallels and Series FACTS Devices on Static Voltage Stability Using MLP Index," in International Symposium on Power Electronics, Electrical Drives, Automation and Motion, 2010.

[25] Mehrdad Ahmadi Kamarposhti, Mostafa Alinezhad, Hamid Lesani, and Nemat Talebi, "Comparison of SVC, STATCOM, TCSC, and UPFC Controllers for Static Voltage Stability Evaluated by Continuation Power Flow Method," in IEEE Electrical Power \& Energy Conference, 2008.

[26] IEEE Standards Coordinating Committee 21. (2008, December) IEEE Application Guide for IEEE Std 1547. Document.

[27] Manitoba HVDC Research Centre Inc. (2005, April) Users Guide on the use of PSCAD. Document.

[28] Bob Saint, "Update on IEEE 1547 Series of Standards for Distributed Resources Interconnection," in Transmission and Distribution Conference and Exposition (T\&D), 2012 IEEE PES , 2012, pp. 1-5.

[29] Colin Schauder, "Impact of FERC 661-A and IEEE 1547 on Photovoltaic Inverter Design," in Transmission and Distribution Conference and Exposition (T\&D), 2012 IEEE PES , pp. 1-6. 
[30] IEEE Industry Applications Society/Power Engineering Society. (1993, April) IEEE Std 519-1992. Document.

[31] Stephen J. Chapman, Electrical Machinery Fundamentals, 4th ed. New York, U.S.: McGraw-Hill, 2010.

[32] Taufik, Introduction to Power Electronics Lecture Notes, 10th ed., 2012.

[33] Angelina Tomova, "Grid Connected PV Inverter Topologies an Overview," in Distributed generation and renewable energy sources, Glascow, UK, 2011.

[34] Athula D. Rajapakse and Dharshana Muthumuni, "Simulation Tools for Photovoltaic System Grid Integration Studies," in IEEE Electrical Power \& Energy Conference.

[35] K. H. Hussein, I. Muta, T. Hoshino, and M. Osakada, "Maximum photovoltaic power tracking : an algorithm for rapidly changing atmospheric conditions," IEEE Proceedings - Generation, Transmission, and Distribution, vol. 142, no. 1, pp. 5964, January 1995.

[36] J. Schonberger, "A single phase multi-string PV inverter with minimal bus capacitance," in Proc. 13th Eur. Conf. Power Electron. Appl., 2009, pp. 1-10.

[37] Haibing Hu, Souhib Hard, Nasser Kutkut, Issa Batarseh, and Z. John Shen, "A Review of Power Decoupling Techniques for Microinverters With Three Different Decoupling Capacitor Locations in PV Systems," IEEE TRANSACTIONS ON POWER ELECTRONICS, vol. 28, no. 6, June 2013. 


\section{Appendix A: Voltage and Current Harmonic Data}

Table A.1: Voltage Harmonic Magnitudes at the PCC During Steady State Operation

\begin{tabular}{|c|c|c|c|c|c|c|c|c|}
\hline $\mathbf{n}$ & V (\% Rated) & $\mathbf{V}(\mathbf{k V})$ & $\mathbf{n}$ & V (\% Rated) & $\mathbf{V}(\mathbf{k V})$ & $\mathbf{n}$ & V (\% Rated) & $\mathbf{V}(\mathbf{k V})$ \\
\hline 1 & 99.45362287 & 12.40186677 & 45 & 0.002236607 & 0.000278905 & 89 & 0.001079131 & 0.000134568 \\
\hline 2 & 0.015027585 & 0.00187394 & 46 & 0.002340528 & 0.000291864 & 90 & 0.001301945 & 0.000162352 \\
\hline 3 & 0.038676079 & 0.004822907 & 47 & 0.002351702 & 0.000293257 & 91 & 0.001110331 & 0.000138458 \\
\hline 4 & 0.043560909 & 0.005432045 & 48 & 0.002119035 & 0.000264244 & 92 & 0.001335703 & 0.000166562 \\
\hline 5 & 0.013463973 & 0.001678957 & 49 & 0.002175735 & 0.000271314 & 93 & 0.001365746 & 0.000170309 \\
\hline 6 & 0.010983657 & 0.001369662 & 50 & 0.002102704 & 0.000262207 & 94 & 0.00132625 & 0.000165383 \\
\hline 7 & 0.011812462 & 0.001473014 & 51 & 0.001960956 & 0.000244531 & 95 & 0.001345915 & 0.000167836 \\
\hline 8 & 0.012775916 & 0.001593157 & 52 & 0.00198847 & 0.000247962 & 96 & 0.001354477 & 0.000168903 \\
\hline 9 & 0.006554417 & 0.000817336 & 53 & 0.002040161 & 0.000254408 & 97 & 0.001351609 & 0.000168546 \\
\hline 10 & 0.008950955 & 0.001116184 & 54 & 0.001861413 & 0.000232118 & 98 & 0.001388407 & 0.000173134 \\
\hline 11 & 0.011580523 & 0.001444091 & 55 & 0.00184635 & 0.00023024 & 99 & 0.001409405 & 0.000175753 \\
\hline 12 & 0.008153359 & 0.001016724 & 56 & 0.001872471 & 0.000233497 & 100 & 0.001403748 & 0.000175047 \\
\hline 13 & 0.007934874 & 0.000989479 & 57 & 0.001724309 & 0.000215021 & 101 & 0.001466566 & 0.000182881 \\
\hline 14 & 0.009501298 & 0.001184812 & 58 & 0.001693318 & 0.000211157 & 102 & 0.001468814 & 0.000183161 \\
\hline 15 & 0.007869641 & 0.000981344 & 59 & 0.001697736 & 0.000211708 & 103 & 0.001525749 & 0.000190261 \\
\hline 16 & 0.007063973 & 0.000880877 & 60 & 0.001682007 & 0.000209746 & 104 & 0.001556827 & 0.000194136 \\
\hline 17 & 0.007911351 & $0.000 s$ & 61 & 0.001574846 & 6383 & 105 & 2453 & 0.0 \\
\hline 18 & 0.006781474 & 0.00084565 & 62 & 0.001605835 & 0.000200248 & 106 & 8993 & 0.00 \\
\hline 19 & 0.006094643 & 0.000760002 & 63 & 0.001595268 & 0.00019893 & 107 & 0.00160779 & 0.000200491 \\
\hline 20 & 0.006378328 & 0.000795378 & 64 & 0.001547933 & 0.000193027 & 108 & 0.001650622 & 0.000205833 \\
\hline 21 & 0.005842947 & 0.000728615 & 65 & 0.001529462 & 0.000190724 & 109 & 0.001717218 & 14137 \\
\hline 22 & 0.00486552 & 0.00060673 & 66 & 0.001575118 & 0.000196417 & 110 & 0.001728917 & 15596 \\
\hline 23 & 0.005102143 & 0.000636237 & 67 & 0.001514669 & 0.000188879 & 111 & 0.001818992 & 0.000226828 \\
\hline 24 & 0.004736663 & 0.000590662 & 68 & 0.00146456 & 0.000182631 & 112 & 0.001843642 & 0.000229902 \\
\hline 25 & 0.003989006 & 0.000497429 & 69 & 0.001524732 & 0.000190134 & 113 & 0.001896481 & 0.000236491 \\
\hline 26 & 0.00393946 & 0.000491251 & 70 & 0.001491804 & 0.000186028 & 114 & 0.001944261 & 0.000242449 \\
\hline 27 & 0.003889565 & 0.000485029 & 71 & 0.001493411 & 0.000186228 & 115 & 0.002044582 & 0.000254959 \\
\hline 28 & 0.003281823 & 0.000409243 & 72 & 0.00148796 & 0.000185549 & 116 & 0.002092291 & 0.000260909 \\
\hline 29 & 0.003175336 & 0.000395964 & 73 & 0.001564794 & 0.00019513 & 117 & 0.002188227 & 0.000272872 \\
\hline 30 & 0.003196191 & 0.000398565 & 74 & 0.001445356 & 0.000180236 & 118 & 0.002263684 & 0.000282281 \\
\hline 31 & 0.002761663 & 0.000344379 & 75 & 0.001479721 & 0.000184521 & 119 & 0.00234522 & 0.000292449 \\
\hline 32 & 0.002597144 & 0.000323864 & 76 & 0.001503307 & 0.000187462 & 120 & 0.002382033 & 0.00029704 \\
\hline 33 & 0.002688114 & 0.000335208 & 77 & 0.001412376 & 0.000176123 & 121 & 0.002533604 & 0.00031594 \\
\hline 34 & 0.002512111 & 0.00031326 & 78 & 0.001436163 & 0.00017909 & 122 & 0.002647134 & 0.000330098 \\
\hline 35 & 0.002393317 & 0.000298447 & 79 & 0.001358942 & 0.00016946 & 123 & 0.002718656 & 0.000339016 \\
\hline 36 & 0.002437192 & 0.000303918 & 80 & 0.001413533 & 0.000176268 & 124 & 0.002833583 & 0.000353348 \\
\hline 37 & 0.002461259 & 0.000306919 & 81 & 0.015828576 & 0.001973823 & 125 & 0.002997371 & 0.000373772 \\
\hline 38 & 0.002288488 & 0.000285374 & 82 & 0.001381324 & 0.000172251 & 126 & 0.003115054 & 0.000388447 \\
\hline 39 & 0.002301661 & 0.000287017 & 83 & 0.001375093 & 0.000171474 & 127 & 0.003204367 & 0.000399585 \\
\hline 40 & 0.002461305 & 0.000306925 & 84 & 0.00142165 & 0.00017728 & & & \\
\hline 41 & 0.002319095 & 0.000289191 & 85 & 0.01550527 & 0.001933507 & & & \\
\hline 42 & 0.00230565 & 0.000287515 & 86 & 0.001341343 & 0.000167265 & & THD & $0.0780 \%$ \\
\hline 43 & 0.002415709 & 0.000301239 & 87 & 0.000978567 & 0.000122027 & & & \\
\hline 44 & 0.002310685 & 0.000288142 & 88 & 0.001325308 & 0.000165266 & & & \\
\hline
\end{tabular}


Table A.2: Current Harmonic Magnitudes at the PCC During Steady State Operation

\begin{tabular}{|c|c|c|c|c|c|c|c|c|}
\hline n & I (\% Rated) & I (A) & n & I (\% Rated) & I (A) & $\mathbf{n}$ & I (\% Rated) & I (A) \\
\hline 1 & 91.22869821 & 84.47594997 & 45 & 0.000521026 & 0.000482459 & 89 & 0.000219219 & 0.000202992 \\
\hline 2 & 0.067886522 & 0.062861562 & 46 & 0.000618691 & 0.000572895 & 90 & 0.000129429 & 0.000119849 \\
\hline 3 & 0.138987976 & 0.128700086 & 47 & 0.00061144 & 0.000566181 & 91 & 0.00018668 & 0.000172862 \\
\hline 4 & 0.122437559 & 0.113374731 & 48 & 0.000499525 & 0.00046255 & 92 & 0.000141364 & 0.0001309 \\
\hline 5 & 0.041676301 & 0.038591421 & 49 & 0.000539809 & 0.000499852 & 93 & 0.000167317 & 0.000154932 \\
\hline 6 & 0.030153042 & 0.027921114 & 50 & 0.000502431 & 0.000465241 & 94 & 0.000122455 & 0.000113391 \\
\hline 7 & 0.017170697 & 0.015899722 & 51 & 0.000410477 & 0.000380094 & 95 & 0.000136659 & 0.000126543 \\
\hline 8 & 0.01515178 & 0.014030245 & 52 & 0.000458842 & 0.000424879 & 96 & 0.000132633 & 0.000122815 \\
\hline 9 & 0.004605535 & 0.004264633 & 53 & 0.000477962 & 0.000442583 & 97 & 0.000124793 & 5555 \\
\hline 10 & 0.008816619 & 0.008164013 & 54 & 0.000376365 & 0.000348507 & 98 & 0.000139752 & 0.000129407 \\
\hline 11 & 0.010959132 & 0.010147937 & 55 & 0.000381662 & 0.000353412 & 99 & 0.000149771 & 0.000138685 \\
\hline 12 & 0.006171795 & 0.005714959 & 56 & 0.000398684 & 0.000369174 & 100 & 0.000133038 & 0.000123191 \\
\hline 13 & 0.006208826 & 0.005749249 & 57 & 0.000324991 & 0.000300935 & 101 & 0.000 & 2761 \\
\hline 14 & 0.007591811 & 0.007029865 & 58 & 0.000293669 & 0.000271932 & 102 & $0.00 c$ & 35381 \\
\hline 15 & 0.005506914 & 0.005099292 & 59 & 0.000318635 & 0.000295049 & 103 & 0.000159242 & 0.000147455 \\
\hline 16 & 0.004913527 & 0.004549828 & 60 & 0.000275655 & 0.000255251 & 104 & 0.000 & 35611 \\
\hline 17 & 0.00563951 & 0.005222074 & 61 & 0.000231621 & 0.000214476 & 105 & 0.000144969 & 4239 \\
\hline 18 & 0.004311243 & 0.003992124 & 62 & 494 & 0.000 & 106 & 0.00 & 3513 \\
\hline 19 & 0.003977629 & 0.003683205 & 63 & 0.000246641 & 0.000228385 & 107 & 0.00013786 & 0.000127656 \\
\hline 20 & 0.004130603 & 0.003824855 & 64 & 0.000206787 & 0.00019148 & 108 & 0.000 & 1306 \\
\hline 21 & 0.003445617 & 0.003190573 & 65 & 0.000206707 & 0.000191406 & 109 & 0.000 & 168 \\
\hline 22 & 0.002769382 & 0.002564392 & 66 & 0.00 & 0.000 & 110 & 0.00 & 32599 \\
\hline 23 & 0.003070343 & 0.002843077 & 67 & 0.000209316 & 0.000193822 & 111 & 0.000154954 & 0.000143485 \\
\hline 24 & 0.002545457 & 0.002357042 & 68 & 0.000188824 & 0.000174848 & 112 & 0.000153167 & 0.000141829 \\
\hline 25 & 0.001980792 & 0.001834174 & 69 & 0.000211636 & 0.00019597 & 113 & 0.00015413 & 2721 \\
\hline 26 & 0.002062301 & 0.001909649 & 70 & 0.000 & 0.0001 & 114 & 0.000 & 0.000144044 \\
\hline 27 & 0.001924641 & 0.001782179 & 71 & 0.000203927 & 0.000188832 & 115 & 0.000163253 & 0.000151169 \\
\hline 28 & 0.00138761 & 0.001284899 & 72 & 0.000215123 & 0.0001992 & 116 & 0.000172543 & 0.000159771 \\
\hline 29 & 0.001419423 & 0.001314358 & 73 & 0.000254475 & 0.000235639 & 117 & 0.000180101 & 0.00016677 \\
\hline 30 & 0.00132665 & 0.001228451 & 74 & 0.000197465 & 0.000182849 & 118 & 0.000188932 & 0.000174947 \\
\hline 31 & 0.000910805 & 0.000843387 & 75 & 0.000210858 & 0.00019525 & 119 & 0.00018659 & 0.000172779 \\
\hline 32 & 0.000895695 & 0.000829396 & 76 & 0.000228428 & 0.00021152 & 120 & 0.000188196 & 0.000174266 \\
\hline 33 & 0.000889563 & 0.000823717 & 77 & 0.000168505 & 0.000156032 & 121 & 0.000198021 & 0.000183363 \\
\hline 34 & 0.000705998 & 0.00065374 & 78 & 0.000188664 & 0.000174699 & 122 & 0.000225487 & 0.000208797 \\
\hline 35 & 0.000614647 & 0.000569151 & 79 & 0.000268962 & 0.000249054 & 123 & 0.000218744 & 0.000202553 \\
\hline 36 & 0.000669719 & 0.000620146 & 80 & 0.00 & 0.000165823 & 124 & 0.00 & 0.000223604 \\
\hline 37 & 0.000621898 & 0.000575865 & 81 & 0.009216296 & 0.008534106 & 125 & 0.000240331 & 0.000222542 \\
\hline 38 & 0.000503263 & 0.000466012 & 82 & 0.000172374 & 0.000159614 & 126 & 0.000264623 & 0.000245036 \\
\hline 39 & 0.000542654 & 0.000502487 & 83 & 0.000181487 & 0.000168053 & 127 & 0.000246472 & 0.000228228 \\
\hline 40 & 0.000641584 & 0.000594094 & 84 & 0.000153957 & 0.000142561 & & & \\
\hline 41 & 0.000518489 & 0.00048011 & 85 & 0.0081946 & 0.007588036 & & & \\
\hline 42 & 0.000553716 & 0.00051273 & 86 & 0.000103927 & $9.62344 \mathrm{E}-05$ & & TDD & $0.21 \%$ \\
\hline 43 & 0.000637197 & 0.000590032 & 87 & $5.90801 \mathrm{E}-05$ & $5.4707 \mathrm{E}-05$ & & & \\
\hline 44 & 0.000576607 & 0.000533926 & 88 & 7.1642E-05 & $6.6339 \mathrm{E}-05$ & & & \\
\hline
\end{tabular}


